\title{
Teachers' Perceptions of Outcomes - Based Science Curriculum: A Case Study from Solomon Islands
}

By

Patrick Daudau

A thesis submitted to the Victoria University of Wellington in partial fulfilment of the requirements for the degree of

Master of Education

Faculty of Education

Victoria University of Wellington

Wellington, New Zealand

February, 2010 


\section{ABSTRACT}

The purpose of this study is to contribute to the debate about the appropriateness of an outcomes - based education (OBE) model for curriculum reform in Solomon Islands. A shift from a curriculum defined by subject content to a curriculum defined by what learners are expected to know, understand, be able to do and appreciate has been promoted. This belief has been highlighted in the Solomon Islands National Education Strategic Plans (2004 - 2006 \& 2007 - 2009), Education Strategic Framework (2007 - 2015) and the approved National Curriculum Statement.

Taking an interpretive-constructivist approach, the study employed a qualitative case study research methodology. The study used a purposeful sample of key curriculum stakeholders, including science teachers, science lecturers, school principal, education officials and public servants who were participating in the reform. Focus group conversation and one-on-one interviews were conducted using semi-structured questions. Interviews were conducted in Solomon Islands Pijin, recorded and transcribed for analysis. Data was collected in Honiara, Solomon Islands, from June to July 2009.

This study explores the conceptualisation of outcomes-based education in a Solomon Islands context and its implication in the development of outcomes-based science curriculum. It examines the relevance and appropriateness of outcomes-based science curriculum to post-school real life situations. The research also explores the extent to which Outcomes-Based Science Curriculum could be effectively taught, learnt and assessed, and how students’ performance, progress and achievements could be efficiently monitored, recorded and reported. The study also discusses potential problems, issues and challenges that might impede the implementation process and concludes with how these obstacles could be solved or mitigated. 


\section{ACKNOWLEDGEMENTS}

This thesis has been completed with the assistance and support of many individuals and organisations. While I cannot acknowledge all due to limited space, a few need mentioning.

First, I give praise to God for wisdom, strength and guidance while studying at Victoria University of Wellington, New Zealand. Sincere thanks to NZAID and the government of New Zealand for their generous assistance. I also acknowledge the Contract Manager and Staff of Victoria International Office for their support and encouragement. Similarly, I would like to thank the Post Graduate Education Office and Student Support Learning Centre for their support and assistance. Sincere thanks to the lecturers of the Faculty of Education for sharing their knowledge and guidance towards the completion of my course work component. Thank you also to the Faculty of Education for the research approval and the trust in allowing me to undertake research in Solomon Islands.

Second, I sincerely thank my supervisor, Associate Professor Kabini Sanga for his guidance. His advice, encouragement and support as a mentor and a counsellor during my studies are appreciated with gratitude. Without his guidance I may not have completed this thesis on time. I also extend my appreciation to Dr Sanga’s family for their support offered to my family while in Wellington.

Third, I sincerely thank Val and Bernard Dooley for proof reading my drafts and Penelope Trought for her thorough reading of the final draft. My sincere thanks to members of the Pacific Leadership Cluster led by Dr Kabini Sanga and Dr Cherie Chu for their inspiration, support, encouragement and mentorship. Thank you also to staff of He Parekereke, Institute for Research and Development in Maori and Pacific Education for creating such a great environment for learning. 
Fourth, I sincerely thank the Solomon Islands community in Wellington for their support and making us part of the family. Sincere appreciation also goes to Dr Dele Babalola, Sarah Crawford and the staff of Kopata Medical Centre for taking care of our health needs. Also thank you to Fr Michael Stieller and parishioners of Waiwhetu Catholic parish for their hospitality and making us part of the parish.

Fifth, I acknowledge the support offered by the Permanent Secretary and staff of the Ministry of Education of Solomon Islands. Sincere thanks to my research participants for their commitment and for providing information for this study. Thank you also goes to School Principals, Education Secretaries, Chief Education Officers, Head of School of Education - Solomon Islands College of Higher Education, Directors of Energy \& Mines, and Environment \& Conservation for encouraging research participants to be co-operative and committed to my research project.

Sixth, I sincerely acknowledge the assistance rendered by my extended family and beloved parents, John Wiki Ratu and Magdalene Kokosi for their love, inspiration and encouragement during the period of data collection in Honiara, Solomon Islands.

Finally and foremost, I sincerely acknowledge my family: wife Tina, daughter Patrina Kokosi Ratu and son Roderick Wiki Ratu for their unfailing love, patience and support during the undertaking of this thesis. I dedicate this thesis to you all. 
ABSTRACT

ACKNOWLEDGEMENTS

TABLE OF CONTENTS

LIST OF FIGURES, TABLES \& ACRONYMS

\section{CHAPTER ONE: INTRODUCTION AND RESEARCH CONTEXT}

1.1 Introduction and Overview 1

1.2 Background to the Study 1

1.3 The Need for this Study 2

1.4 My Interest in Curriculum Studies 3

1.5 The Purpose of this Study 3

$1.6 \quad$ Research Questions 4

$\begin{array}{lll}1.7 & \text { Significance of the Study } & 5\end{array}$

$\begin{array}{lll}1.8 & \text { Context of the Study } & 5\end{array}$

1.9 Structure of the Thesis 13

\section{CHAPTER TWO: THE LITERATURE REVIEW}

$\begin{array}{lll}2.1 & 14\end{array}$

2.2 The Outcomes-based Education Model and Curriculum Approach 14

$2.3 \quad$ Responding to Criticisms of Outcomes-based Education 26

$\begin{array}{lll}2.4 & \text { Education Curricula in the Pacific Region } & 30\end{array}$

\section{CHAPTER THREE: THE RESEARCH METHODOLOGY}

$3.1 \quad$ Introduction and Overview 33

3.2 Theoretical Orientation 33

3.3 The Methodological Framework 37

$\begin{array}{lll}3.4 & \text { Research Process } & 43\end{array}$

3.5 Data Collection and Analysis 46

3.6 Validity Issues of the study 50

3.7 My Role as the Researcher $\quad 51$

$\begin{array}{lll}3.8 & \text { Summary } & 51\end{array}$ 


\section{CHAPTER FOUR: INTERVIEW - DESCRIPTIONS AND FINDINGS}

4.1 Introduction and Overview 52

4.2 Conceptualising Outcomes-based Education 53

4.3 Conceptualising Outcomes-based Science Curriculum 56

4.4 Strategies for Implementing Outcomes-based Science Curriculum 59

4.5 Problems, Issues and Challenges, and Ways for Addressing Obstacles 66

$\begin{array}{lll}4.6 & \text { Summary } & 75\end{array}$

\section{CHAPTER FIVE: ANALYSIS AND DISCUSSION}

$\begin{array}{lll}5.1 & \text { Introduction and Overview }\end{array}$

5.2 Conceptualisation of Outcomes-based Education 77

5.3 Appropriateness of Outcomes-based Education as a Curriculum Approach 81

5.4 Conceptualisation of Outcomes-based Science Curriculum 82

5.5 Perceived Teaching, Learning and Teacher Support Strategies 84

5.6 Perceived Assessment Strategies 98

5.7 Perceived Monitoring, Recording and Reporting Systems 102

5.8 Potential Problems, Issues and Challenges, and Perceived Strategies 104

$\begin{array}{lll}5.9 & \text { Summary } & 108\end{array}$

CHAPTER SIX: SUMMARY OF FINDINGS, RESEARCH CONTRIBUTIONS, CONCLUSIONS, IMPLICATIONS AND RECOMMENDATIONS

$\begin{array}{lll}6.1 & \text { Introduction and Overview } & 110\end{array}$

$\begin{array}{lll}6.2 & \text { Summary of Findings } & 110\end{array}$

$\begin{array}{lll}6.3 & \text { Research Contributions } & 116\end{array}$

6.4 Research Implications of the Study 117

$\begin{array}{lll}6.5 & \text { Recommendations for Action } & 118\end{array}$

$\begin{array}{lll}6.6 & \text { Research Limitations } & 119\end{array}$

$\begin{array}{lll}6.7 & \text { Further Research Studies } & 120\end{array}$

$\begin{array}{lll}6.8 & \text { Final Thought } & 121\end{array}$

$\begin{array}{lr}\text { REFERENCES } & 122\end{array}$

$\begin{array}{lr}\text { APPENDICES } & 130\end{array}$ 


\section{LIST OF FIGURES, TABLES AND ACRONYMS}

\section{Figures}

Figure $1 \quad$ Map of Solomon Islands in Oceania

Figure 2 Map of Provinces in Solomon Islands

Figure 3 Curriculum Haus Framework for OBSC, Solomon Islands

\section{Tables}

Table $1 \quad$ Distribution of Secondary Schools, Solomon Islands

Table 2 Coding of Research Participants

\section{Acronyms}

$\begin{array}{ll}\text { CDC } & \text { Curriculum Development Centre } \\ \text { CRRP } & \text { Curriculum Review and Reform Programme } \\ \text { ECE } & \text { Early Childhood Education } \\ \text { OBE } & \text { Outcomes-Based Education } \\ \text { OBSC } & \text { Outcomes-Based Science Curriculum } \\ \text { MOE } & \text { Ministry of Education } \\ \text { NESU } & \text { National Examination and Selection Unit } \\ \text { NZAID } & \text { New Zealand Agency for International Development } \\ \text { SICHE } & \text { Solomon Islands College of Higher Education } \\ \text { SIVB } & \text { Solomon Islands Visitors Bureau } \\ \text { SOE } & \text { School of Education } \\ \text { TVET } & \text { Technical Vocational Education and Training }\end{array}$




\section{CHAPTER ONE}

\section{INTRODUCTION AND RESEARCH CONTEXT}

\subsection{Introduction and Overview}

This chapter presents an introduction to the research project and an overview of the entire chapter. First, it provides information on the need for conducting this study. Second, it presents the purpose, research questions and significance of the research project. Third, it provides the background information about Solomon Islands and research contexts. Finally it concludes with the organisational structure of the thesis.

\subsection{Background to the Study}

Prior to the introduction of formal education, Solomon Islands societies used systems of indigenous education (Bugotu, Maeke, Paia, Ramoni \& Arnold, 1973) in which knowledge and skills were passed on orally from one generation to another. Education was informal and based on cultural knowledge and practices (Thaman, 2002). Like other Pacific Island countries, the post-independence Solomon Islands formal education system has continued to be influenced by the pre-independence colonial administration inherited from Great Britain, directed by colonialists and missionaries, and comprising a hierarchical system of Government policy and bureaucracy. The colonial education system aimed to train Solomon Islanders to fill clerical and administrative roles in Honiara and other urban centers. The curriculum was largely irrelevant (Ward, Sikua \& Banks, 2005). Its structure predominantly reflected foreign knowledge, skills, values and attitudes and did not cater for the learning needs of Solomon Islanders (MOE, 2006). The school curriculum seemed to ignore foundational knowledge on good citizenship, life skills and economy related activities that were essential for post-school life in Solomon Islands (Rodi, Rore, Manurapu, Sadakabatu \& Herriot, 2001). 


\subsection{The Need for the Study}

The experiences of the recent ethnic tension in Solomon Islands, as observed by Sanga and Walker (2005), have forced the Solomon Islands government to re-think its education system, and undertake major reforms in the education sector. The Ministry of Education (MOE) has adopted outcomes-based education (OBE) as a broad framework for universal basic education in Solomon Islands (MOE, 2006).

OBE was introduced in Solomon Islands four years ago under the current Curriculum Review and Reform Programme (CRRP). The OBE curriculum was developed by teachers, lecturers and teacher educators, officers from the public service and the private sector, and officials of the MOE. Somehow, officers concerned were not given the opportunity to study the OBE model and learn about the experiences and failures in other countries. There was no study of its suitability for the Solomon Islands education system. There was no research on OBE to ascertain failures of the current objectives-based curriculum and the need for a change. Furthermore, there were no resources on alternative curriculum theories and models. However even without study or preparation, it was passed on to the subject advisory committees to develop OBE curricula from the OBE model.

Given the current developmental stage of the Outcomes-Based Science Curriculum (OBSC), this study is required to explore how OBE is conceptualised, to what extent OBSC is appropriate or relevant and how such a curriculum could be effectively implemented in Solomon Islands. Furthermore, bearing in mind that the school curriculum is expected to prepare students to become productive and responsible citizens, how would OBSC contribute to meeting these requirements, particularly preparing students to be competent for post-school life in Solomon Islands? 


\subsection{My Interest in Curriculum Studies}

The motivation to undertake research in curriculum studies was based on my experience as a parent, teacher, school administrator and curriculum officer. My interest started when I was a secondary science teacher in 1991. During my teaching experience, I began thinking about the extent to which secondary science curriculum is relevant or appropriate for Solomon Islanders. My interest was further enhanced when I assumed responsibility at the Curriculum Development Centre (CDC) as Principal Curriculum Development Officer for secondary science. Being engaged in the first ever major CRRP, how would the OBE model achieve educational goals in Solomon Islands? My participation and experiences in the curriculum reform raised questions about the suitability and sustainability of the OBE model and the implementation of outcomes-based syllabuses.

The international literature also highlighted critical issues about the adoption and implementation of OBE in many countries around the globe, including the Pacific region. These emerging issues are critical and could impede implementation of OBSC in Solomon Islands. This further motivated my interest in investigating teacher's perceptions of how OBE is conceptualised, the appropriateness of OBSC and how such a curriculum could be effectively implemented in Solomon Islands secondary schools.

\subsection{Purpose of the Study}

This study sought to explore secondary science teachers’ perceptions of implementing OBSC in Solomon Islands. The purpose of my study was to explore teachers' perceptions of the conceptualisation of OBE model and curriculum approach, appropriateness of OBSC and how such a curriculum could be effectively taught, learnt and assessed, as well as how students’ performance, progress and achievements could be monitored, recorded and reported. The research would also identify potential problems, issues, and challenges that might impede implementation of OBSC and ways of addressing these obstacles. 
While OBE is viewed in various ways internationally, it is a new initiative in Solomon Islands. It is a new curriculum approach that could change the mindset and role of science teachers in secondary schools. Significantly, this study will benefit students and parents as they are searching for the real value of education in Solomon Islands. This study will also point towards a comprehensive curriculum by integrating Technical, Vocational Education and Training (TVET) policy for preparing students for future life (MOE, 2005b; MOE, 2007) and achieving millennium goals (MOE, 2007). Acquiring background information on the OBE model and notable experiences from other countries could assist Solomon Islands in its preparation towards the implementation of OBSC in secondary schools.

\section{$1.6 \quad$ Research Questions}

This study is underpinned by the following core question: “What are science teachers' perceptions of implementing OBSC in Solomon Islands secondary schools?”. The core question was simplified into subquestions for the convenience of gathering data for this study. In particular, the sub-questions of this research were:

1. How do science teachers conceptualise OBE and to what extent is OBSC appropriate?

2. What are the teaching and learning strategies for enhancing effective delivery and better understanding of OBSC?

3. How would science teachers assess OBSC and effectively monitor, record and report students' performance, progress and achievements?

4. What are the potential problems, issues, and challenges that might impede implementation of OBSC? 


\subsection{Significance of the Study}

Potentially, the research has contributions to make to secondary science teachers, teacher educators and trainees, officers of the CDC and the MOE and other key stakeholders. This study is likely to identify strategies that science teachers can use in the teaching and learning processes and assessment practices as well as monitoring, recording and reporting of students' performance and achievements. Furthermore, this study should also identify potential problems, issues, and challenges that may impede implementation of OBSC and ways of addressing these. The findings of this study will contribute towards the development of a module that can be used for upgrading teacher education and training and for providing teacher in-service training for teacher trainees and practicing science teachers. This is an inaugural research on OBE, and therefore its findings will also be useful for raising awareness and for development of both student books and teacher guides that are suitable for the learning and teaching of science in Solomon Islands. Furthermore it could help improve assessment systems and quality assurance mechanisms in secondary schools (Ward, Sikua \& Banks, 2005).

\subsection{The Context of the Study}

\subsubsection{Geographical and Physical Features}

In order to appreciate the importance of curriculum development in the Solomon Islands, a brief introduction to where the research project was carried out is useful for understanding the research context. Solomon Islands is located between $5^{\circ} \mathrm{S}$ and $12^{\circ} \mathrm{S}$ latitude and $155^{\circ} \mathrm{E}$ and $170^{\circ} \mathrm{E}$ longitude. It has a total area of $600,000 \mathrm{~km}^{2}$. Of this area only $29,785 \mathrm{~km}^{2}$ is land (Solomon Islands Visitors Bureau, 2006). Solomon Islands is made up of a double chain archipelago consisting of six larger islands and hundreds of smaller ones (Douglas \& Douglas 1994). The six larger islands are Choiseul, New Georgia, Santa Ysabel, Guadalcanal, Malaita and Makira. 
Figure 1: Map of Solomon Islands in Oceania

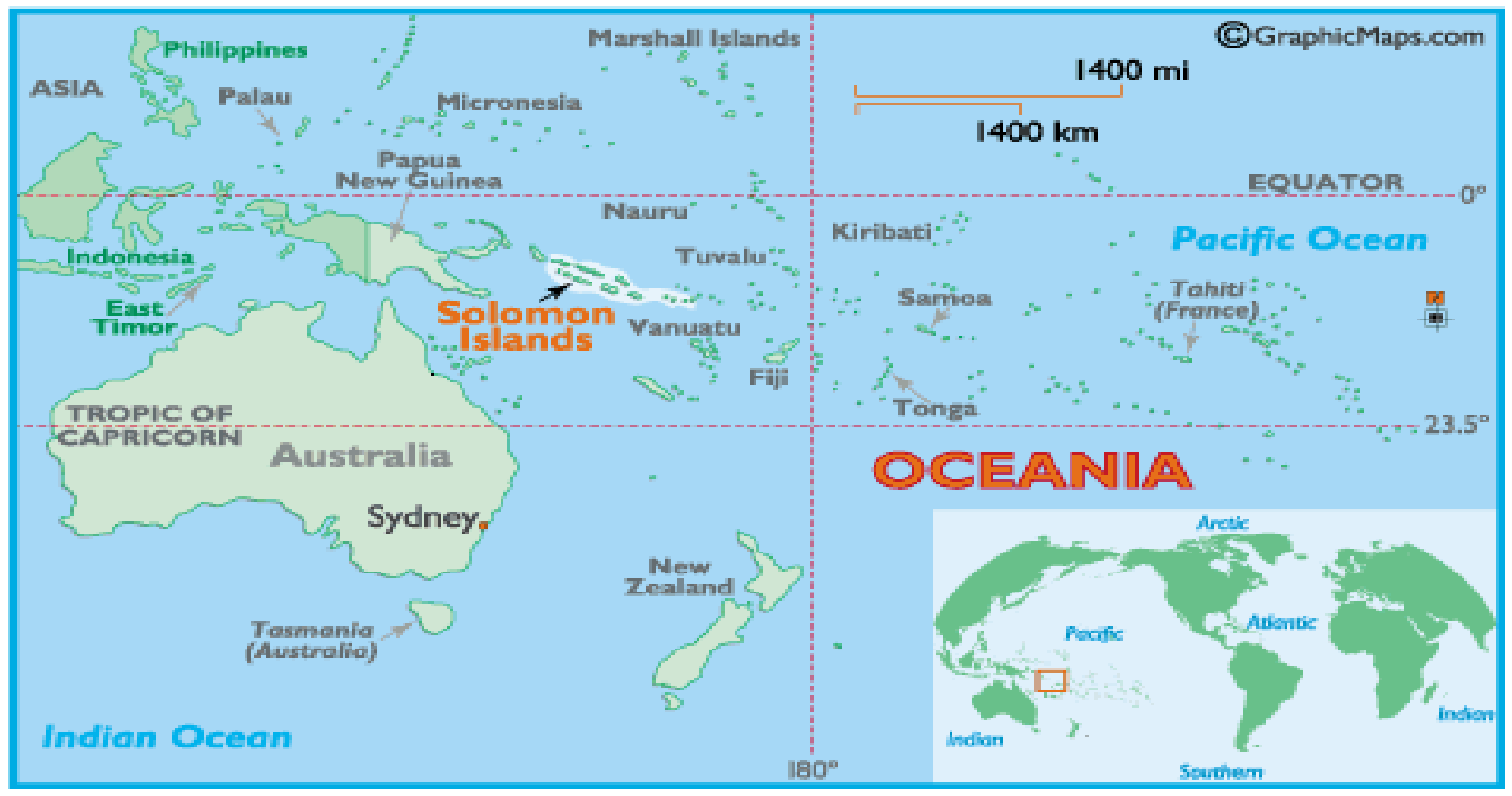

Source: Retrieved January 20, 2009, from www.worldatlas.com/webimage/countrys/oceania/sb.htm

Figure 2: Map of Provinces in Solomon Islands

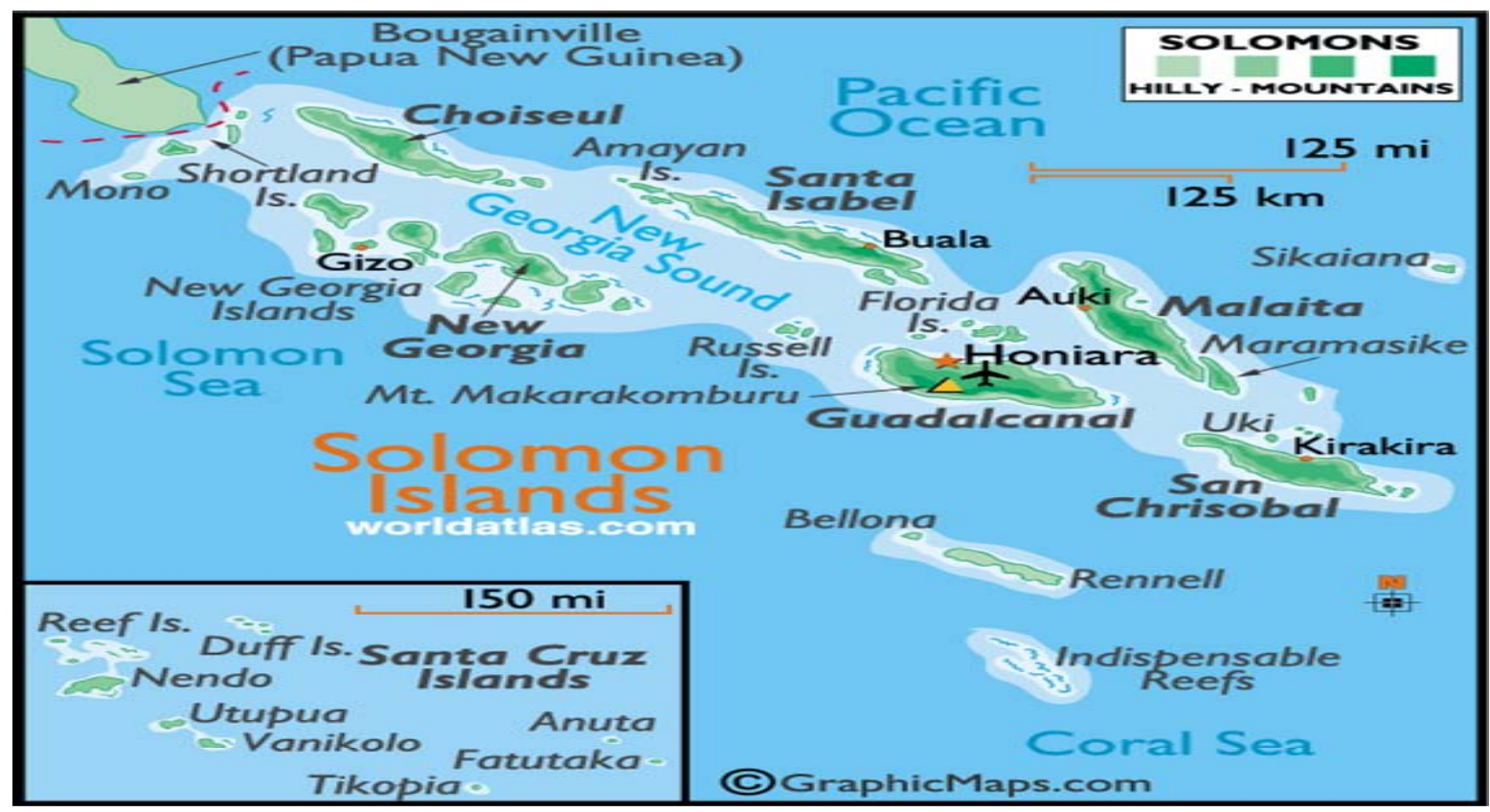

Source: Retrieved January 20, 2009, from www.worldatlas.com/webimage/countrys/oceania/sb.htm 


\subsubsection{Historical and Political Context}

Archeological and linguistic evidence shows that Solomon Islands were settled between $4000-5000$ years ago by people from South East Asia (SIVB, 2006). The migration pattern reached what are known as Vanuatu, New Caledonia, Fiji and the Polynesian islands of Tonga and Samoa (SIVB, 2006). There is evidence of the return of some Polynesians some time later whose descendants are now settled on atolls that border Solomon Islands northern and eastern boundaries (SIVB, 2006).

It was not until the $16^{\text {th }}$ century that the Europeans learned of the Solomon Islands. Spanish explorer Alvaro de Mendana made the first contact in 1568 (SIVB, 2006). Mendana then named the isles the Solomon Islands after he found alluvial gold believed to be the source of King Solomon's great wealth. It was through his influence that many of the islands in the archipelago bear Spanish names (SIVB, 2006).

The exploration continued with the Dutch and French explorers followed by the Germans and British (SIVB, 2006). The islands of New Georgia, Guadalcanal, Makira and Malaita became a British

protectorate in 1893 with Tulagi proclaimed the protectorate capital in 1896 (SIVB, 2006). The islands of Santa Cruz, Renell and Bellona were included between 1898 and 1899. The Shortlands, Choiseul, Santa Isabel, and Ontong Java were added from the protectorate until 1900 (SIVB, 2006). The Solomon Islands gained independence from Britain on July 7, 1978. The nation has since continued to follow the Westminster system of democracy with the British monarchy retained as the head of state, represented in the country by the governor general (SIVB, 2006). 


\subsubsection{The Socio - Cultural Context}

The Solomon Islands has a diverse culture with many languages, customs and traditional beliefs. The population of Solomon Islands was 460,100 people according to 2004 estimates (SIVB, 2006). 93.3\% are Melanesians, 4\% Polynesians, 1.5\% Micronesians and less than 1\% are Europeans and Asians (SIVB, 2006). Today about 70 - $80 \%$ of the total population live a subsistence lifestyle in the rural villages and islands, away from the main urban centers (SIVB, 2006). They depend much on subsistence farming and fishing for family consumption and survival. They continue to live in a simple and traditional life that needs support from family, tribal and community members for survival. Furthermore, they speak more than 120 different vernaculars and languages (SIVB, 2006). However, Solomon Pijin is the lingua franca used throughout the country.

The capital of Solomon Islands, Honiara, is located on the island of Guadalcanal with more than 30,000 inhabitants (SIVB, 2006). The provincial government is divided into 10 administrative areas of which 9 are provinces, administered by elected provincial assemblies and headed by provincial premiers, and the tenth is the city of Honiara, administered by a city council and headed by a mayor. The provincial headquarters are Auki, Buala, Gizo, Kirakira, Lata, Taro, Tegoa and Tulagi. About 95\% of the population is Christian. The main denominations are the Church of Melanesia (Anglican) about 25\%, Roman Catholic, 19\%, South Sea Evangical Church (SSEC), 17\%, United Church (Methodist), 11\% and Seventh Day Adventists (SDA), 10\% (SIVB, 2006). More recently other smaller religious groups have come into Solomon Islands, notably the Bahai faith, Jehovah’s Witness, Assembly of God, Baptist, Church of Living God, Church of Nazarene, the Pentecostals and Muslims (SIVB, 2006). 


\subsubsection{The Education System}

The education system in Solomon Islands is administered under the Education Act of 1978 (MOE, 2005a) providing the legal basis on which the education system is managed and administered. The act confers the operation of primary schools, secondary schools, tertiary institutions and more recently includes Early Childhood Education (ECE) and vocational schools (Fitoo, 2009). Since the education system was set up, it has continued to be influenced by colonial systems. According to Potter (2005), formal education was first introduced in the early 1960s. This education system was designed for a small elite group of students only. In the past, education was based on the academic model derived from the colonial administrators with the aim of training Solomon Islanders to become office administrators. The academic curriculum has led to the expectation of paid employment and is referred to as 'education for employment'. A number of attempts were made to change the education system to aim students towards self sufficiency once their formal education was completed. The philosophy of 'education for what' was initiated and apparently failed due to enormous pressure from parents and students (MOE, 2005b). The concept of education for employment has remained in the minds of parents, students and other key stakeholders. Consequently when the majority of school leavers fail to find paid employment, they become frustrated and see themselves as failures of the education system (MOE, 2005b).

The education system is highly centralised whereby all functions and responsibilities are controlled and administered by the national government. This includes the approval and establishment of new schools, recruitment, promotion, training and payment of teachers, the examination system and development and dissemination of curriculum materials to schools. The education system is comprised of ECE which enrols children from age 3 to 5, Pre Class at age 6, Primary education from age 7 to12 and Secondary education from age 13 to 19 . There are more than 560 primary schools and 192 secondary schools (MOE 
Report, 2008). These schools are administered by different education authorities. Distribution of secondary schools is given in table 1.

Table 1: Distribution of secondary schools by provinces, including Honiara City Council

\begin{tabular}{|l|c|c|c|c|}
\hline \multicolumn{1}{|c|}{ Province } & \multicolumn{3}{|c|}{ Type of School } & Total \\
\hline & CHS & PSS & NSS & \\
\hline Central & 9 & 1 & 0 & 10 \\
\hline Choiseul & 12 & 1 & 0 & 13 \\
\hline Guadalcanal & 28 & 3 & 3 & 34 \\
\hline Honiara City & 16 & 1 & 1 & 18 \\
\hline Isabel & 5 & 2 & 0 & 7 \\
\hline Makira \& Ulawa & 17 & 1 & 2 & 20 \\
\hline Malaita & 49 & 3 & 1 & 53 \\
\hline Rennell \& Bellona & 1 & 1 & 0 & 2 \\
\hline Temotu & 5 & 1 & 0 & 6 \\
\hline Western & 25 & 2 & 2 & 29 \\
\hline TOTAL & $\mathbf{1 6 7}$ & $\mathbf{1 6}$ & $\mathbf{9}$ & $\mathbf{1 9 2}$ \\
\hline
\end{tabular}

(Source: MOE Report, 2008)

The secondary school system has three types of schools. Community High Schools (CHS) are administered by the different province and church agencies. They offer secondary education from Form 1 to 3 and enrol students from the nearby communities. Provincial Secondary Schools (PSS) are administered by the provincial governments. They offer secondary education from Form 1 to 5 and enrol students from the whole province. National Secondary Schools (NSS) are administered by church agencies and the state. They offer secondary education from Form 1 to 6 or 7 and enrol students nationwide. There are three examination exiting points: Solomon Islands School Entrance (SISE) at the end of grade 6; Solomon Islands National Form 3 Certificate (SINF3) at the end of Form 3; and Solomon Islands School Certificate (SISC) at the end of Form 5. These examination and assessment systems are centrally administered by the National Examination and Selection Unit (NESU) of the MOE. The sixth form and seventh form curriculum and examinations are administered outside of Solomon Islands by the South Pacific Board for Educational Assessment (SPBEA) and the University of the South Pacific (USP). 
According to Ward, Sikua and Banks (2005, p. 325), "the education sector faces severe problems of low and uneven access, lack of resources, deficient facilities, high drop-out and push-out rates, low standards and achievements, questionable curriculum relevance, inappropriate assessment systems, and ineffective quality assurance mechanisms”.

\subsubsection{The Secondary School Curriculum}

The CDC is part of the MOE. The Centre is responsible for the development and distribution of curriculum materials for both primary and secondary schools. The responsibility covers both primary and secondary education from Grade 1 to Form 5. The focus of this study is on the secondary science curriculum for Forms 1 to 3. Prior to independence, the secondary curriculum was based on imported and foreign curriculum. It was not until the mid 1980's that Solomon Islanders were involved in writing curriculum materials. The secondary curriculum is designed to offer academic subjects such as English, Mathematics, Science, Social Studies and practical subjects such as Business studies, Agriculture, Home Economics, Industrial Arts, Christian Education, Physical Education and Creative Arts. The curriculum offers general knowledge content for the first three years of secondary education whilst more specialised knowledge content is included in Forms 4 and 5 in the senior secondary levels. The curricula for Forms 6 and 7 are written and administered by regional agencies outside of Solomon Islands. There is an acute shortage of curriculum material in secondary schools throughout Solomon Islands. Little revision has been done on the subjects. Most subjects were written in the early eighties and are still used today. The only exceptions are Home Economics, Mathematics, English and Creative Arts which were revised in the early nineties and Science in the late nineties. This has caused a lot of problems not only in the reviewing of the current secondary school curriculum but also a shortage of curriculum materials through rereprinting and re-supplying of curriculum materials to secondary schools throughout Solomon Islands. 


\subsubsection{The Curriculum Review and Reform Programme}

One notable assistance by NZAID is the funding of the CRRP. The reform began in September 2003 with practical subjects. In 2004, all secondary subjects and Social Studies, Science and Health in the primary curriculum were included. The CRRP is one of the core components of the Solomon Islands National Education Strategic Plan (MOE, 2006). Secondary Health Education was added to the existing 11 subjects with the aim of teaching school-aged children basic health knowledge, skills and values on safe and healthy practices as well as ways for combating diseases and dealing with other critical health issues.

The CRRP also provides a vision in response to what has been described as the failure of the education system being a contributing factor to the ethnic unrest in Solomon Islands. It has been argued that the school curriculum lacks basic skills, attitudes and values that are significant for good citizenship and nation building in Solomon Islands (MOE, 2006). It therefore requires changes to the school curriculum to meet needs and challenges in our communities. A comprehensive curriculum that provides school-aged children with the opportunity to learn and appreciate knowledge, skills and values that they can use after their formal education is paramount. The basic aim for the CRRP is to develop a comprehensive curriculum which will equip students leaving at each exit point, especially considering the rate of unemployment and lack of spaces in the senior secondary schools (Ward, Sikua \& Banks, 2005; MOE, 2005b; MOE, 2006; MOE, 2007). The CRRP has also taken into account policies that were developed to facilitate curriculum planning and development. For instance, the TVET policy emphasises the balancing of practical skills with the existing academic content in the school curriculum in the ten years of Universal Basic Education policy that begins at the preparatory year and continues through to the end of the third year of secondary education. 


\subsection{Structure of the Thesis}

Chapter One is an introduction to the study. It gives an overview of the research context of the study. This chapter describes the need for this study, the researcher's interest, the purpose of the research, research questions and the significance of the study. Background information on the geographical and physical features, and the socio - cultural, political and educational developments has been described in setting the scene and context of the study. Chapter Two is the literature review. This chapter documents literature on the OBE model and curriculum approach. It describes the perceptions and opinions of international researchers on the topic and draws lessons that can be applied to the study. Critical perspectives in favour of and criticisms of OBE are highlighted. The chapter concludes with the prospects and challenges of curricula in Pacific Island countries. Chapter Three is the research methodology. This chapter explains how the study was conducted and how the data was processed, analyzed, presented and triangulated. As well, it describes the theoretical and methodological framework that underpins the study and explains how the ethical requirements were managed and supervised.

Chapter Four is the description of the study findings. This chapter gives an oral description of the raw interview data. The data was tape recorded and transcribed for data analysis. Data was collected using one on one interview and focus group conversations. Chapter Five contains data analysis and discussion. This chapter describes how the research data is analyzed, presented and interpreted. These were organised and discussed according to broad themes that were convenient for the discussion of the research findings. Finally Chapter Six is the conclusion part of the study. It summarises the research findings, research contributions, implications and recommendations. Furthermore, it explains potential future research areas that could be undertaken to support this study.

In the next chapter, I will present the literature review for this study. 


\section{CHAPTER TWO}

\section{THE LITERATURE REVIEW}

\subsection{Introduction and Overview}

Chapter One provided the introduction and research context of this study. This chapter presents a literature review of OBE and the philosophy and principles of this education model. It further examines proponents' views and criticisms of OBE. Finally, this chapter concludes with the current status, challenges and prospects of education curricula in the Pacific region.

\subsection{Introduction to the OBE model and Curriculum Approach}

\subsubsection{Philosophy of OBE Model}

Research on OBE has attracted considerable attention in developing countries, including Solomon Islands. Killen (2003) and Hall (2005) point out that OBE, like many other concepts in education has been interpreted and applied in many different ways. This has caused confusion and criticism because of the way people view the application of OBE as incorporating three distinct but related aspects. These elements being: OBE as a theory of education; a systematic structure for education; and a particular approach to instructional practice (Killen, 2007). Spady (1994, p. 1) defines OBE as “focusing and organizing everything in an education system around what is essential for all students to be able to do successfully at the end of their learning experiences. This means starting with a clear picture of what is important for students to be able to do, then organising the curriculum, instructions, and assessment to make sure this learning ultimately happens”. In other words, this philosophy rejects the traditional focus of what the school provides for students, in favour of making students demonstrate what they "know and are able to do” in the form of significant outcomes at the end of a learning activity. 
In order for us to understand the approaches underpinning the OBE model, we have to examine Spady's definition of OBE. First, there is the use of outcomes as opposed to objectives. Kings and Evans (1991) note that outcomes are the end products of any instructional process. Such outcomes are observable, measurable and must impact on the learner. In contrast, Killen (2003) states that objectives are commonly used in schools to describe specific things that students must do at the end of each instruction. Objectives are usually seen as short term goals that students can achieve by the end of a lesson. Killen (2007) argues that to distinguish 'outcomes' from 'objectives', Spady (1994, p. 18) defines outcomes as "high quality culminating demonstrations of learning in context.” In other words, outcomes are demonstrations of learning. These are things that learners can do as a result of their learning. The second aspect of Spady's definition was that outcomes describe significant learning, not trivial learning. For Spady, learning is not significant unless the outcomes represent the complexities of real life and give prominence to the actual roles in life students would face after leaving formal education (Killen, 2007). This vision is used in building school programmes for achieving future needs of students and of the society. O’Neil (1994) points out that such a vision is driven by outcomes that students must display at the end of their educational experience. The third aspect of the definition involves the demonstration of achievements in appropriate contexts. Spady (1998) argues that these factors directly affect the content, complexity and competencies that the demonstration requires. Killen (2007) also affirms that all students should be expected to demonstrate high quality learning as a result of deep understanding and a high level of competence. Therefore to clarify the big picture about the outcomes approach, OBE places a lot of responsibility on the designers of the new curriculum. As stated, the curriculum process begins with the identification of essential outcomes that students can learn and apply in post-school real life situations. It also requires outcomes to be expressed in a way that will help teachers in their planning and instructional practices (Killen, 2007). Finally, Spady’s approach also places the responsibility on funding agencies and 
administrators at all levels to provide sufficient resources as well as providing conducive learning and teaching environments within which teachers can implement OBE.

\subsubsection{Key Principles of OBE}

A number of authors (Spady, 1993; Acharya, 2006; Killen, 2007) state that there are four basic principles that guide the development and implementation of OBE. First is the issue of clarity of learning outcomes, which emphasizes the significance and culminating exit outcomes as the focus of the learning process. These outcomes are considered to be observable, measurable and attainable. Further, OBE should let students know what they are aiming for, including the expectations in the classroom. Second, is the 'designing backwards or downwards' process involved in the development of the OBE model. The learning outcomes are identified first as the focus and later linked to all planning, teaching, and assessment decisions, all of which are directly connected to these outcomes. Third, is the issue of consistency, and high expectations of success. This process sets the expectation that OBE is for all learners and they must succeed by achieving high educational standards. This is the philosophy that OBE

uses as its foundation for promoting and facilitating high achievement. Fourth, is the issue of providing opportunities so that students can explore and expand on new knowledge. Further, it involves developing curriculum to give scope for every learner to learn at his or her own pace and also cater for individual needs and differences, thus requiring time and availability of resources for students to attain successful exiting outcomes.

\subsubsection{Forms of OBE}

Spady (1993) identifies the three forms of OBE approach as traditional, transitional and transformational. First, traditional OBE is based on colonial approaches to curriculum where established disciplines have priority. There is a strong focus on the content and year level organization and what is in the classroom is 
generally divorced from the real world. The focus is on measuring students' mastery of the curriculum. The learning outcomes cannot be generalised across the curriculum or other contexts and are performed or demonstrated only in schools. Second, transitional OBE moves the focus away from teaching subjects to promoting higher order competencies such as critical thinking, problem solving, and communication skills; going from being in the classroom to being successful after graduation in terms of life-long learning. The learning outcomes can be generalised across the curriculum and require a substantial degree of integration, synthesis, and functional application, thereby encouraging interdisciplinary approaches to developing the outcomes (Killen, 2007). Third, transformational OBE is future-orientated and focuses on the general capabilities of young people and their ability to do complex tasks in situations relating directly to real life. Learning is no longer based on year levels and the belief that students must succeed in a set period of time. The learning outcomes can be generalised across the curriculum or other performance contexts and require a much higher degree of ownership, integration, synthesis and functional application of prior learning to respond to the complexity of real life situations (Killen, 2003). In other words, not all outcomes are created equal; some require much more complex learning and demonstration of higher skills than others (Killen, 2007).

\subsubsection{Instructional Guide and Planning for OBE}

Another area of concern is the use of clear and specific outcomes for Instructional Guide and Planning (Acharya, 2006). The Instructional Guide and Planning strategy under the OBE system takes four major steps. First, deciding on the outcomes. It is very important to define the outcomes of a programme in a specific and precise manner. Spady \& Marshall (1994) wrote: “Outcomes are clear, observable demonstrations of student learning that occur after a significant set of learning experiences.... Typically, these demonstrations, or performances, reflect three things: (1) what the student knows; (2) what the student can actually do with what he or she knows; and (3) the student's confidence and motivation in 
carrying out the demonstration. A well-defined outcome will have clearly defined content and will be demonstrated through a well-defined process beginning with a directive or request such as 'explain,' ‘organize,' or 'produce'.”

Acharya (2006) points out that most outcomes and standards should be described in terms of three dimensions. First is the dimension of 'content' which can be viewed from simple to complex, the dimension of 'context' which takes the view from simple to complex and the dimension of 'competence' which can be viewed from low to high. Second, is demonstrating the outcomes. Expected achievement levels will be defined by setting 'benchmarks' for each level of the programme. Each benchmark is a skill that must be demonstrated by the student. Unlike the outcomes, the list of benchmarks is different at every level of study. Benchmarks should specifically define the goals of the curriculum and determine ways to assess whether students have reached these goals at that level of study. Third, is deciding on content and teaching strategies. One of the most common questions among teachers is 'what experiences will I need to provide?' and 'do I know much about my students?' At the beginning of each class, teachers will delineate expectations and outcomes to make the students feel like they are part of decisions being made in the classroom (Acharya, 2006).

\subsubsection{Models for Implementing OBE}

There are two general approaches to implementing OBE (Acharya, 2006). First is the 'whole-class' model which seeks to bring all learners in a classroom up to a high level of learning before proceeding further. Second is the 'flexible' model which uses flexible grouping, continuous progress, technological approaches and instructional management. The latter model requires the instructor to make attempts to meet each student at his or her level of competency and build upon the 'strengths already there' throughout the subject (Acharya, 2006; Reid, 2005). In addition, a classroom culture of mutual respect 
should have been built and the teachers have a great deal of information about each student and the learning environment. It is significant to note that a specific textbook is not used for these classes (Acharya, 2006; Maha, 2009). Since a regular textbook would bring a sense of confinement, it is preferable to use a varied range of reference books and authentic materials (Acharya, 2006). Each year, units of study would be developed according to the changing needs of the students and integrated into the curricula (Acharya, 2006; Reid, 2005). In this manner one could build upon the interests of the students and individualise their classroom experience (Burns \& Squires, 1987). Tower (1996) notes four points that could be used to make the OBE system work effectively in schools. First, it is essential that what students need to learn must be clearly identified and explained. Second, students’ progress is primarily based on demonstrated achievements to prove learning has taken place. Third, it is essential that multiple resources and assessment strategies need to be available to meet the needs of each student. Fourth, adequate time and teacher assistance needs to be available in order for students to reach their potential.

\subsubsection{Some Implications on Assessment}

Killen (2007) points out that there must be a close alignment between outcomes that students are required to achieve and assessment tasks that show their achievements. Without this alignment the assessment results will not be reliable and the inferences drawn from the assessment results will not be valid (Hall, 2008). Therefore, as required by the OBE model, assessment in the classroom must reflect the key principles of OBE. First, is the principle of clarity of outcomes. If the principle of clarity of focus is followed, then all assessment must be directly linked to significant outcomes that are required for students to achieve. This is to ensure that assessment criteria used in the science classroom are valid. They must be able to measure what they are intended to measure and any inferences drawn from the assessment can be considered valid as well. Furthermore, there must be a direct link between the outcomes and the assessment tasks to make them reliable, so that results gathered from the assessment is 
consistent and fair. Second, is the principle of designing downwards or backwards. It is important that the focus of assessment is on both short and long term outcomes. It would mean that the learning that students are expected to experience and regular assessments will go beyond the classroom. Therefore, it would require assessments that are integrated with other sources for meeting these outcomes. Third, is the principle of high expectation. If the principle of high expectations is followed, then assessments must be challenging and must provide an opportunity for students to demonstrate deep understanding and high levels of achievements. Killen (2007) points out that this would increase teachers' workload which would of course show their commitment to the students. Teachers as facilitators must recognize and reward such excellence and student achievements. Fourth, is the principle of expanded opportunity. If the principle of expanded opportunity is followed, teachers as facilitators must be aware that a student who does not achieve a high level of performance at their first attempt, must be provided with further opportunities to learn and demonstrate his or her learning. Killen (2007) claims that teachers would face time constraints and demands for resources. It is essential that teachers take a flexible approach to assessment in the classroom.

\subsubsection{Claims in Favour of OBE}

Proponents view OBE as a valuable replacement of the traditional objective model. OBE proponents believe that all students can learn regardless of ability, race, socio - economic status and gender (Maha, 2009). Proponents view students taking the OBE system as competent and will complete rigorous academic course work so that they leave high school prepared for further education. Students who leave the school system will also acquire essential knowledge for making a living in their communities. There will be high morale with student learning amongst staff and the school administration. Students should be measured against standards rather than measuring students against one another (Hall, 2005a). We are trying to keep pace with the rate of globalisation and therefore must reach or maintain expected standards. 
Students must demonstrate that they have met the standards rather than take a free ride to the next level of education. We do not want to provide an education that is the gateway to unemployment. Furthermore, the adoption of measurable standards is seen as a means of ensuring that the content and skills covered by the standards will be a high priority in the education of students (Muralidhar, 2009).

Thaman (2002) recommends that most Pacific Island countries should consider adopting the OBE model. It has the advantage of organising the school curriculum into more specific and structured learning outcomes, which students can acquire and competently apply in their rural communities. The learning strategies must reflect how students learn in their cultural settings to promote effective learning in the classroom (Bakalevu, 2009; Maneipuri, 2002; Pasikale, 1996). Doing so would strengthen the philosophies of indigenous education as a means for survival and continuity in the region (Thaman, 2009; Gegeo \& Gegeo, 2000) and avoiding the loss of cultural knowledge and practices (Sanga, 2009).

Although there have been negative experiences in the practice of OBE curriculum in Australia and other countries, the literature has failed to state clearly the significant areas of difference in the conceptualization and implementation of OBE. According to Norman (2006), unlike in Western Australia, curriculum development in Papua New Guinea is centralised and has resulted in the development of various syllabuses for implementation. Each syllabus has outcomes. He further argued that it would be misleading to tell parents that because of OBE, teachers are now expecting their students to create their own knowledge, although this could be an alternative learning approach for exploration in the future. Norman (2006) argues that because of the OBE curriculum, some teachers are being able to assist their students to construct and create their own meanings in the classroom. Teachers are capable of doing this and will improve with more support. It would be untrue to say that OBE teachers are letting the students themselves decide what they will learn and how much they will learn. Norman (2006) asserts 
that the OBE curriculum has however enabled teachers to change from being teacher-centered to being facilitators and making many significant changes as well as providing opportunities for students to engage in critical thinking. Furthermore, students are still assessed through examinations that are guided by the OBE model. In this way, as Killen (2007) points out, assessment practices and criteria are more focused, credible and reliable. The OBE model then is seen to be fair to students in many ways that are not fully understood under the objective-based approach.

Interestingly, the expected benchmarks of OBE would not entirely be based on the expectations and curriculum standards of either Australia, the US, Britain, or New Zealand. In the same manner, it is rather inappropriate to condemn OBE as lowering academic standards without having a clear definition of the standards concerned. In the Papua New Guinea situation, it cannot be denied that in the initial stages, a lot of work was involved in developing OBE curriculum and teachers had to do a lot of preparation and needed a lot of teaching and learning resources. Over time the amount of work would be expected to be reduced. The participation of stakeholders and the community is also an important achievement of OBE which leads to more responsibility and ownership of the school curriculum (Norman, 2006). It means that parents also continue their responsibility of supporting their children to meet educational aspirations. OBE also has the luxury of local autonomy. Given such observations of Papua New Guinea, for OBE to be implemented successfully, the schools, parents, stakeholders and provincial and national government need to work together and seriously consider supporting OBE and education reform in Solomon Islands.

\subsubsection{Criticisms of OBE}

The OBE has been interpreted and applied in many different ways. The international literature shows the relative merits of OBE, identifying shortfalls and criticisms, (Donnelly, 2007; Berlach, 2004; Hayes, 2007; Acharya, 2006; Maha, 2009). Everywhere OBE has been implemented, it has led to claims of 
'dumbing down' the curriculum, thus making school education less academic and more about making students feel good about what they learn rather than focusing on what they should be learning in the classroom. Donnelley (2007) argues that the adoption of OBE in the United States is considered a "failed and largely irrelevant experiment” (p. 1 - 3). Consequently, all American states have moved away from the outcomes education model and towards a more academically based, year level specific and teacher friendly model of curriculum development. He further argues that Western Australia has now moved away from the OBE model back to traditional classroom learning with examination-based assessment using grades and percentages that parents can understand. Generally for some Australian states, the adoption of OBE in Australia has failed and or at least has been less than successful (Donnelley, 2007).

Inappropriate outcomes are part of the criticism of the OBE system. Many people oppose OBE reforms because they dislike proposed outcomes. Opponents think that the standards are either too easy, too hard, or wrongly conceived. Most fear that the focus on achievement by all students will result in 'dumbing down' the academic competence to a level achievable even by weak students. Critics are unhappy with having all students meet a minimum standard, instead of most students meeting a much higher standard. Others viewed that the standards might be too low or too high. Hayes (2007) describes OBE as "the sunken ship in the Pacific Ocean” (p. 1). Berlach (2004), from the University of Notre Dame in Australia, describes OBE as “death of knowledge” because of the lack of conceptual clarity (p. 3). He points out that "the definition, philosophical and epistemological approach in OBE is a miasma, confusing and has been placed by vagaries and misleading constructs since its inception” (Berlach, 2004, p. 4). The death of knowledge jargon warrants further investigation for wider conceptual understanding of the OBE model and its curriculum approach. 
According to Hayes (2007) and Renagi (2010), OBE could not be sustained in the Papua New Guinea school system with their limited resources and infrastructure. The average class size is 50 and in many rural primary schools, children are still sitting on the floor (Hayes, 2007, p.1). A number of authors (Berlach, 2004; Hayes, 2007; Renagi, 2010) note also that there would be a huge demand in both time and resources, thus giving enormous pressure to teachers as key implementers who would suffer from the overload of assessment, monitoring, recording and reporting. Arguably, there is a danger that an over emphasis on the mere meeting of the outcomes may lead to "mediocrity and complacency" on the part of students (Berlach, 2004, p. 4).

New Zealand first introduced its outcomes-focused curriculum in 1992 (New Zealand MOE, 2007). Since then, there has been an increasing pace of social change, population diversity, technology and complexity. It was argued that the national curriculum, through its education system, must respond to these challenges ensuring that young citizens have the very best educational opportunities (New Zealand MOE, 2007). For this reason, subsequent reviews have been conducted to cut a much clearer educational pathway in New Zealand. The new school curriculum in New Zealand, however, has good intentions but needs to be backed up by good teachers and the right amount of resourcing if it is to succeed (Bentley, 2007). The “curriculum's outcomes focus puts a premium on highly skilled teachers, something that New Zealand lacks” (Bentley, 2007, p.1). Hall (2005a) argues that OBE curricula are non-prescriptive and as such need teachers with high skill levels to guide and motivate students in a complex learning environment. New Zealand has many good teachers but those with the levels of skills required to implement outcomes-based curriculum are missing right across the country (Bentley, 2007). It is becoming increasingly difficult to recruit quality graduates to deliver the OBE model. According to Hall (1996), there needs to be a clarification on the use of the concept 'outcomes' compared to objectives, and designing of the curriculum and assessment practices for achieving the aims of the education system. Furthermore, 
Bentley (2007) adds that the curriculum's intentions are good but its success or failure will rest on how it is implemented, requiring high quality and well resourced teachers.

In a Melanesian context, teacher qualification and experience would be a major problem. Hayes (2007) argues that the majority of primary teachers in Papua New Guinea have only grade 10 education and two or three years at the teachers college. Therefore, teachers may not be competent to deliver the outcomesbased curriculum as it requires more time, planning and resources. He further argues that the "only sustainable approach to mass education in most Pacific Island countries is the use of a prescriptive, locally relevant, skills-based, academically sound objective-based curriculum” (Hayes, 2007, p. 1). Such a curriculum would be supported by teacher-based materials that are practical for use in larger classrooms with few resources and poor infrastructure. This would also draw attention to the importance and suitability of a normative form of assessment as opposed to the reduced importance of examinations in the OBE. Maha (2009) and Renagi (2010) reports that a learner-centered approach would require a number of outcomes in the syllabus document which may be too many for the teachers to remember, recognise and administer with students in the classroom. A number of authors (Hall, 2005a; Maha, 2009; Renagi, 2010) note that OBE would require an assessment system that is administratively too heavy and demanding.

The government of South Africa has embarked on several notable initiatives including changing the curriculum into an OBE model of learning (Department of Education, 1997 cited in Jita, Maree \& Ndlalane, 2007). According to Atweh \& Keitel (2007), despite all efforts made to change the schooling and education system in South Africa, the implementation of OBE has failed and most classrooms do not seem to have been affected by this change. Further, teachers were yet to embrace the new curriculum discourses and practices, and rote learning will continue to be the dominant feature of teaching and 
learning in most classrooms (Jita, et.al, 2007). Furthermore, coupled with the structural legacies of the past, most teachers are lacking in their subject content and pedagogical content knowledge.

Neyland (2007) also notes that the "scientific management of education" and its natural offspring the "OBE curriculum" is now largely taken for granted by mathematics and science educators in a growing number of countries. He argues that "it is a movement with a single source that has set of ideas born of the assembly line efficiency in the United States and applied there to education” (p. 115). It now represents the orthodox consensus in education theory throughout a growing portion of the world and is now quite impossible to avoid because its central feature is mandatory in nature and has now been made compulsory through government legislation (Neyland, 2007). Neyland (2007) further argues that issues of mathematics and science education are no longer chosen by teachers. It is driven mainly by theorists and economists (Wise, 1979 cited in Neyland, 2007). It is in fact "a blue print designed in one influential country and subsequently, imposed in other countries and a component of the modern day cultural imperialism with many of the hallmarks from its precursors” (Neyland, 2007, p. 115).

\section{$2.3 \quad$ Responding to Criticisms of OBE}

In conclusion, I would like to summarize the criticisms and provide responses in an attempt to clarify some of these confusions and misunderstandings. The criticisms will be categorized into issues relating to philosophy, systems and resources, values, content, assessment and standards and curriculum framework.

\subsubsection{Philosophical Issues}

Some critics claim that it is either impossible or inappropriate to describe what we want students to learn as outcomes before we think about the content and learning activities. Killen (2007) argues that such

criticisms do not have a firm basis, provided we have developed appropriate outcomes. He argues that 
there is a need for proper understanding of outcomes and reasons why students are sent to schools. The decision of what outcomes should be included in the school curriculum has usually been made by curriculum officers and their committees. Killen (2007) argues that no one could ever come up with sets of outcomes that everyone agrees with. He suggests that all outcomes should be seen as problematic and anyone who disagrees should suggest appropriate ones rather than being counter productive by claiming that no outcomes are appropriate. The distinction between outcomes and objectives is crucial. Hall (1996) argues that objectives focus more on the teaching and learning processes whereas outcomes focus more on achievements. However, the second principle of the designing backwards or downwards of OBE has taken into account the processes referred to as the roles of objectives.

\subsubsection{Systematic and Resource Issues}

The second group of critics of OBE focuses on the systems and resource issues (Jansen, 1999 cited in Killen, 2007). Killen (2007) reports that the literature has highlighted that OBE cannot work because the systems are introduced too rapidly, or that teachers are not prepared, or that there are insufficient resources and facilities. It must be understood that these are on-going difficulties that existed even before the introduction of OBE (Killen, 2003). The introduction of OBE has in fact merely highlighted these difficulties; it has not created them (Killen, 2007). In some countries, these are real obstacles to major education initiatives and reforms.

\subsubsection{Values Issues}

The literature reports criticisms relating to values in the OBE curriculum. According to Killen (2003), criticisms range from the claim that OBE side steps the important issue of values in the curriculum to the claim that OBE promotes wrong values. Killen (2007) states that Spady (1994) "makes it very clear that the purpose of school education is to prepare learners for life beyond schools so that they can function 
effectively in their occupational, family, civic and recreational roles” (p. 63). He further argues that Spady (1994) encourages OBE policy makers and developers to ensure that outcomes are defined with culminating outcomes that learners can apply in appropriate contexts in their communities. Quite clearly, any attempt to describe what matters in the school system should be driven by values and by the central question of what education is for (Killen, 2003). Killen (2007) points out that "OBE encourages, rather than stifles, debate about what values should or should not be embedded in the school curriculum” (p.58).

\subsubsection{Content Issues}

Some critics claim that OBE trivializes curriculum content (Jansen, 1999 cited in Killen, 2007) by implying that content is not important. Killen (2007) argues that this is a baseless claim, pointing to the importance of content as a vehicle for achieving learning outcomes. He further argued that the issue of who decides what content is to be studied in the school curriculum does not matter. The content must help learners achieve outcomes that have been specified and are succinctly stated. Another area of criticism is that OBE fragments curriculum knowledge and as such overlooks the important cross curricula and interdisciplinary demands encountered in learning a complex task (Jansen, 1999 cited in Killen, 2007).

This is not true. As Killen (2007) points out, OBE is based around building outcomes for long term significance. He agrees with Spady (1994) who says "such outcomes emphasize complex performance abilities that cut across discrete subject areas” (p. 51).

\subsubsection{Assessment and Standards Issues}

There are often criticisms of OBE based on the perception that it "dumbs down" the curriculum by lowering the standards and that no student fails (Donnelly, 2007). Killen (2007) argues that some of these criticisms have been based on Spady's opposition to testing on a fixed schedule and his basic principle that teachers should give students more than one chance to learn and demonstrate key outcomes. Spady 
(1994, p. 14) points out that a traditional norm-referenced assessment system that compares students with one another "inherently limit some students" chance of success, no matter how high their achievement might be. But the criterion-referenced assessment system that compares students’ performances to clearly set standards applies the same standards to all students, imposing no limits on how many students will reach a given performance level (Hall \& Jones, 2004; Hall, 2005a).

OBE does require teachers to approach assessment differently from the way it is approached in the content -driven curriculum that uses mainly norm-referenced assessment. Killen (2007) notes that one of the major changes is the emphasis placed on defining the standards expected of the students, rather than having the upper limit of performance defined by the highest achieving student. Further, this emphasis is also based on aligning results with outcomes that students should have achieved (Killen, 2003). The approaches to assessment required by OBE may be different, but they certainly do not mandate the lowering of standards (Killen, 2007).

\subsubsection{Curriculum Framework Issues}

Curriculum framework is seen as a very important guide for the successful development of a new curriculum. Killen (2007) agrees that when a new curriculum is being developed, a committee usually does the work. Inevitably the final curriculum would reflect the views and compromise of the committee in order to complete the task. For instance, in the Solomon Islands, school teachers are usually involved in the curriculum decision making (McGee, 1997) as part of the curriculum development process (Print, 1993; Brandy, 1995) and curriculum construction (Grundy, 1987; Brady \& Kennedy, 1999). Given the same task, a different committee would have different views and resolve compromises in a different way. As Killen (2007) agrees, the curriculum committees have to listen to other voices, putting forward a wide range of views based on different views, motives and purposes. No matter how dedicated the committees 
might be, the end result would be a document that contains some details that will appear unacceptable to other stakeholders (Killen, 2003). It must be understood that no system of education is perfect, and no system will work unless curriculum officers, teachers, administrators and key stakeholders are really committed to it (Killen, 2007).

\subsection{Education Curricula in the Pacific Region}

Thaman (2009) argues that education curricula in most Pacific Island countries are culturally-based and eurocentric. They seem to inherit the type of education system left behind by their former colonial governments and bureaucrats (Thaman, 2002). The suitability and relevance of the curriculum is what concerns the current education system in the Pacific region (Thaman, 2009; Bakalevu, 2009; Taufe’ulungaki, 2009; Manu, 2009; Teaero, 2009; Sanga, 2009). Thaman (2002) and Maha (2009) argue that Pacific Island countries should adopt the outcomes based system of education, and develop a model of curriculum that promotes a better way for students to learn and demonstrate acquired knowledge, skills

and values competently. The way they are taught must also be in line with our indigenous methods of teaching and learning in a Pacific based culture (Maneipuri, 2002; Bakalevu, 2009; Manu'atu, 2009; McKinley, 2009; Koya, 2009; Sanga, 2009).

The education system must adopt a curriculum model that captures our traditional knowledge, skills, values, beliefs and practices to keep it alive and relevant for future generations (Teaero, 2009; Nabobo Baba, 2009). Furthermore, the learning in the classroom must first acknowledge and value prior and existing knowledge, skills and experience of students before moving on to new and abstract ideas in the class (Sanga, 2004; Manu’atu, 2009; Bakalevu, 2009; Johansson - Fua, 2009). The curriculum must embrace the knowledge students have and use as they enter formal schooling. Curriculum in the Pacific region must be responsive to the changing needs within individuals, the communities and national needs 
of each country (Sanga, 2004; Thaman, 2009; Manu, 2009). According to Thaman (2009), there must a drastic change to curriculum design, development and how it is to be implemented to curb high failure rates in school examinations in the region. There is an urgent need for rethinking the content and delivery of the education curricula in Pacific Island countries. The need exists to integrate indigenous knowledge and practices that are of value and which are the basis of societal survival and continuity (Thaman, 2002; Gegeo \& Gegeo, 2000; Sanga, 2009; Unaisi - Bobo, 2009). This is also necessary to counter the threat of knowledge loss in Pacific Island communities (Sanga, 2009). Teaching and learning in the region must embrace traditional ways of teaching and learning in a Pacific context. The teaching strategies involved must confirm effective pedagogy and grounded understanding of pedagogical content. Likewise, learning strategies organized for learners must also involve participatory and interactive learning. This would require practical activities and 'hands-on' experiences or 'learning by doing'. According to Gegeo (1998), Gegeo \& Gegeo (2000) and Sanga (2009), it would need integration of our indigenous knowledge and practices into the formal school curriculum. Assessment practices undertaken in the region must take into account the manner in which assessments are traditionally conducted and its purpose in the Pacific context (Maha. 2009). Assessment must be conducted with clearly stated criteria that are appropriate, fair and relevant to the context of learning and wider educational settings in the region (Fasi, 2009; Muralidhar, 2009).

There are challenges in developing a responsive curriculum for the Pacific region. First is the challenge dealing with Pacific Islands curricula viewed to be following a "linear progression” (Thaman, 2009) which is based on an imported curriculum. There is a need for adopting a circular progression to embrace our cultures, values, beliefs and ways of knowing and doing (Pasikale, 1996; Thaman, 2009; Manu’atu, 2009; Teaero, 2009; Sanga, 2009). Second, is the challenge for individual countries to develop a curriculum which is responsive to the needs of multi-cultural and diverse communities. Such curricula 
must be based on research conducted on indigenous philosophies, peoples and communities (Sanga, 2004). Third, is the challenge for developing a unified curriculum for achieving common educational goals in the region. Collaboratively, this would require intensive effort from all stakeholders, given the geographical location, diversity and lack of school resources, facilities and infrastructure in the education system.

In the next chapter, I will describe and discuss the research methodology. 


\section{CHAPTER THREE}

\section{THE RESEARCH METHODOLOGY}

\subsection{Introduction and Overview}

Chapter Two provided literature review on the philosophy, principles, positive claims and criticisms of the OBE model as well as views on the challenges and prospects of education curricula in the Pacific region. This chapter presents the theoretical orientations and methodogological framework for this study. It concludes with research processes and procedures of data collection, recording, transcription and analysis.

\subsection{Theoretical Orientation}

\subsubsection{Research Paradigms}

A research paradigm is defined as "a perspective about research held by a community of researchers that is based on a shared set of assumptions, concepts, values, and practices” (Johnson \& Christensen, 2008, p. 33). It is an approach to thinking, planning and doing research. The emergence of paradigms was argued by Johnson and Christensen (2008) to help human beings advance their knowledge and solve problems. Therefore, as argued by Burns (2000) the search for better answers to important questions in the field of education will probably continue. Johnson and Christensen (2008) pointed out that the three major research paradigms or approaches are quantitative research, qualitative research and mixed research.

The following characteristics are stated to make a clear distinction between the three paradigms. Quantitative research relies on the collection of quantitative or numerical data; qualitative research relies 
on qualitative or non numerical data such as words and pictures; and mixed research involves a mixture of quantitative and qualitative research methods. The exact mixture considered appropriate will depend on the research questions and the context of issues facing the researcher (Johnson \& Christensen, 2008). The focus of quantitative and qualitative paradigms also differs in terms of application. Johnson \& Christensen (2008) give the following descriptions: Quantitative research primarily follows the confirmatory scientific method because its focus is on hypothesis testing and testing the hypothesis with numerical data to support the hypothesis. On the other hand, qualitative research primarily follows the exploratory scientific method. It is used to describe what is seen and to generate new ideas and theories. Qualitative research is used when little is known about a topic to motivate researchers to learn more about it.

In the context of educational research, research is described as a way of knowing (Bouma, 1996) and is about creating new knowledge based on evidence and making sense of evidence collected (Gillham, 2000). According to Cohen, Manion \& Morrison (2000), Burns (2000) and Johnson and Christensen (2008), research is the means for discovering and appreciating the world around us, particularly finding answers to problems. Therefore, the choice of paradigm and method for any research study should be appropriate to what the researcher is trying to find out (Punch, 1998). For this research, the qualitative research methodology was used to explore practicing and former secondary science teachers’ perceptions of OBE and appropriateness or relevance of OBSC in Solomon Islands.

\subsubsection{Qualitative Research Paradigm}

Glesne (2006) describes qualitative research methodology as an umbrella term that covers many different constructivist and some post positivist research approaches. These approaches were developed in different academic disciplines, with their own backgrounds, histories, foci and philosophies. Denzin and 
Lincoln (2008) give a definition of qualitative research methodology as being a situated activity that gives a researcher a set of interpretive and material practices that enables him to make sense of the world around him. Qualitative research uses experiences of people in their natural settings to try and make sense of social reality (Denzin \& Lincoln, 2005; Punch, 1998; Johnson \& Christensen, 2008). Denzin and Lincoln (2005, p. 3) add that "qualitative research involves an interpretive, naturalistic approach to the world. This means that qualitative researchers study things in their natural settings, attempting to make sense of, or interpret, phenomena in terms of the meanings people bring to them”. Additionally, qualitative research takes a holistic approach to interpreting data that involves humans (Punch, 1998 2005). It involves different ways of doing qualitative research and involves inductive reasoning (Punch, 2005; Johnson \& Christensen, 2008). In this context, this study employs a qualitative approach. Using a qualitative approach is relevant as it involves studying the experiences of practicing and former science teachers. A qualitative approach also enables teacher’s experiences to be studied in their real life settings, in their schools and in the Solomon Islands context. Thus involving fieldwork as a qualitative method allows the researcher to go out into the field to study the experiences of the participants (Punch, 2005; Johnson \& Christensen, 2008).

One other important aspect of qualitative study is that the researcher plays a major part in collecting and interpreting the data (Denzin and Lincoln, 1998). Data and social phenomena are interpreted through the eyes of the researcher (Johnson \& Christensen, 2008). The two authors (Johnson and Christensen 2008) stated that interpretive researchers also recognise that they are part of, rather than separate from, the research topics they investigate. They also not only consider their work impact on the participants but also the participant's impact upon the researcher. The role of the researcher in this study is important. Establishing the background knowledge and experiences of the study participants is necessary to gain a deeper understanding of the experiences from practicing and former secondary science teachers. 


\subsubsection{Interpretive - Constructivist Paradigm}

Punch (1998) and Johnson and Christensen (2008) note that it is the research topic and questions that determine the research approach. The decision to use qualitative research is directly related to the nature of the research and as such to represent views from people's natural settings; interpretations and meanings that they bring with them (Denzin \& Lincoln, 2003; Johnson \& Christensen, 2008). The qualitative research employs an interpretive-constructivism paradigm. Such a perspective holds that "meaning is constructed by human beings as they engage in the world they are interpreting and make sense of based on their historical and social perspectives” (Creswell, 2003, p. 9). In this approach, people’s knowledge, views, interpretations and interactions are meaningful properties for the researcher. It is viewed by Mason (1996) as a "legitimate way for collecting data on ontological properties, to interact with people, to talk to them and to gain access to their accounts, experiences and articulations” (p. 39). Moreover, it is richer to have data from face to face discussions and listening to people's views, experiences and perceptions. The organization and interpretation of research data is significant to the critical analysis of the data. Being involved in collecting the data enables the researcher to make a critical analysis and offer suggestions (Johnson \& Christensen, 2008).

Johnson and Christensen (2008) note pattern theories as explanations that develop during natural or qualitative research. These theories represent a pattern of interconnected thoughts and parts linked to a whole. However, it contains interconnected concepts and relationships that can be used as metaphors and analogies to make relationships “make sense” (Creswell, 1994). According to Johnson and Christensen (2008), pattern theories are systems of ideas that have the ability to inform. The concepts and relations at the same time form a mutually reinforcing, coherent and closed system. The researcher will then use information gathered and develop themes until a theory or pattern emerges (Creswell, 1994). This inductive approach also provides suggestions for placement of theories in the qualitative research 
(Creswell, 1994; Burns, 2000; Johnson \& Christensen, 2008). So we come to the culminating aspect of the entire study. According to Creswell (1994), the development of a theory grounded in the data, whether the end product is a pattern, a generalization or a valid visual model, represents a new theory developed by the researcher. So it holds possible recommendations and suggestions that may be appropriate for implementation in secondary schools.

\subsection{Methodological Framework}

\subsubsection{A Case Study Approach}

This study employs an exploratory case study. Using a case study as suggested by Yin (2003), will enable the researcher to understand a complex social phenomenon. In this case, the case study was used in order to understand perceptions of curriculum stakeholders about the newly developed OBSC in Solomon Islands. Such an approach allows the investigation to retain "the holistic characteristics of the real life events” (Yin, 2003, p.46) and deals with a variety of self evident documents. Yin (2003) considers a case study to be more compelling and more robust. Yin further notes that analytical conclusions can arise independently within a case study. Consequently, differing perspectives are obtained according to the perceptions and organization of different participants in the case study.

According to Punch (2005), the aim of a case study is to understand the case in depth, in its natural setting, recognizing the complexity of its contents. As mentioned, a qualitative case study was preferred for this study because the study focuses on selected curriculum stakeholders who have been involved in in-depth one-on-one interviews and focus group discussions (Yin, 2003; Johnson \& Christensen, 2008). The study used a purposeful sample of practicing and former secondary science teachers who have participated in the CRRP. Doing so has allowed the researcher to gather a balanced view from the respondents based on their teaching experience and has also allowed them to share their views on their 
personal experience as members of the science advisory and working group committees. So the researcher has been able to interact with respondents and listen to their views, opinions, and experiences within the context of the study (Mason, 1996; Johnson \& Christensen, 2008).

\subsubsection{Semi - Structured Interviews}

The study used two basic methods of gathering data: the focus group discussions and one-on-one interview. Semi-structured interviewing was the appropriate method for gathering data in a case study (Patton, 1987; Johnson \& Christensen, 2008). Such an interviewing strategy is used in case studies for the purpose of allowing participants to express their views and to allow time for the researcher to observe and take notes (Johnson \& Christensen, 2008). Cohen, et. al, (2007) and Warsal (2009), suggests that semistructured interviewing allows researchers access to people's views and opinions and, to capture their articulations. Furthermore, "semi-structured interviewing is appropriate because participants are able to express themselves freely without the interviewer controlling the discussion as well as help develop connectedness with the interviewees” (Warsal, 2009, p. 46).

For this study, using semi-structured interviewing allowed the researcher, not only to obtain authentic data but also to develop good relationships with the participants (Warsal, 2009). The same author further argued that when interviewing professional colleagues, it is important to establish trust and respect. Doing so enables participants to develop ideas, construct meaning, and contribute effectively. Using open-ended questions are also important for effective interactions between the interviewer and interviewees. In this way the interviewer would be able to record views and opinions of the participants more accurately (Malasa, 2007). In a case study, however, the introductory question is very important. Such questions, according to Warsal (2009) are icebreaker questions, because they make the participants feel less nervous and allowing the conversation to flow effectively. 


\subsubsection{Limitations of Using Semi - Structured Interviews}

A number of authors (Cohen, et.al, 2007; Johnson \& Christensen, 2008) reported that having interviews can create a hierarchical relationship between the researcher and the participants. According to Warsal (2009), the structuring of the questions allows the researcher to be in control of the discussion. Further, it was also important to build positive relationships and feel connected with the participants to allow them to talk freely and communicate well (Warsal, 2009). Some of the practicing and former science teacher participants in this study were my old colleagues. They were members of the science advisory and working committees. Having such connections with the participants as reported by Warsal (2009) would minimise the hierarchy in the relationship. Warsal (2009) further noted that "while establishing rapport is important during interviews, it is also important that this relationship does not allow the respondents to communicate in a way just to please the researcher” (p.46). May (1997), Patton (1987) and Johnson and Christensen (2008) suggest that qualitative interviewing can be time consuming. For this study, transcribing from Solomon Islands Pijin to English took a lot of time. According to Warsal (2009), "when interviewing non-English speakers it is important to transcribe into the language used first, and then translate to English” (p. 46). From her experience, she however, found that some of the words may differ and may distort the data. To avoid the distortion of data, I therefore ensured the translation of the data is done accurately to maintain validity and authenticity of the data collected and transcribed.

\subsubsection{Focus Group Interview}

In case studies, a focus group discussion is a useful tool for the following reasons. It is more natural than other methods. It offers an opportunity for constructing meanings among the participants and gives them power to participate (Krueger \& Casey, 2000). Further, interactions among participants, as claimed by Cohen (2003), will lead to useful data outcomes. Similarly, the method allows the researcher to use group synergy to maximize, recall and highlight the diversity of perspectives, thereby providing a richer and 
more qualitative perspective (Anderson, 2002). In addition, focus group discussions can create a context in which participants feel free to express their opinions and make judgments for themselves on questions posed by the researcher. However, it is crucial to note that in case studies, questions for focus groups must be carefully worded so that they genuinely appear about the topic (Yin 2003). The role of the researcher is generally to facilitate discussions through directives, encouraging participants to express their opinions and carefully asking follow up questions (Krueger \& Casey, 2000). According to Krueger and Casey (2000) and Warsal (2009), the researcher is the moderator and puts forward the topic of discussion but does not participate in the conversation, allowing participants to express their views freely. The researcher instead acts as a facilitator, allowing the discussions to flow freely while making observations (Krueger \& Casey, 2000). The researcher only intervenes "when there is difficulty in the flow of the discussions, or when the discussion is out of focus and context” (Warsal, 2009, p.46).

In this study, "prompts were used to guide the discussions as well as encouraging the conversations to continue, while observing meanings and constructing arguments on the themes” (Warsal, 2009, p.47). Instructions on procedures were explained prior to the group discussions as respondents were new to group conversation. In accordance with Krueger and Casey (2000), these protocols were followed to enable the researcher to control the discussion, take notes and also identify who is saying what. A focus group discussion was held with 8 respondents. “The size of a focus group is very important and having a smaller number, for instance, 6 - 8 participants would be sufficient” (Warsal, 2009, p.49). For this study, 8 participants from the MOE, SOE of SICHE, public service and different secondary schools in Honiara were asked to participate. Respondents were selected from different organisations, education authorities, schools based on their qualifications, teaching subjects, experience, gender and geographical locations in Solomon Islands. 


\subsubsection{Limitations of Focus Group Interview}

There are limitations to focus group interviews. First, there is the difficulty of control (Cohen, et.al, 2007; Warsal, 2009). According to Warsal (2009), it is more difficult for the researcher to control the discussion in a focus discussion group. Further she reported that the "presence of the researcher in a focus group may affect the participants in conveying accurate information and this would affect the validity of the data collected” (Warsal, 2009, p.48). In this study, this could have happened because of my position and previous involvement with the CRRP at the CDC. Having anticipated such effects, I had to ensure that my presence did not have an impact on the participants. For this group discussion, I asked one question at a time followed by making observations and taking notes. Second, according to Krueger \& Casey (2000) and Warsal (2009), it is difficult to analyze the huge amount of data collected in a group discussion. It is also "time-consuming and demands a lot of work, particularly the need to take account of what is said during the conversation” (Warsal, 2009, p.47). Third, the information given by one member of the focus group can influence what other respondents' might want to say during the focus group conversation.

\subsubsection{One-On-One Interview}

For this study, the one-on-one interview has the following advantages. First as noted by Bell (2006), the researcher can "easily follow up ideas, probe responses and investigate motives and feelings from the interviewee (p. 157)”. Second, as Anderson (2002) notes, there is more value able to be taken from each respondent. It also allows for more in-depth analysis and more detail information from each respondent. Third, the one-on-one interview enables the interviewee to describe his or her perceptions and experience. Further, according to Patton (1987) and Johnson and Christensen (2008), the researcher has the ability to control the interview by asking and rephrasing questions during the interview. In this way, respondents know what the question is so that he or she can respond accurately. Patton (1987) and Johnson and 
Christensen, (2008) point out that the researcher must be sure of what questions to ask, and in what order and must ensure that the questions asked must kept reasonably neutral.

For this study, the one-on-one interview was conducted with 14 respondents using a semi structured format and open-ended questions. Some of the respondents were officers from the NESU, Inspectorate Unit and CDC who oversaw and were involved in the planning and development of the OBSC. Others were teacher educators, lecturers, school principals and experienced science teachers from 6 different secondary schools in Honiara, Solomon Islands.

\subsubsection{Limitations of One-On-One Interview}

There are some limitations in conducting one-on-one interview. Unlike a group interview, this is a face to face interview which involves two persons only; the researcher and the respondents. According to Wengraf (2001) and Johnson and Christensen (2008), the presence of the researcher can cause some degree of disturbance which may affect the procedure of the interview. Punch (2005) notes that the researcher must be in control and ensure that the interviewing process is conducted freely for the purposes of collecting accurate and reliable data. For this study, as an insider, I felt that respondents were not free to respond to some of the questions due to the perception of seeing the researcher as someone who knew more than they did about the nature of the study, as well as being an officer at the CDC and the MOE. According to Malasa (2007) and Fitoo (2009), these circumstances could have a direct impact on the data collected because of the relationship between the researcher and respondents in the context of Solomon Islands. In such cases, respondents who are insecure during the one-on-one interviews, because of respect issues, may not be able to communicate properly. Consequently, the data respondents give may not reflect their experiences and understanding. The data collected may therefore affect the findings of the study. 


\subsection{The Research Process}

As stated, this research employed an in depth one-on-one interview and focus group using semistructured questions. A semi-structured interview and focus group guide was developed for the study with core and sub research questions. In this way, it allowed greater flexibility for the participants to express their views on research questions and other information to help establish positive rapport.

\subsubsection{Site and Sample}

The participants for this study were drawn from different organisations involving 22 respondents. There were 8 respondents in the focus group interview and 14 respondents in one-on-one interviews. These participants had all been involved in the CRRP and were responsible for the development of the OBSC in Solomon Islands. The following participants took part in this study. The focus group interview involved 2 secondary science teachers, 1 science lecturer from the SOE of SICHE, 2 public servants and 3 officers representing different divisions of the MOE. The one-on-one interview involved 2 science lecturers, 1 school principal, and 7 secondary science teachers who were selected from six different secondary schools in Honiara, Solomon Islands. In addition, 4 officials of the Solomon Islands MOE, representing the NESU, CDC and Inspectorate divisions also participated in the study.

\subsubsection{Procedures for Selecting Research Participants}

This study used a purposeful sampling strategy to select the organisations and study participants. In such a method, the sites and participants were not randomly selected. Instead, they were selected according to specific criteria (Wierma, 1995). The study adopted the concept of sampling strategy which required the researcher to select sample and sites to help the researcher generate a specific concept within the chosen theory (Creswell, 2008; Cohen, et.al, 2007; Johnson \& Christensen, 2008). Sites were chosen to involve key stakeholders including teachers, school principals, lecturers and officials of the MOE. In this study, 
two identified strategies were used to collect and confirm data using the triangulation method (See section 3.6.5, page 49). The institutions identified for participating in the study included, the SOE of the SICHE, government ministries, secondary schools and the MOE. The methods assumed satisfy the criteria for obtaining valuable information as outlined by Patton (2002) and Johnson \& Christensen (2008) from which the researcher could collect data that was significant and of central importance to the study. Stakeholders' focus groups participants were limited to those who had participated in the development of OBSC and who had been members of the science advisory and working group committees. Limiting the number of participants was based on a number of considerations. First, there was the importance and relevance of the first hand information from their experience in the CRRP. Second, stakeholders who were teachers had teaching experiences, so could give positive feedback to the study. Third, officials from SICHE and the MOE had useful insights from their experience in curriculum planning and development, and assessment and pedagogical content knowledge that would contribute positively to the study.

\subsubsection{Ethical Procedures Adopted for this Study}

This research conformed to the Victoria University of Wellington Human Research Ethics Regulations and the relevant sections of the Solomon Islands Research Act of 1982. This research project adapted acceptable notions in research ethics from the literature (Clark, 1997; Bell, 1999; Burns, 2000; Cohen, Manion \& Morrison, 2000; Creswell, 2003; Mutch, 2005; Israel \& Hay, 2006; Johnson \& Christensen, 2008) and ensured that the following principles were being followed.

\subsubsection{Access to Participants, Consent and Voluntary Participation}

The researcher informed the research participants about the purpose and procedure of the study so that they understood the nature of the research and any likely impact it would have on them. In addition, participants were asked to sign consent forms upon acceptance for participation before they engaged in 
the research. This was to acknowledge that the participants' rights would be protected during the data collection process. They were fully aware of their rights to withdraw from the research without fear of consequence. Furthermore, participants were fully informed of the fact that their participation was voluntarily and they were not being coerced to participate because of my position at the CDC.

\subsubsection{Confidentiality, Anonymity, Privacy and Safety of Participants}

This study ensured that the confidentiality of data, anonymity, privacy and safety of participants would be observed and maintained. The research participants were assured that the data they provided would remain confidential and would not be disclosed in any manner without their consent. In view of the small and close-knit communities in the Solomon Islands, maintaining anonymity for the participants was a challenge, especially when using one-on-one interviews (Malasa, 2007). However, the identities of participants were protected and recorded voices gathered were anonymously analyzed for study purposes only. The interview data collected from participants was not attributed to any specific participant but was analyzed using identification codes to ensure anonymity. Raw interview data and recordings were kept securely and will be destroyed six months after submission of the thesis. Furthermore, respondents participating in the study were guaranteed that neither their identity nor their institutions would be revealed in the final research report. Finally, this study ensured that the questions asked were focused specifically on the research questions to avoid the participants' privacy being invaded or their time being improperly used. The research participants understood the implications of their participation and that they would not knowingly be subjected to any physical, psychological, emotional or cultural harm during the entire period of data collection. 


\subsubsection{Social and Cultural Consideration}

The Solomon Islands has its own social and cultural issues (Malasa, 2007; Fitoo, 2009). Respondents were encouraged to ensure that they were happy about their participation in the study. According to the experiences of a number of authors (Malasa, 2007; Fitoo, 2009; Warsal (2009), the researcher had to maintain integrity, confidentiality and anonymity of about the nature of the study and research participants. This assurance enhanced trust and rapport with the research participants. The importance of reciprocity, or giving something back to the participants was considered (Malasa, 2007; Fitoo, 2009; Warsal, 2009). Gifts were given to respondents as tokens of appreciation for their participation and contributions to the entire study. As an outsider going into the schools and government offices, certain protocols had to be observed. For this study, permission was solicited through appropriate and relevant authorities before seeing the participants.

\subsection{Data collection and Analysis Strategies}

\subsubsection{Procedures before Conducting Interviews}

According to the Solomon Islands Research Act, permission was sought to conduct research with my respondents through the Chairman of Research committee. First, the Under Secretary of MOE was consulted and briefed about the research project. Ministry officials were asked to participate and participation was voluntary. Approval was then granted by the Research Committee. Second, education secretaries and the chief education officers of the different education authorities were asked about interviewing secondary science teachers. There was an explanation of the nature of the study and discussions about likely possible science teacher respondents. Third, the researcher went to see the Director of Environment and Conservation, and Mines and Energy. Selected officers within this

department, who are public servants, were identified and informed about the study. Fourth, the Head of SOE at SICHE was consulted. Lecturers were identified and informed about the study. Finally, the 
researcher went to see school principals to see science teachers on behalf of the school administration. An explanation about the study was given and teachers who were asked to participate were met personally. During each meeting, relevant research documents including the ethics approval letter from the Victoria University of Wellington Faculty of Education Human Ethics Committee and the research permit from the MOE were handed to the heads of organizations and respondents. Respective heads of organizations were given ample time to consider the request. Upon acceptance, the signing of relevant documents took place prior to the researcher seeing the interviewees. Respondents were also asked to read the explanatory information and upon acceptance they signed consent forms before being interviewed. As stated, they were also assured that their participation was voluntary.

\subsubsection{Conducting Focus Group Interviews}

Prior to conducting group interview, I explained the procedures for the focus group. Ground rules for the group interview were discussed and agreed upon. The focus group interview was conducted at the CDC,

on Thursday $2^{\text {nd }}$ July 2009 from $4.00-6.00$ pm. 8 respondents actually attended the focus group interview. An MP 3 recorder was used for recording the interview. I began the interview by asking warmup questions as a way of settling and engaging informants into the group discussion. I asked each question in a friendly manner to allow informants to respond freely to the research questions. I also rephrased the questions when necessary to assist each respondent with the clarity of the question. Furthermore, prompt questions were asked to encourage discussion from all respondents. Informants were very interested in participating in the group discussion and their responses were well received and acknowledged. 


\subsubsection{Conducting One-On-One Interviews}

Prior to conducting one-on-one interviews, I explained the procedures for the interview. Ground rules were explained for the interviews. All interviews were conducted at the informants' office or in their science classroom. An MP 3 recorder was used for recording the interviews. I began with warm up questions as a way of settling and engaging each interviewee. I asked each question in a friendly manner to allow each respondent to answer the research questions freely. I also rephrased the questions when necessary to clarify each question. Furthermore, prompt questions were asked to guide the discussion appropriately. The respondents appeared interested in participating and their responses were well received and acknowledged. All interviews were conducted during their lunch hour from $12.00-1.00$ pm, after work from 4.30 - 5.30 pm or during weekends on Saturdays from $9.00-11.30$ am.

\subsubsection{Data Recording}

Data recording for focus group discussions and one-on-one interviews depended on semi-structured interviews using open ended questions. An MP 3 recorder was used to record the discussions. As suggested by Johnson and Christensen (2008), tape recording is the best method of recording data as raw materials can remain for later studies although in this case they would be destroyed, while taking notes involves the researchers' interpretation. The questions were asked in Solomon Islands Pijin, a common language used throughout the country. I then transcribed the recording at the end of each interview. The scripts were analyzed using organised coding systems and stored in the computer according to coded files for analysis and access. 


\subsubsection{Data Transcription}

Data recorded onto a tape recorder was transcribed manually. This was done by listening to the scripts. The scripts were recorded in Solomon Islands Pijin and transcribed into English for data analysis. Extreme care was taken to ensure data was transcribed properly (Patton, 1987) to maintain the accuracy and integrity of the data (Johnson \& Christensen, 2008).

\subsubsection{Data Triangulation}

The data collected from qualitative interviews and focus group discussions was organized and validated through a triangulation process. This is a process where information and relevant data is checked and verified on the case being investigated. Triangulation is a powerful way of demonstrating concurrent validity, particularly in qualitative research (Johnson \& Christensen, 2008). Furthermore, the researcher’s experiences and reflections are used as part of the data. This process forms the basis of testing and checking the validity of data collected. Moreover, data gathered was triangulated using two different data collection methods and sources used for the case study.

\subsubsection{Data Analysis Strategies}

I chose to use the content analysis approach described by Johnson and Christensen (2008). This method looks at the content of the interviews of all participants and searches for common themes and ideas. This has allowed a comparison and contrasting of themes within the interviews. The researcher used the narrative approach in order to get a more complete view of the case from the stakeholders. Wierma (1995) argues that qualitative data analysis begins soon after the transcribed scripts are systematically recorded. In some cases both are done together. For this study, data was analyzed using a coding process. The process identified themes and concepts in the data through comparisons, categorisations, interpretations, descriptions and synthesis (Ezzy, 2002; Copper, 1998). Such a process creates meaning 
out of the text data; examining codes for overlaps as well as reducing and collapsing codes into broad themes (Creswell, 2008) and consequently narrowing data into fewer and more precise themes (Creswell, 2003).

For this study, I used guidelines provided by Creswell (2003). The steps to coding and analyzing the data are described as follows. First, was getting a sense of the whole data, followed by reading through all the transcripts and taking note of ideas as they came to mind. Second, was to pick one document of choice, consider its meaning, write it down in words and make a code for it. The process of coding by identifying text segments and assigning a code word was used. The codes were then grouped together into patterns to provide an answer to the theme questions. During the phases of data collection and analysis, all data analysis was managed carefully in accordance with the guidelines of research and ethics practice.

\subsection{Validity Issues of the Study}

Validity is whether a research has described the intended focus or what it was supposed to describe and whether your conclusions are valid (Burns, 2000;; Cohen et al., 2007; Johnson \& Christensen, 2008; Warsal, 2009). Validity ensures that all biases of the research have been acknowledged, to maintain the validity of the study (Hall \& Jones, 2004; Cohen, et.al, 2007; Hall, 2008). For this study, being a Solomon Islander and my position at the CDC of the MOE enabled trust and rapport. Because of this, "the perceived hierarchical relationship between the researcher and participant was minimised, thus reducing potential biases in the study” (Warsal, 2009, p.50). My presence would have contributed to positive engagement, enriching the data for the study. For research to be "accepted and trusted it must show that it can be transferred to other contexts” (Warsal, 2009, p.50). Research must also be able to show that it has credibility and reliability (Hall \& Jones, 2004). The study also aims at gathering data from the experiences of other countries, particularly the success and failures of how OBE was 
implemented, and what are the lessons to be leant for the context of the Solomon Islands. The findings of the research were evaluated based on the perceptions of practicing and former secondary science teachers who were participating in the current CRRP in Solomon Islands.

\subsection{My Role as the Researcher}

As the researcher taking an interpretive-constructivist approach, it can be assumed that my role was also partly that of a participant in this study. It is acknowledged that this role was conducted for and with participants. Therefore, the subjectivity of my work and its value-bound nature are acknowledged. Having said that, I also identified the research tools as well as selecting the participants for the study. As a Solomon Islander and former employee of the MOE, particularly at the CDC, my views would not be considered as unreasonable. Instead, my views and opinions were enriching for the purpose of this study.

\subsection{Summary}

This chapter has presented the theoretical orientation for the study. These are the theoretical perspectives that are important for understanding the nature of the research, its assumptions about methodology, how the study was carried out and the framework for conducting the research. Further, the chapter describes the procedures and processes involved in conducting the research, particularly how the research data was collected, transcribed, triangulated and analyzed for reporting.

In the next chapter, I will present the results and findings for this thesis. 


\section{CHAPTER FOUR}

\section{INTERVIEW - DESCRIPTION AND FINDINGS}

\subsection{Introduction and Overview}

Chapter Three has provided the theoretical perspectives and methodological framework of this study. This chapter presents the results and findings of the study. The findings are organised into four broad themes. First, is the conceptualisation of OBE. Second, is the conceptualisation of OBSC and the perception about the relevance or appropriateness of OBSC. Third, is the perception of how OBSC could be taught, learnt and assessed as well as how to monitor and report students' performance and achievement. Fourth, is the perception on potential problems, issues and challenges that might impede implementation of OBSC. The chapter concludes with a brief summary of the key findings of the study.

In this chapter, individual respondents are represented by codes to protect the anonymity and confidentiality of respondents. Data collected from the focus group was recorded individually but summarised in the form of group data according to the broad themes of the study. To protect the confidentiality of the respondents, names of the discussion panel were replaced with a coding system. This was done to place the importance on the content of the discussion and not so much on the person who was actually giving the information for the study. Specifically, the following are used in this chapter: practicing science teacher respondents names were replaced with the coding system using PSST 1, 2, 3, 4, 5, 6 and 7. Former science teachers' names were replaced with the coding: SOESL 1 and 2 for science lecturers; CHSP for the community high school principal; PCDOS for the principal curriculum development officer - secondary; SCDOP for the senior curriculum development officer- primary; MOEAO for the assessment officer; and MOEIO for the inspectorate officer. Respondents of focus 
discussion group panel names were replaced by the code FDGP. The coding system used is shown in Table 2 below:

Table 2. Codes representing respondents employed for this study

\begin{tabular}{|l|l|l|}
\hline & Interviewee and Respondents & Codes Used \\
\hline 1 & Practicing Secondary Science Teachers & PSST 1, 2, 3, 4, 5, 6 and 7 \\
\hline 2 & School of Education Science Lecturers & SOESL 1 \& 2 \\
\hline 3 & Community High School Principal & CHSP \\
\hline 4 & Principal Curriculum Development Officer - Secondary & PCDOS \\
\hline 5 & Senior Curriculum Development Officer - Primary & SCDOP \\
\hline 6 & Ministry of Education Assessment Officer & MOEAO \\
\hline 7 & Ministry of Education Inspectorate Officer & MOEIO \\
\hline 8 & Focus Discussion Group Panel & FDGP \\
\hline
\end{tabular}

\subsection{Conceptualisation of OBE}

This theme provides a description of findings on the conceptualisation of OBE. Specifically, it explains how $\mathrm{OBE}$ is defined, the reasons for adopting $\mathrm{OBE}$, OBE as a curriculum approach, $\mathrm{OBE}$ as the basis for school curriculum and the contribution to curriculum review and reform in Solomon Islands.

\subsubsection{Defining OBE}

Respondents of the study perceived OBE in a variety of ways. First, OBE was defined as the structured learning of specified outcomes. One respondent said it is an education model that focuses on what students can actually do with what they are taught (PSST1). Another respondent thought that this type of education model involves activity-based learning (PSST6). In a similar way, two respondents explained that OBE is a student-centered approach which involves active and equal participation that allows students to interact and create their own learning (PCDOS \& SCDOP). This same point was elaborated by FDGP, how this model, in many ways, is similar to our indigenous education, particularly the teaching, and learning processes assessment practices. Second, respondent science teachers defined outcomes- 
based education as a multi-disciplinary approach based on the philosophy that all students can learn and succeed if clear outcomes are given and supported with learning and teaching resources. Such an education model is thought to enhance students' confidence and to enable them to face new challenges. One of the respondents from the MOE defined OBE as an outcomes-led approach where the focus is on student learning and involves students' prior knowledge and learning experiences. According to this respondent, the knowledge students come to the classroom with is valuable and should be expanded on for integrating new knowledge. Another respondent (FDGP) viewed OBE as a new paradigm for learning because it promotes the shift from the traditional approach of learning to a competency-based approach. Finally, PSST4 holds the view that the OBE model provides an avenue by which to enhance students' thinking abilities to critique, analyse and solve problems.

\subsubsection{Reasons for Adopting OBE}

Respondents of the study perceived a number of reasons for adopting OBE. First, OBE represents a shift from students learning from a body of theoretical knowledge to knowledge, skills, and values that can be applied and appreciated when they have left the school system. Respondent science teachers pointed out that the need for adopting an OBE curriculum would be to meet our own needs in the Solomon Islands context. According to the same respondent, OBE is able to measure what students are capable of doing, an aspect of learning that the current objective-based curriculum often fails to do. In a similar way, PSST3 is of the view that OBE is likely to assist students' understanding of concepts and content that goes much deeper than just finding the right answers. The same point was further explained by one respondent how OBE is likely to help students because they must demonstrate skills through taking on

more challenging tasks in their learning process (PSST2). Finally, FDGP holds the view that the notion of up-skilling students is the driving force of the OBE which encourages lifelong skills, necessary for survival in our communities. 


\subsubsection{OBE as a Curriculum Approach}

Respondents of the study thought that the concept of outcomes-based curriculum was derived from the philosophy of OBE. As one school principal put it, this philosophy aims at making education more relevant for the majority of students (CHSP). Respondent science teachers pointed out that the OBE syllabuses are based on the outcomes-based approach. Such an approach was supported by two respondents saying that it does not focus on the content but on how learners may be able to apply what they have learnt in practical ways (PSST4 \& PSST6). According to one respondent the focus of schooling has to be changed from subject content to the needs of the students (PSST6). The same respondent explained in another way that the learning approach is primarily based on students achieving significant outcomes rather than just learning the subject content (PSST6). Such a curriculum approach must ensure learning outcomes are appropriate and reflect real life situations that students will face after leaving formal schooling (PSST4). The same respondent added that the learning outcomes must be achievable, measurable and demonstrable in the learning activities so that students can actively learn and be able to apply them in new situations. Finally, FDGP noted that acquiring appropriate knowledge, skills, attitudes, and values is more important than the time it is usually taken.

\subsubsection{OBE as the Basis for School Curriculum in Solomon Islands}

$\mathrm{OBE}$ is deemed by respondents as the foundation and basis for the school curriculum. According to FDGP, the curriculum shift is essential for making changes in the school curriculum and the focus is to prepare students for post-school real life situations. Another respondent thought that students should acquire content and skills which would enrich their lives culturally, intellectually and spiritually (PCDOS). It was also viewed by PSST5 as “a system that acknowledges the ability and potential of students as learners and is based on success rather than failure”. Furthermore, FDGP added that OBE in Solomon Islands involves the process of “designing the curriculum downwards or backwards”. The same 
point was further explained by two respondents (SCDOP \& PCDOS) based on how curriculum was designed by asking what knowledge, understandings, skills, attitudes and values would be useful to students, both those leaving the school system and those continuing with further education. Finally, according to science teachers, the "curriculum therefore starts with the vision of the end product" that we want learners to achieve, working backwards to decide how we can achieve this vision.

\subsubsection{Contribution of OBE to Education Reform}

The implementation of an OBE model is considered to offer significant improvement to students' learning. According to one respondent, students will be able to learn new skills and values that have not been included in the current curriculum (PSST1). Such an education model, according to SCDOP, is likely to have a significant impact on the knowledge and skills that are applicable to earn a living. Another respondent felt that the new approach to curriculum development would also improve the quality of teaching and learning through the student books and teachers guides (PCDOS), thereby improving the standard of teaching and learning processes in secondary schools. Furthermore, teacher educator

respondents thought that the OBE approach would make positive impacts through in-service training of science teachers as well as upgrading teacher education and training at SOE of the SICHE. Finally, FDGP pointed out that the adoption of OBE is likely to create a more knowledgeable learning community.

\subsection{Conceptualisation of OBSC}

This theme describes the findings on how OBSC is defined in the context of the OBE model. Specifically, it provides an explanation on the rationale, relevance, appropriateness and significance of OBSC in Solomon Islands. 


\subsubsection{Defining OBSC}

Respondents of the study perceived OBSC to be developed from the OBE model. By nature, science is a practical subject and, according to PSST4, it involves learning about things around us and about what they are made of, how they work and how we can benefit from them. According to one respondent, OBSC will capture unique traditional or indigenous knowledge, skills and cultural values that are important to Solomon Islanders (PSST1). Another respondent (PCDOS) pointed out the importance of OBSC in the school curriculum:

"Science has become the basis for the teaching and understanding of other subjects like Agriculture, Technology, Social studies, Health, Physical education, Health and Home Economics”.

Further, it links the knowledge, skills, and values that students learn in the classroom to our culture (SCDOP). The same point was further elaborated on by MOEIO how it integrates relevant indigenous and traditional science knowledge, skills, and values that we have been using in our societies before the arrival of Europeans. PSST3 affirmed that it is important for students to learn and acquire important scientific knowledge, skills and values that they can use for survival and continuity in our communities. Another respondent also thought there was a need for science teachers to make use of indigenous ways of learning in the home or rural settings (CHSP). In this way, science learning in the classroom is linked with the outside world (PSST5). Finally, according to science teacher respondents, students will learn science better if their prior knowledge is used in the teaching and learning process in the classroom.

\subsubsection{Rationale of OBSC in Solomon Islands}

Respondents of the study thought that OBSC is contextually appropriate for Solomon Islands. According to science teachers, the rationale for OBSC is to give all school age children the opportunity to learn about science. Science teacher respondents held the perspective that science involves learning about nature and natural processes and how these affect people and their environments. One respondent was of 
the view that learning science is important for the application of scientific knowledge, skills, and values in communities (FDGP). Another respondent thought that OBSC is designed to feature important indigenous or traditional knowledge, skills, and values which are scientifically relevant to home settings (SCDOP). As FDGP puts it:

"There is the knowledge of weather and climate patterns, navigation skills, conservation methods and practices, agricultural and fishing methods and practices that is important for survival and the livelihood of rural communities that could be incorporated in the OBSC”.

In this way, MEOIO argued that school-aged children are likely to learn and appreciate the beauty of their culture and national heritage by using essential knowledge and practices of their own culture. As expressed by the same respondent, Solomon Islanders have the right to learn and appreciate the science content that embodies life long skills that are relevant to their culture and everyday living (MOEIO). However, PSST4 noted that it would require appropriate resources in order to effectively deliver the content of OBSC.

\subsubsection{Significance of Learning OBSC in Solomon Islands}

The implementation of OBSC should significantly improve the understanding of science in Solomon Islands. According to the science teachers, OBSC would feature practical aspects of science that could be applied in the outside world. In another way, the knowledge, skills, attitudes and values would allow them to learn and appreciate part of their cultural beliefs, values, and traditions that have never been documented (PSST1). Respondents of the study held the view that OBSC is able to document unique indigenous and traditional knowledge and practices in Solomon Islands. Supporting the same point, CHSP stated that the development of relevant materials would be essential to support the teaching and learning of OBSC and this would improve the quality of resource materials as well as improving the teaching and learning processes in secondary schools throughout Solomon Islands. 


\subsection{Strategies for Implementing OBSC}

This theme provides a description of the findings on how OBSC would be implemented in relation to the OBE model. It also explains how OBSC could be taught, learnt and assessed, as well as how student's performance, progress and achievement could be monitored, recorded and reported.

\subsubsection{Teaching OBSC in Solomon Islands Secondary Schools}

The teaching of OBSC must involve practical lessons with clear instructions and purpose. Secondary science teacher respondents suggested that teachers must use a variety of teaching approaches to motivate learning in a science classroom. According to one respondent, this would require effective pedagogical content and positive teacher actions and support (PSST4). Since OBE is student-centered, teachers are seen as facilitators in the classroom and must ensure learning is taking place effectively (FDGP). Another respondent stated that students must be encouraged to learn and acquire knowledge and skills of reflective thought and action (PSST4). PSST5 added that for effective delivery of OBSC, teachers must use appropriate teaching resources, facilities and infrastructure to provide a conducive learning environment for students. Science teacher respondents noted that teachers must approach teaching through an activitybased approach. This would mean students each taking an active part (PSST1 \& PSST7). Similarly, science teachers must engage students in activities which use student's prior knowledge (PCDOS). In supporting the same idea, FDGP affirmed that this would be essential for making connections between prior learning and new learning experiences. Science teacher respondents thought that the approach of using activity-based teaching would provide good opportunities for students to make use of the learning process. Such an approach would also create positive teacher-student relationships on both a short and long term basis in the science classroom (FDGP). Finally, respondents of the study were of the view that effective teaching strategies should include the use of teacher demonstration, practical activities, and 
small groups with a lot of discussion, role-play, case studies, and engaging students in research, investigation and writing tasks.

\subsubsection{Learning OBSC in Solomon Islands Secondary Schools}

The learning of OBSC must be focused on students. According to one respondent, the learning activity must place learners in the center of the learning activity (PSST3). Another respondent also thought that students must be encouraged to participate through interactive learning (PSST2). The same point was elaborated on by SCDOP, saying that this would allow students to be involved in scientific investigations. In supporting the same idea, PSST6 pointed out that equal opportunity must be given to students for the exploration of new ideas and concepts. Doing so would enhance critical thinking, solving of problems and drawing scientific conclusions (PSST5). Science teacher respondents also thought that student's participation in learning would be encouraged by working in smaller groups. Similarly, this would encourage active participation, irrespective of their ethnicity, gender and the range of abilities (PSST3). PSST7 also expressed that in the event of there being is a mixture of faster and slower learners in the group, students could help one another to improve peer thinking ability, and to participate in critical discussions. Finally, PSST4 added that students working in smaller groups would collectively gain confidence to share their own opinions and views in a science class.

Respondents of the study also supported the approach of student-centered learning. Such an approach would motivate students to become active learners and so break down the barriers of passive learning. Further, PSST4 added that there is a need for science teachers to facilitate effective learning strategies through activity-based learning or the hands-on approach. Additionally, PSST7 affirmed that students must be given questions in follow up activities to engage and motivate them during the learning activity. PSST3 stated that it is essential to recognize students' prior knowledge in the learning process. However, 
two respondents argued that students must be given time and resources to facilitate effective learning that is contextual and meaningful in the classroom (PSST6 \& FGDP). Finally, respondent science teachers and FDGP argued that learning strategies to enhance students' effective learning should include the use of participatory, interactive, exploratory, self guided and enquiry learning approaches.

\subsubsection{Assessing OBSC in Solomon Islands Secondary Schools}

The assessment of OBSC must be based on specific and clearly defined outcomes. Respondents from the study perceived assessment to be observable and measurable. According to one respondent, the way assessments are structured in the OBE approach would be likely to make assessment much easier because the tasks required are clearly and specifically stated (MEOAO). The same respondent observed that assessment is the end product of the curriculum and is for testing whether science outcomes taught in schools are delivered effectively and are clearly understood by students. In a similar way, PSST6 and SCDOP held the view that assessment should be prescribed by the curriculum and require assessment outcomes that are succinct and accessible.

\subsubsection{Continuous Assessment on a Regular Basis}

OBSC requires regular and continuous assessment in the science classroom. According to FDGP, there is a need to strengthen the on-going assessments on student competency and achievement. Science teacher respondents were of the view that this would involve assessing learners not just by written tests and examinations but by observing competency and student achievements. This is because it would involve assessing student's achievements on a regular basis and would be done as internal assessment (FDGP). PSST1 also added that this type of assessment is important because it would be an ongoing process and reflects student's potential and abilities. In a similar way, assessments would assist science teachers in providing relevant feedback to students (MOEAO). According to one respondent, continuous assessment 
is the most effective way of assessing students' knowledge, skills, values and attitudes (PSST2). In supporting this, PSST6 pointed out the need to conduct more formative assessment for the purpose of making fair and appropriate judgments on individual student achievements.

Respondents agreed that the current school based assessment in science which was introduced in the past ten years is in fact an effective form of continuous assessment in the school system. According to FDGP and PSST5, such assessment has been a reliable form of assessment because it has required students to perform practical activities in the science classroom. According to one respondent, the use of research projects in this recent school-based assessment has also been an advantage because it gives students opportunities to acquire research skills that are useful for conducting science investigations (PSST4). However, SCDOP suggested that this form of assessment would still demand more resources but that could be improved for effective assessment in the science classroom.

\subsubsection{Appropriateness of Using a Criterion-Referenced Assessment}

Respondents of the study thought the criterion-reference assessment was suitable for assessing OBSC.

Science teacher respondents stated that this form of assessment sets written criteria that students must demonstrate at the end of each learning activity. The same respondents expressed the view that this type of assessment would involve assessing students according to pre-set assessment criteria. According to one respondent, the demonstration of outcomes in the OBE model requires an assessment based on written and agreed criteria (PSST3). Another respondent affirmed that such an assessment is likely to assess students on a more regular basis and would therefore better reflect individual students' abilities (SOESL1). On the other hand, OBE puts little emphasis on a summative form of assessment (PSST5). This form of assessment is similar to norm-referenced assessment which is usually conducted at the end of a learning period (FDGP). This would mean that the assessment would only last a few hours and the 
judgment a teacher makes on the students’ performance and achievement would be based only on a short span of time during a written examination (PCDOS). However, as SCDOP and MOEAO pointed out, this could be seen as unfair because it does not reflect the true potential and ability of students. Additionally, learning difficulties and unforeseen circumstances experienced by students prior to any high stake examinations could not be identified and these could impede students' performances (PCDOS). According to science teacher respondents, assessment based solely on an examination is too limited and simply compares one student with another rather than making judgments on individual students' understanding.

\subsubsection{Competency and Achievement - Based Assessments}

Respondents saw that assessment tasks should be directly linked to science outcomes in order to judge students’ competency and achievements effectively. According to one respondent, competency-based assessment would be required for assessing practical skills whereas achievement based-assessment would require a rubric scale with written descriptors to show the level of achievement (PSST4). One respondent gave an example, stating that for each sub strand or unit, the use of a rubric scale with explicit descriptors for each learning outcome would be essential (SCDOP). The rubric scale could use a linear or composite numbering system. FDGP expressed that science teachers must use a variety of assessment activities and take into account the context of learning and the different learning styles involved. According to PSST4, this would enable science teachers to make assessments that are specific, and reflect the real potential and abilities of individual students. In supporting the same point, PSST6 pointed out this could also assist science teachers to extract fairer assessment on individual student's achievement for each unit or for work covered during a semester or the whole year for each year level. Finally, FDGP added that it would make monitoring and reporting much easier thereby making the system work more smoothly. 


\subsubsection{Monitoring, Recording and Reporting of Students' Performance, Progress and Achievements}

The monitoring, recording and reporting of students' performance, progress and achievements is fundamental for schools' transparency and accountability. According to the school principal, there is a need for an effective monitoring, recording and reporting system (CHSP). The same respondent observed that this is an important process to provide more regular feedback to students and parents. Such an initiative has the potential to improve students' self esteem, and being successful at school (MOEAO).

\subsubsection{Monitoring System}

An effective monitoring system is essential for monitoring students' performance and achievements. According to one respondent, a good monitoring system plays an important role in schools (PSST4). Further, it links schools with teachers, students, parents, and key stakeholders (CHSP). Therefore an effective monitoring system with clear guidelines and procedures is essential (PSST4). According to one respondent, in order for OBE to work, it would require teachers' commitment to supporting the monitoring system (MOEIO). The same respondent stated that a realistic monitoring system would require the use of student files or folios. According to FDGP, this document would be used for recording all students' marks for assessing during the year. The same respondent thought that these marks could be used for monitoring students' performance and achievements on a regular basis. Further, MOEIO added that the records could be used in teacher-student and teacher-student-parent interviews. According to one respondent, these records could also be used for providing feedback on students' performance and for forecasting future achievements (SCDOP). Such an approach could be very effective and be used for monitoring students' achievements (SOESL2). According to one respondent, the use of student files would be an important tool for keeping good records of students' marks (PSST6). Science teacher respondents also thought that it would be helpful for the school administration to keep a good record of how each student performed for providing accurate information. The same respondents explained that the 
student file should be given to students when they transfer to their new school. Moreover, SCDOP suggests that a copy of the same record should be retained at the old school.

\subsubsection{Recording System}

An effective recording system is essential for keeping accurate information and data. According to FDGP, effective monitoring of students’ performances and achievements would require a good recording system. Another respondent added that the recording system should be simple and accessible to all teachers (PSST5) and that it should be structured with a format that teachers were able to read and understand. According to the school principal, OBE would require a simple recording system that would help teachers to keep a record of students' marks for assessment tasks and make fair judgments on students' performance and achievements (CHSP). Further, MOEIO affirmed the need for a student record book to be used for this purpose. Another respondent also thought that this document should have a number of columns to include, for instance, student names, assessment tasks or events, grade or marks, blank spaces for teachers' comments and spaces for remedial work that needed to be done by the student (PSST4). In this way, the teacher would be able to keep an accurate record of each assessment task (FDGP). Finally, FDGP and PCDOS stated that the student record book should be prepared, printed, and distributed to schools for uniformity and consistency of good recording.

\subsubsection{Reporting System}

An effective reporting system is essential for reporting students' performance and achievements. FDGP held the view that effective reporting of students' performances and achievements would need a good reporting system. According to one respondent, the reporting system should be simple and accessible to all teachers (MOEAO). The same respondent explained that the reporting style had to be structured in a format that parents, teachers and key stakeholders could read and understand. Further, CHSP added that 
the main purpose of the report was to inform parents about their child's performance, progress and achievements. Another respondent also thought that the current school reports fail to address the purposes of school reporting (MOEIO). This is because the report is too general and does not inform parents on specific issues affecting the learning of their children (PSST6). According to the school principal, the current school reports contain marks and percentages for each subject and brief comments on students' achievements. In supporting the same point, another respondent stated that OBE would require a descriptive form of reporting which would inform parents about specific aspects affecting the students' learning experience (PCDOS). Finally, FDGP and SCDOP noted that the reporting system should use a document that would have to be prepared, printed and distributed to schools for uniformity and consistency of good reporting.

\subsection{Problems, Issues and Challenges, and Ways for Addressing Obstacles}

This theme provides a description of the findings on potential problems, issues and challenges in relation to the implementation of OBSC in secondary schools. Furthermore, it describes possible strategies that could be used to address impediments or obstacles prior to the implementation process.

\subsubsection{Problems, Issues and Challenges}

\subsubsection{Lack of Learning and Teaching Resources}

Respondents of the study saw the need for more learning and teaching resources. According to science teacher respondents, resources would be important for effective learning and teaching of OBSC. Without appropriate and sufficient resources students could not participate well in the learning process (FGDP). PSST7 added that without better resources teachers would not be able to teach effectively. Further, FDGP added that the lack of learning and teaching resources is perceived as one of the main problems that could impede the implementation process. According to the MOE officials, it could be crucial that school 
administrations and relevant education authorities ensure appropriate and sufficient learning and teaching resources be provided to secondary schools. Finally, PCDOS concluded that for effective delivery of OBSC, schools would require relevant student and teacher resources, scientific materials, consumables, apparatus, and equipment (PCDOS).

\subsubsection{Inadequate Facilities and School Infrastructure}

There is an urgent need for relevant and adequate facilities and infrastructures. PSST7 explained that appropriate facilities and infrastructures would be important school requirements for effective learning and teaching of OBSC. In a similar way, the school principal stated that without appropriate facilities and infrastructures students cannot interact well in the learning process (CHSP). Another respondent also thought that because science is a practical subject it requires specialized classrooms such as laboratories and consumables or materials for students’ practical (PSST2). To fully implement the OBSC, PSST7 noted that it would be necessary for all secondary schools to have a resourced science laboratory. In supporting the same point, CHSP stated that we cannot use an ordinary classroom for conducting science practicals and experiments in our secondary school”.

\subsubsection{3 ～Lack of Qualified and Competent Teachers}

There is a great need for more qualified and competent science teachers. According to FDGP, science teachers are seen as the key implementers of the OBSC. PCDOS added that we would need qualified, well trained and competent science teachers for the effective delivery of OBSC. In a similar way, PSST2 stated that without qualified and competent science teachers, the implementation process will fail. 


\subsubsection{Reduction in Time Allocation for Teaching Science}

The reduction of allocated time for the teaching of OBSC has stunned secondary science teachers. According to science teacher respondents, this was very surprising because the reduction of the number of periods per week from 7 periods to 4 would not allow science teachers to deliver expected learning outcomes. In a similar way, FDGP expressed that even with the current time allocation of 7 periods, science teachers have had to conduct extra classes outside of official school hours. In reality, PCDOS noted that teachers were already finding it hard to cover planned objectives for the whole year. Furthermore, PSST5 reiterated that science is a practical subject requiring delivery of both theoretical and practical aspects of the content and as such required more time. PCDOS and SCDOP added that the reduction of time would pressurize science teachers to be unable to teach the required learning outcomes. However, according to another respondent, this would also motivate science teachers to prioritize the learning outcomes so that what was covered would be really well planned (SOESL1).

\subsubsection{Overcrowding in the Science Classroom}

Overcrowding in secondary schools is due to the high number of students enrolled per class and this has raised considerable concern among science teachers and school administrations. According to two respondents (CHSP \& PSST5), overcrowding in science classes will not help science teachers deliver OBSC. The same respondents were of the view that teachers would have to find alternative ways of conducting science practicals and experiments. In supporting the same point, FDGP noted that the influx of student enrollments not only requires more teaching and learning resources but also demands time and space in the classroom. Science teacher respondents also thought that the delivery of OBSC would require lower enrolments so that it did not require excessive resources. Alternatively, the school principal suggested that there would need to be enough resources for every student in the class (CHSP). 
Consequently, as noted by PSST3, this would also help teachers to control and manage their classes more effectively.

\subsubsection{Teacher Resistance to Deliver OBSC}

Science teachers would need to be well informed about OBE and OBSC. According to one respondent, if science teachers were well informed about the new curriculum approach and pedagogical content knowledge, they would be willing to adopt the curriculum shift and impart new changes in the science classroom (SOESL2). On the other hand, if they are not well informed about OBE, OBSC and its implications, teachers would be reluctant to use the new teaching pedagogy in delivering the curriculum and would resist new changes (FDGP). The respondent (PSST6) feared that teacher resistance would probably affect the implementation process and be likely to create inconsistency, affecting initial evaluation of the OBE model and OBSC.

\subsubsection{Lack of Inclusive School Culture}

Inclusive school culture is vital to the holistic development of students. Such a culture provides an environment conducive for students and teachers to interact as a learning community (PSST7). According to PSST4, inclusive school culture is vital and seen as part of the school as an institution that can shape students attitudes and behaviour to become responsible and good future leaders. Furthermore, FDGP noted that school culture must change according to the requirements of OBE so that OBSC can be effectively implemented. According to MOEIO, school culture would play an important part in the implementation of OBSC and as such provide a conducive learning environment to support the implementation process. Furthermore, as PSST5 explained the school culture reinforces good learning in the classroom to engage students better; particularly in the way they interact and exchange ideas in the 
science classroom. In support of this view, FDGP, argued that the school culture must create a supportive learning environment for effective learning and teaching in secondary schools.

\subsubsection{Lack of Policy on Classroom Assessment}

Appropriate policy on classroom assessment is very important for assessment and monitoring of OBSC. According to one respondent, such policies are essential for consistent assessment, monitoring and reporting (MOEAO). Science teacher respondents thought that teachers would only carry out assessment procedures if an appropriate policy on classroom assessment was established by the MOE. In supporting the same view, PSST7 added that science teachers would need to be well informed about such policies and their implementation in the classroom. Another respondent held the view that assessment is the final process to test whether curriculum outcomes are effectively taught and whether students have learnt and acquired desired knowledge, skills, values or attitudes (MOEAO). Finally, FDGP added that there is a need for assessment policy with clear criteria and guidelines for carrying out assessments in the science classroom.

\subsubsection{Teacher Education and Training in Solomon Islands}

There is an urgent need for the integration of OBE and OBSC in teacher education and training in Solomon Islands. According to one respondent, such integration is essential for teacher trainees to learn and acquire new pedagogical content knowledge (SOESL1). Respondent teacher educators also expressed the need for lecturers at the teacher education institution to take the initiative of participating in curriculum development programmes at the CDC. In a similar way, science teacher respondents added that current teachers in the field must be educated through in-service training on OBE and OBSC so that they can learn and acquire the required pedagogical content knowledge. Furthermore, teacher educator respondents added that effective pedagogy to deliver OBSC would be essential for the implementation 
process. PCDOS and SCDOP also supported the idea of having a positive link between the CDC and SOE of SICHE. According to FDGP, this is essential for building positive relationships between teacher trainees and their lecturers and curriculum officers.

\subsubsection{Governments Commitment and Support Towards Curriculum Development and Implementation}

The government's commitment and support towards curriculum initiatives is crucial. Respondent science teachers expressed views on the sustainability of funding and the provision of technical assistance for the implementation process. According to FDGP, the government would need to show commitment and support for the implementation phase of the CRRP. Furthermore, PSST4 pointed out that the implementation phase "will fail” if sufficient teaching and learning resources are not provided. FDGP argued that the MOE, through the national government, must ensure that resources, facilities and infrastructures are provided for secondary schools. Likewise, the school principal stated that the number of practicing science teachers in the teaching pool should be identified for equitable posting around the country (CHSP). According to FDGP, this would assist the MOE and relevant education authorities to administer teacher recruitment and posting effectively for implementing OBSC. The school principal and teacher educators also expressed the need for the government to place a high priority on teacher training. It is crucial that we produce quality science teachers for the implementation of OBSC (SOESL2). However, FDGP explains that this would require funding and support for teacher education and training programmes and for the welfare of science teacher trainees.

\subsubsection{Strategies for Solving Identified Problems, Issues and Challenges}

Having identified potential problems, issues and challenges that might impede the implementation process, it is appropriate to strategize and find possible solutions. Respondents of the study expressed 
concern about how these problems, issues and challenges could be addressed to minimise the negative effects of the implementation process. According to FDGP, possible measures and actions would need to be taken to improve the current situation before the implementation process could begin.

\subsubsection{Stakeholder Awareness of OBE and OBSC}

Awareness of OBE and OBSC is essential for the implementation process. PCDOS and SCDOP supported the idea of running awareness programs for teachers, school administrations, parents and key stakeholders. According to one respondent, this would be a very necessary informative process which would include the content, pedagogy and logistics for the implementation process (PSST7). FDGP gave an example of how written documents could be developed, printed and distributed to schools, education stakeholders and interested parties. Respondents of the study also expressed the need for clear explanations of OBE and OBSC for ensuring a good understanding amongst science teachers. Respondents of the study also suggested using curriculum officers to explain to science teachers how the new syllabus was structured, how to use the syllabus documents and to explain the new concepts used in the student textbooks and teacher guides.

\subsubsection{Supplying Appropriate Learning and Teaching Resources}

The implementation process would require appropriate and sufficient learning and teaching resources. Respondents of the study expressed concern about not having sufficient resources for effective learning and teaching of OBSC. According to science teacher respondents, science is a practical subject and as such requires specialized resources, consumables and equipment for teaching and carrying out science practicals and investigations. In supporting the same point, FDGP added that the MOE, through the national government would have to ensure that its obligations were met to secure funding for appropriate 
learning and teaching resources. These resources would include: student books, teachers guides, basic materials, consumables, apparatus and equipment (PSST6).

\subsubsection{Providing Adequate School Facilities and Infrastructures}

The implementation of OBSC would require appropriate and relevant school facilities and infrastructure. Respondents of the study were of the view that specialised facilities and classroom should be provided for the effective learning and teaching of OBSC. Teacher educators and science teacher respondents expressed that "without proper facilities and a basic science laboratory, there will be difficulties in the teaching and learning of science”.

\subsubsection{Conducting Teacher In-service Training and Capacity Building}

Teacher in-service training and capacity building are very important for teachers as practitioners and for their professional development. Respondents of the study expressed concern that science teachers should be provided with in-service training on OBE and pedagogical content knowledge of OBSC. In supporting the same point, SOESL1 and SOESL2 added that knowledge on education philosophies, learning theories and teaching methodologies was essential and would need to be included for the in-service training. Respondents of the study expressed that it would be essential for effective delivery of the OBSC, that teachers be really well prepared beforehand.

\subsubsection{Involving School Board of Management}

School board members are key decision makers in the school system. According to FDGP, there would be a need for positive involvement of those members in the implementation process. PSST4 pointed out that there would be a need for the school board to assist the respective school administrations and be proactive in implementing OBSC. According to the respondents, such responsibilities could be delegated 
to the school board to assist teachers in the planning and monitoring of the school curriculum. One respondent thought that the school board could assist by checking that science teachers are prepared with lesson plans (CHSP). To support this point, MOEAO explained that this may need more consultation with the MOE.

\subsubsection{Strengthening and Implementing Education Policies}

There is an urgent need for MOE to evaluate current policies. According to FDGP, effective implementation of OBSC would require a collaborative link between the relevant divisions of the MOE and the CDC. As stated earlier, this would mean the curriculum officers would not be implementing OBSC in isolation from the rest of the divisions. To do this, PSST4 explained that the MOE would have to ensure that other relevant policies were strengthened and implemented alongside curriculum implementation protocols. According to the respondents of this study, policies on teacher-student ratio, classroom assessment, the standard of school facilities and infrastructure, teacher inspection and monitoring, and teacher education and training should be strengthened or even created for the implementation process. Doing so would assist and improve the operation of the ministry and its monitoring systems (FDGP).

\subsubsection{Establishing Inter and Intra Links with MOE and Stakeholders}

Respondents of the study held the view that internal links within the MOE are essential for not only for an effective working relationship between different divisions in the Ministry but also linking its core functions and responsibilities to the education sector. PCDOS and SCDOP expressed the opinion that the CDC should not work in isolation from other relevant divisions. According to one respondent, this would be important because the implementation process would have an impact on the functions and responsibility of other divisions (PSST1). 
The external link between MOE and those actually providing the teacher education is essential for harmonizing not only the working relationship between these institutions but also linking core functions and responsibilities back to the education sector. According to SOESL1 and SOESL2, the role played by the SOE of SICHE is vital for building collegial relationship with the CDC and the MOE. Teacher educators have expressed the need for such a link because at the end of the teacher education programme, our teacher graduates would be teaching the curriculum developed at the CDC. The same point was further explained by SOESL2 that such links would create a good relationship with CDC and MOE as well as empowering lecturers and teacher educators to carry out their roles.

Another important external link is between the MOE and various other education authorities which include provincial education authorities, church agencies and the national government. According to one respondent, the role played by all education authorities is crucial for the effective implementation process (PCDOS). According to respondents of this study, it is important that the education authority office, school administrations and teachers are well informed about OBE and OBSC. The importance of linking between authorities was expressed by a school principal as a "worthwhile process as it involves the awareness of all education stakeholders” (CHSP).

\subsection{Summary}

OBE is a new paradigm for learning which focuses on students acquiring knowledge, skills and values. It is an outcomes-focused approach which employs a student-centered approach to learning and teaching. It is based on the philosophy that students are potential learners with the ability to learn and succeed. OBSC is a syllabus developed from the OBE model. Such a curriculum would provide essential scientific knowledge, skills and values through the education system. These things would not only be useful for students continuing on to further education but should also be for those leaving the school system. The 
implementation of OBSC would require teachers to play a role as facilitators of learning. Equal opportunities must be given for all students to reach their full capacity as learners. A suitable assessment system would have to employ explicit learning outcomes and agreed criteria. A simple, user-friendly and unified monitoring, recording and reporting system would be required to enable teachers and parents to discuss students' learning. In order for OBSC to be implemented effectively, the government would need to show commitment in providing relevant teaching and learning resources, sufficient facilities and infrastructure. The integration of the OBE model and appropriate pedagogical content knowledge of OBSC would be essential for teacher in-service training and the teacher education and training programmes. Finally a nation-wide awareness of OBE and OBSC would be crucial to the curriculum development process, particularly at the implementation phase of this policy in Solomon Islands.

In the next chapter, I will present the analysis and discussions of this thesis. 


\section{CHAPTER FIVE}

\section{ANALYSIS AND DISCUSSION}

\subsection{Introduction and Overview}

Chapter Four provided descriptions of the findings of this study. This chapter presents an analysis of the data gathered and discusses the findings. The data is analyzed and organised into four broad themes. First is an analysis of how OBE is conceptualised. Second is an analysis of how OBSC is conceptualised and the perceptions of the relevance and significance of OBSC. Third is an analysis of the perceptions of how OBSC can be taught, learnt and assessed as well as how to monitor, record and report students' performance, progress and achievement. Fourth is an analysis of potential problems, issues and challenges that might impede implementation of OBSC as well as offering solutions to the obstacles. The chapter ends with a brief conclusion, summarising the analyses and findings of the study.

\subsection{Conceptualisation of OBE}

According to the study, the OBE model is considered to be the appropriate way to fulfill the goals of the CRRP. Further, OBE also promises a high level of learning for all students compared to the current school curriculum which concentrates on brighter learners and emphasises academic learning. Such a model places a greater emphasis on relevant curriculum that prepares learners practically for post-school real life situations. Respondents viewed OBE as a philosophy by which all students could learn in order to succeed. Such a philosophy clearly states learning outcomes that are significant for students to achieve. The study also reveals that OBE is viewed as a blending of traditional and transitional OBE approaches. It is conceptualised as being outcomes-focused, learner-centered and assessment-driven, and is based on 
success rather than failure and it is similar to indigenous ways of teaching and learning in the Solomon Islands context.

\subsubsection{Blending Traditional -Transitional OBE}

The data reveals that Solomon Islands is taking a multi-cultural approach to OBE, thereby incorporating Spady's (1993) traditional and transitional approaches. In this way, OBE focuses on multi-cultural underpinnings and diversity. To concur with Banks (2001) and Mahalingam and McCarthy (2000), respondents commented that the Solomon Islands OBE also advocates lifelong learning. Respondents held the view of enhancing holistic development in all students irrespective of ethnicity, race or gender. Furthermore, the blending of the traditional and transitional OBE approaches is likely to enhance the acquisition of essential knowledge, skills and values that are important for survival and continuity in postschool life situations in the context of Solomon Islands.

\subsubsection{OBE as an Outcomes - Focused Approach}

According to the respondents, OBE is described as an outcomes - focused or outcomes - led approach. Such an approach is concerned about what students actually demonstrate in the end. In such a model, the outcomes are seen as end products of learning. In a similar way, curriculum starts with a vision of the end product. Therefore, the strategies used in the process of achieving these outcomes are very important and must be understood by teachers as facilitators and students as knowledge receivers. The data shows that the downwards or backwards idea of OBE would require that outcomes be constructed to align with actual teaching and learning in the science classroom (Killen, 2003). Furthermore, the learning outcomes are defined in terms of what learners are expected to understand, know, be able to do and appreciate. These are significant outcomes that are considered to be observable, measurable and achievable (Spady, 1993). Respondents suggested that when supported with sufficient learning, teaching resources and 
appropriate facilities and infrastructure, students would be able to gain new knowledge, understanding, skills and values and attitudes, as well as being able to expand on them in new situations and contexts.

\subsubsection{OBE as a Learner-Centered Approach}

The data shows that OBE is defined as a learner-centered learning approach. Such an approach sees students as learners and as integral to the learning activity. Respondents asserted that OBE is practically oriented and involves hands-on activities. This learning process is activity-based, requiring students' active participation. Further, learners are not passive listeners but take an active part in the process of learning with the teacher. These ideas concur with Reid's (2005) view that learning is a co-operative effort between the learner and teacher. It would seem that this approach would encourage learners to be responsible for their own learning, to think for themselves in order to form their own ideas and opinions rather than simply absorbing the knowledge and ideas of the teacher. In this way, they are encouraged to become critical and analytical thinkers, thus enabling them to expand on their knowledge and face new challenges.

\subsubsection{OBE as an Assessment-Driven Approach}

This study considers assessment to be the driving force for OBE. Respondents claimed that learners would be assessed not just by traditional written tests and examinations but by practical competency. Such an assessment approach shifts from the traditional knowledge approach to a competency-based one. This approach would be essential for assessing practical skills (Absolum, 2006). The data also reveals that OBE is suitable for competency and achievement-based assessment. It means that parents could be effectively informed about their children’s performance, progress and achievements, as well as providing positive feedback for improving teaching and learning in the classroom. This approach supports Hall's (2005a) and Absolum's (2006) argument that it is important for teachers to take account of students' 
learning and to ensure a fair report of how students perform and what they have achieved through assessment in the classroom. Respondents also suggested that assessment in a science classroom would need to be properly planned and communicated, to ensure validity and reliability, and would have to involve students directly.

\subsubsection{OBE is Based on Success not Failure}

Respondents stated that the OBE system is based on the philosophy of success rather than failure. This is a positive perception about the OBE approach which teachers as facilitators must acknowledge for purposeful learning. Teachers had to ensure that all learners acquire adequate mastery of the knowledge, skills and understanding which would be useful to them after completing their formal education. Respondents affirmed that the OBE approach is intended to address the needs of the majority of school leavers exiting the school system at the end of the basic education in Solomon Islands. Such a philosophy encourages positive learning for all and being successful, rather than just providing an over-academic learning in the classroom. Further, the philosophy focuses on students' potential and ability to learn in order to be successful and also values students' prior knowledge, learning, and experiences. The knowledge students bring to the classroom is valuable and should be expanded for better understanding and acquisition of new knowledge and skills. In this way, students can be positive about learning and setting a clear direction for future endeavours in life.

\subsubsection{OBE is Similar to Indigenous Teaching and Learning Strategies}

Respondents claimed that OBE has a practically orientated outlook. Such an approach focuses on the way students learn and acquire essential knowledge, skills, attitudes, and values. The data seems to suggest that the OBE approach is similar to aspects of the indigenous ways of teaching and learning in Solomon Islands. Such a link enables the curriculum to capture essential knowledge, skills and practices that are 
relevant to Solomon Islanders. In his description of Ausae pedagogy, Sanga (2009) argues that such an approach draws out important knowledge and insights that had previously been hidden and is culturally grounded in educational understanding and practices. Similarly, the OBE emphasises learning by doing, or by observation and experimentation. This is related to the traditional Solomon Islands ways of learning by doing. The data also shows that the current curriculum does not encourage the teaching and learning of diverse knowledge and practices, thus creating a gap between the indigenous ways of learning and the current one. In agreeing with Sanga (2009), respondents claimed that this could result in the loss of important traditional knowledge and practices. To counter such a threat of knowledge loss would require educators, policy makers, and curriculum specialists to re-think ways of incorporating such knowledge and practices in the OBSC. In the Solomon Islands context the learning activities in a science classroom need to be organised around learning strategies used within our indigenous education protocols. Respondents also suggested that the teaching and learning activities planned for students must take into consideration ways of knowing and doing in the home context. Bakalevu (1996), Pasikale (1996) and Gegeo and Gegeo (2000) note the possibilities inherent in the recognition of students' traditional knowledge that could clarify the understanding of abstract concepts in the OBSC.

\subsection{Appropriateness of OBE as a Curriculum Approach}

This study discusses how the curriculum being developed in Solomon Islands is derived from the OBE model. Such a model focuses on the promotion of practical learning that would lead to an effective demonstration of significant outcomes. The data shows that OBE will enhance a paradigm shift in the teaching, learning and assessment in the science classroom. The shift promotes moving from the traditional approach of the banking education system to a learner-centered approach (MOE, 2008). The banking education system presumes learners to be passive vessels or containers to be filled with knowledge by teachers. Respondents realised that such an approach starts with the assumption that the 
learners know little or nothing and the teacher is there to impart knowledge to learners. Rather, the data indicates that teaching, learning and assessment in the classroom should use interactive and participatory learning. The OBE curriculum, however, is based on what has been called the problem-posing approach to education (MOE, 2008), which presumes that learners already have their own ideas, knowledge and skills based on previous experiences. Building on such knowledge and experiences will assist learners to think about their own ideas and experiences as well as expand on new knowledge and skills (Education \& Support Agency, 1995). To restate, the OBE syllabus does not focus so much on the content of the subject but on how learners are able to make use of that content. In this way, the emphasis is not on learning knowledge alone but rather on the ability to acquire skills, both practical and intellectual, to enable learners to use the knowledge they acquire. The data also reveals that the OBE curriculum involves the process of designing downwards or backwards (Killen, 2007). Such a design process is conducted by asking what knowledge, understandings, skills, attitudes and values are considered to be useful for students and then developing the teaching, learning and assessment strategies to accomplish the desired outcomes. In this way, the learning outcomes are aligned with the teaching and learning process, as well as assessment practices in the science classroom.

\subsection{Conceptualisation of OBSC}

\subsubsection{Defining OBSC in Solomon Islands}

Respondents defined OBSC as an outcomes-focused science curriculum. Such a curriculum encourages the learning of important scientific knowledge, understanding, skills, attitudes, and values. Specifically, the outcomes are designed so that students can learn and apply their learning within the school system. The data shows that the teaching and learning of OBSC would be likely to involve such process skills as investigating, interpreting and explaining our natural, physical world and the wider universe. It would also involve generating and testing ideas, gathering evidence, making observations, and carrying out 
investigations, modeling, communicating and debating with others. Respondents also claimed that OBSC would promote students performing these skills individually or collectively in order to develop scientific knowledge, understandings and skills. Finally, science is a practical subject and as such teaching it has considerable challenges which require appropriate teaching and learning resources.

\subsubsection{Rationale of OBSC in Solomon Islands}

Respondents claimed that science should involve people investigating the living, physical, material and technological components of their environment and make sense of them in a logical way. Because of this, the learning style of OBSC is fundamental to understanding the world in which we live and work. Such a learning approach is likely to help students to clarify ideas, ask questions, to test hypotheses through measurement and observation and to use findings to establish the value and worth of an idea. OBSC wants to show that science is a universal subject and to acknowledge the contribution that different cultural perspectives make to develop the understanding of science right from the beginning of learning science at primary school (MOE, 2007). The data reveals that the inclusion of local and traditional knowledge about the natural and physical world will enrich the OBSC. It must be understood that science has a major influence in many aspects of students' daily lives, at work, at play and at home. Respondents claimed that the importance of science demands a really good understanding of science and a comprehensive science education for all students (MOE, 2006).

\subsubsection{Significance of OBSC in Solomon Islands}

According to the study, the implementation of OBSC would give opportunities for all school-aged children to learn and understand how science affects and influences human lives in Solomon Islands communities. The data also suggests that OBSC is designed so that students can learn important indigenous knowledge and skills, and appreciate traditional values and attitudes. Geographically, most 
rural based Solomon Islanders are located along the coast and so require a better understanding of how marine resources are used and managed. Respondents claims that there is a lot of knowledge of natural phenomenon, weather and climate patterns, navigation skills, conservation methods and practices, agricultural and fishing methods that is important for our survival and livelihood. Such knowledge and practices have been commonly used and are part of the indigenous culture, values and traditions. Respondents pointed out that Solomon Islanders have used this body of knowledge in past decades. Surprisingly this knowledge is not documented in current learning materials. It is envisaged that OBSC will document relevant indigenous knowledge on resource use, management and other important knowledge and practices. This study also reveals that an understanding of science in secondary schools will complement existing indigenous knowledge on appropriate uses, practices and management of our marine and other natural resources.

\subsection{Perceived Teaching, Learning and Teacher Support Strategies 5.5.1 Teaching Strategies for Effective Delivery of OBSC}

The data suggests that activity-based teaching approaches are suitable for delivery of OBSC. Such an approach is aimed at engaging learners by means of practical learning. In other words, it involves learning and teaching by doing. Respondents agree that an activity-based strategy is crucial to stimulate critical thinking, communication and solving problems in the learning process. Such strategies would encourage learners to participate and interact well. In this way, students would be able to use knowledge they came in with and connect them with real life experiences. The following teaching strategies are offered for effective delivery of OBSC. 


\subsubsection{Practical Activities}

Using practical activities as a teaching strategy would lead to a better practical understanding of science. Respondents suggested more use of both classroom experiments and field investigation. Such an approach would enhance effective participation and interaction. It would also allow students to participate in hands-on activities and the application of practical skills. Doing so would provide opportunities for students to observe, record, interpret and conduct analysis as well as develop skills in the handling of science apparatus both inside and outside the classroom (Killen, 2003). Therefore, classroom organization is an important factor for enhancing effective learning. Respondents were of the view that with simple and clear instructions, and better learning resources, students should be able to put theoretical understanding into practice and make appropriate scientific conclusions, thus encouraging students to work scientifically and improve critical thinking, analysis and communication skills (Killen, 2007). In implementing OBSC, the work of Daudau (2007) would help students to report their findings and make conclusions as well as improving their skills in writing scientific reports.

\subsubsection{Student Discussions}

Using discussion as a teaching strategy would encourage student participation and interaction. Respondents affirmed that this approach would motivate students to be actively involved in sharing ideas and would require critical thinking and deeper understanding. Lowe (1984, p. 10), cited in Killen (2003), claims that "discussion if done right is a marvelous tool for teaching and learning". In such cases, planning a discussion is essential. Apparently, teachers as facilitators must ensure students are clear of the topic and how it is to be discussed. Respondents thought that using such an approach would empower students to participate and engage well in dialogue. It would also motivate students' logical and critical thinking in an open forum (Killen, 2003). Consequently, students would be encouraged to share their ideas, integrate, apply and evaluate their knowledge in the context of the discussion (Killen, 2007). 


\subsubsection{Group Work}

Using group work as a teaching strategy would enhance participatory and interactive learning. Respondents viewed this approach as an effective tool for positive engagement. In this approach, teachers would allow students to form small groups for interaction and building motivation within the group. Killen (2003) points out that both group learning and whole class discussion is useful. For science learning, using such an approach would work effectively because of the practical aspects in the learning. Group learning through small groups should be encouraged because it will shift students from being passive to becoming active learners, thus allowing students to use their prior knowledge and experiences (Killen, 2003). Further, the same approach would also encourage students to work on a task that would otherwise be too complex to be undertaken by individuals (Killen, 2007). Students would also be encouraged to do practical activities, investigations and field trips outside the classroom.

\subsubsection{Co-operative Learning}

Using co-operative learning as a teaching strategy would enhance effective collaboration and communication. Respondents agreed that this approach would be good for establishing relationships between peers in the learning activity. Co-operative learning is instructional learning that would require everyone to work together to help each member achieve a common learning goal or outcome (Killen, 2003). Such a teaching strategy is based on the belief that learners can achieve desired outcomes by working collaboratively rather than by working alone or simply by receiving information passively from science teachers. Agreeing with Killen (2007), respondents added that in order for this to happen students must be co-operative and show positive inter-dependence, face to face interaction, have appropriate interpersonal skills and become reflective learners. The co-operative learning would be encouraged by practical activities and investigations through field trips and excursions. These are opportunities for students to work individually and not having to rely on science teachers in the classroom (Killen, 2007). 
Furthermore, this approach would help students to change their views on spoon-feeding and develop views of learning through doing (Killen, 2003). This would help boost student confidence, self esteem and develop their cognitive, linguistic and social abilities (Killen, 2007).

\subsubsection{Problem-Solving}

Using problem solving as a teaching strategy would motivate students to identify problems and work towards finding solutions. Respondents suggested that this would be an important teaching strategy for motivating students to engage in critical analysis and creative in problem solving. Mayo, Donnelly, Nash \& Schwartz (1993, p. 227), cited in Killen (2007), define problem solving as a strategy for “ posing significant, contextualized, real world situations, and providing resources, guidance and instructions to learners as they develop content knowledge and problem solving skills”. Such an approach can be used in a single lesson or could be integrated in a series of activities (Killen, 2007). In this context, students are motivated to identify the core problems and look at ways of solving a problem. In science teaching, the teachers must ensure that the problem is stated clearly and supported with resources that would facilitate effective decision making. Furthermore, students would have the opportunity to look at real life issues and suggest ways of solving them by reaching constructive conclusions (Killen, 2003). In this way, students can take part in solving environmental and health related issues. This would promote the use of team work, critical thinking as well as assisting students to shape their own learning (Killen, 2007).

\subsubsection{Case Studies}

Using case studies as a teaching strategy would stimulate students learning. This is where the teacher would give real life examples which the students would work on. Respondents had the view that such an approach would involve students in the decision making process and enable them to experience the challenge of finding solutions. Killen (2003, p. 240) defines a case study as "a story with a hidden 
message and a narrative that actually describes an action or decision to solve a problem”. In case studies, students would be more focused and engaged in collective analysis of different issues, and gain a deeper understanding of the issues involved (Killen, 2007). In doing so, students would be taught how to deal with a "case” and how to solve situations amicably. Agreeing with Killen (2003), respondents claimed that a case study approach is similar to a constructivist teaching approach. Such a teaching strategy encompasses the idea that learners need to engage in active learning first and effective use of past experiences before challenging and reconstructing their own understandings (Killen, 2007). In science teaching, students need to put the real issues emerging from the case study into context and to look at constructive and useful ways of solving the issues. This would help students develop deeper understanding of concepts and issues, and present them in a logical and systematic way (Killen, 2007).

\subsubsection{Role-Plays}

Using role play as a teaching strategy would motivate students to dramatize real situations. Respondents believed that this would be an opportunity for students to experience the processes of dealing with real life issues. Such an approach would also create positive links with real life situations. Killen (2003, p. 226) defines role play as "a form of acting in which the general roles of actors are defined and they do not have scripts to follow”. In a role play, students would be given roles and responsibilities to demonstrate the character and messages through the role play. Such a strategy would increase students’ knowledge and understanding through engagement in the role play, having to search for relevant information and make sound decisions (Killen, 2003). Furthermore, respondents thought that this would help students develop self confidence; self esteem and improve communication skills, thus helping students explore a lot of situations outside of their experience and the likely consequences of their actions (Killen, 2007). 


\subsubsection{Student Research}

Using student research as a teaching strategy would encourage students to learn and apply research skills. Respondents thought that using this approach would involve students undertaking scientific investigation. Agreeing with Killen (2003), the study concur that research is either based on the students own findings, interpreting and using information that has been discovered or developed by someone else. Stern, \& Kalof, (1996) states that research can be seen as gathering, interpreting and using information that did not exist before the research was conducted or being based on some form of experiment. In such cases, "research should generate new knowledge and should be much more than regurgitation of existing knowledge (Killen, 2003, p. 211). In support of Bakalevu (1998) and Pasikale (1996), respondents claimed that many Solomon Islanders fear engaging in research. Further, they were not motivated to research because of the fear that they would not succeed. The study has shown that using such a strategy would encourage students to learn research skills, and to apply the skills in a systematic way. In this way, students would be given the opportunity to begin research at an early age, thus helping students to build confidence and develop positive attitudes about their own learning (Killen, 2007).

\subsubsection{Student Writing}

Using student writing as a teaching strategy would engage students in thinking logically about improving their writing skills. Respondents affirmed that this would be an opportunity for students to improve their writing skills. Such a strategy would enhance creativity and originality. Agreeing with Killen (2003), respondents added that students should not be passive learners; they need to talk about what they are learning, write about it, relate it to past learning experiences and most importantly, apply it to their daily lives. Such an approach would allow students to be critical of their work. In this way, students would be motivated to become critical thinkers and be able to develop concepts that are logically structured with constructive thoughts and ideas (Killen, 2003). The study also reveals that this approach would encourage 
students to explore new ideas through writing, gaining a deeper understanding of concepts and at the same time improving their writing skills. Such an approach would allow students to study scenarios that would stimulate creativity, critical thinking and the application of scientific knowledge (Killen, 2007).

\subsubsection{Learning Strategies for Better Understanding of OBSC}

The OBE model requires a learner-centered learning approach. The data suggests that students would learn and understand science better through more participation and interaction. In agreeing with Bell (1993), respondents believed that students come to science lessons with their own knowledge and explanations of how and why things behave the way they do. Some respondents claimed that learning in the science classroom should be seen as a process rather than being viewed negatively as simply filling up student's empty brains. Bell (1993) describes learning as a process where students are developing and changing existing ideas into new ones. In other words, learning must be seen as a conceptual change, construction and acceptance of new ideas as well as the process of restructuring existing ideas (Bell, 1993). Such a theory is called the "constructivist view of learning” and recognises that students construct new ideas rather than absorbing them, and that learners actively generate meaning from their own experiences (p. 23).

Respondents also claimed that effective learning strategies are necessary to impact on students learning in a science classroom. Using such strategies would create enthusiasm and motivation in student learning; they would feel connected and comfortable in the classroom. Agreeing with Reid (2005), respondents said that having a positive self esteem is crucial for learning because it provides the learner with confidence, motivation and the ability to face new problems and challenges. Such an approach could help students develop awareness of their own perceptions as learners, thus making positive steps towards their 
own successful learning (Reid, 2005). In this way, students are likely to become more successful. The following learning strategies are provided for enhancing students' better understanding of OBSC.

\subsubsection{Learner-Centered Learning}

This study reveals that students learn better through the learner-centered approach. Such an approach would need to be supported with the appropriate resources and learning environment. Further, respondents claimed that learning activities needed to involve students, placing them at the center of the learning process. Reid (2005, p. 10), states that "students must be aware of their abilities to maximize their learning potential through the process of meta-cognitive approaches”. According to this, students should direct their own learning and monitor their learning experiences. Agreeing with Reid (2005), some respondents also noted the importance of identifying barriers to students' learning and to finding ways of solving them for more effective performance and achievement. Further, contextual learning is seen as a catalyst in promoting students' learning in a science classroom. In supporting Bell's (1993) claim, respondents agreed that what is essential for students learning is that it is done within a context they understand. If this is so, students are likely to feel comfortable in a science classroom and become part of the learning space. However, respondents also pointed out that students have different learning abilities and as so learn better in different conditions. In this way, respondents suggested that for enhancing effective learning, it requires effective teaching approaches and strategies to ensure that learners are presented with tasks and activities within their range of experiences and understanding (Vygotsky, 1962 \& 1987, cited in Reid 2005). 


\subsubsection{Activity-Based Learning}

The study indicates that students would learn better in activity-based or hands-on activities. This would involve students in participatory and interactive learning. Respondents suggested that science teachers must ensure that students are actively involved in science activities, making their own observations and interpreting the data themselves. In this way, students' participation in interactive learning must be more enriching as they gain knowledge and skills through the science activities. Furthermore, the data shows that students would learn to draw useful insights and make scientific conclusions. To concur with Reid (2005), science learning would involve collaboration. For instance, experiments might be done jointly and learners would each have to take responsibilities during the experiment and in so doing would promote interpersonal learning and provide opportunities for knowledge sharing. In support of Reid (2005), respondents affirmed that collaborative learning is a powerful social activity in a learning environment.

\subsubsection{Participatory Learning}

Students' participation is essential for positive engagement in learning. Respondents agreed that this learning strategy would improve students' participation as each student had an opportunity to share their knowledge. In support of Pasikale (1996), some respondents agreed that most Solomon Islands students are too shy to participate in class. Further, students are reluctant to participate for fear of making mistakes. The data reveals that participatory learning would encourage and promote effective learning and gaining of students' confidence. Such a learning approach is necessary to build good relationships and maintain the link between the teaching and learning processes. 


\subsubsection{Interactive Learning}

Students' interaction during a learning activity is important for having fruitful group discussions. Respondents recommended that this learning strategy would help students interact and get to know each other while at the same time promote knowledge sharing. In agreement with Pasikale (1996), the data claims that most Solomon Islanders are too shy to talk and interact with peers in the classroom context. Such a learning strategy would provide an opportunity to change this mentality and promote effective learning. The use of such approach is to break down such barriers to maximizing learning opportunities.

\subsubsection{Co-operative Learning}

Students would learn better through sharing about what they know and their learning experiences. Respondents pointed out that this learning strategy would assist students to express and share ideas amongst their peers. In this way, students would be given the opportunity to share their own knowledge and experience. In support of Bell (1993), some respondents felt that students would be able to make good analyses out of available information and data, and be able to draw scientific conclusions. Reid (2005) defines learning as a behaviour that can be influenced and enhanced by another behavior. Respondents affirmed that this type of behaviour can be achieved through utilizing the behavioural principles of reward and reinforcement that can be applied by sharing in smaller groups in a science class (Reid, 2005). In supporting the claims of Reid (2005), some respondents suggested that successful completing of smaller tasks would motivate learners by making the learning process not only successful but also enjoyable and manageable.

\subsubsection{Exploratory Learning}

Students would learn better when involved in exploratory learning. Respondents believed that this learning strategy would help students to apply logical thinking and reasoning and develop their own 
learning. In this approach students would be given the opportunity to explore and make sense of new knowledge, concepts and ideologies and be able to expand thinking beyond their existing knowledge. To concur with Bell (1993), some respondents were of the view that following the OBE model students would develop good critical thinking abilities and be able to expand it into new knowledge. Students could be assisted to explore how what they are learning in the classroom relates to outside the classroom (Luft, Bell \& Ges-Newsome 2008).

\subsubsection{Self-Guided Learning}

Students would learn better if involved in self guided learning. Respondents pointed out that this learning strategy would guide students to learn effectively. The data reveals that science teachers would have to ensure that students were given the opportunity to make critiques through class discussion in a systematic and scientific way. In this approach students would be given enough knowledge to make sense of key concepts and ideologies to be able to arrive at new knowledge. Agreeing with Bell (1993), some respondents thought that students would develop critical thinking abilities and be able to make informed decisions about their own learning. Similarly, students would be empowered to work individually with limited resources. Furthermore, students would develop positive learning attitudes as they progressed in their learning in a science classroom.

\subsubsection{Enquiry Learning}

Students would learn better if they took responsibility for their own learning. They would need to ask questions about how and why things happened. This would also mean that students could evaluate their learning and suggest their own future direction of how to learn better in the science classroom (Luft, Bell \& Ges -Newsome, 2008). This study too agrees that this learning strategy would allow students to think about their own learning and suggest ways of improving their ability to learn better based on good 
critiques and meaningful analyses. Respondents claimed that the ability of students to evaluate and make informed judgments of their own learning is beneficial not only for themselves as individual students but also for the teacher as facilitators of their learning. Supporting Reid (2005), respondents also suggested that students need to understand both the learning processes and the actual content. If they could do this, students would be able to identify their own learning differences and difficulties as well as developing learning strategies for better understanding of science in the classroom.

\subsubsection{Teacher Support for Enhancing Effective Learning}

According to the findings, effective support for classroom pedagogy is crucial for promoting participatory and interactive learning. Agreeing with Reid (2005) and Bentley and Watts (1989), respondents concurred that there is evidence about the kinds of teaching support that has a positive impact on students' learning. Such supports would be essential with the OBE model. According to the respondents, providing such support would be likely to promote effective learning in the classroom, thus enhancing students' performance and achievement. To concur with Manu'atu (2009), Koya (2009), Bakalevu (2009), Maha (2009) and Sanga (2009), students' success depends on an appropriate pedagogical content knowledge, supported by teachers as facilitators in the classroom. The following strategies are suggested for science teachers to use for supporting students' effective learning of OBSC.

\subsubsection{Creating a Supportive Learning Space}

Students will learn better if they feel accepted and know that the knowledge they bring to the science classroom is acknowledged and appreciated. Supporting Driver (1985), respondents claimed that students feeling at home in the learning environment are crucial to their learning. Respondents also agreed that building positive relationships in the classroom would create the support that students would benefit from in their learning. The study reveals that "effective science teachers would be able to promote positive 
relationships in the classroom which are likely to provide the learning environment needed for effective learning” (New Zealand MOE, 2007, p. 34). Further, science teachers must also extend the relationship into the wider community so that the community shares in advancing the students learning. Agreeing with Driver (1985), respondents affirmed that having a positive link between the students learning and the teachers support is crucial for all effective learning.

\subsubsection{Encouraging Critical Thinking}

Encouraging critical thinking is essential for students' success. As Driver (1985) expressed, science teachers should play their role of encouraging students to think critically about what they learn. Respondents agreed that as facilitators, teachers need to provide opportunities for students to reflect on content learnt and apply it to new situations. In this way, students would "assimilate new learning, relate it to what they already know and experience, adapt it for their own purposes and would be able to translate thought into action” (New Zealand MOE, 2007, p. 34). All this would be assisting students to develop creativity, good reasoning and critical thinking. The data suggests it would be helpful for science teachers to encourage students' critical thinking and give opportunities for them to experience a variety of tasks in the learning activities. For instance the use of investigative projects would stimulate student's critical thinking, creativity and originality. To concur with Driver (1985), respondents also claimed that this approach would stimulate students' imaginations towards creating their own inventions which would enhance learning in the science classroom.

\subsubsection{Enhancing the Application of New Learning}

Being clear about the relevance of new learning is important for students to establish what they have already learnt and what new knowledge they are aiming to learn. Respondents suggested that science teachers must ensure that students are well informed about their learning in the science classroom. In this 
way, "students would be able to learn more effectively when they understand what they are learning, the reasons for learning it and how the knowledge will be applied” (New Zealand MOE, 2007, p. 34). The data also claims that effective teachers must ensure students are interested about what they are learning and be able to gather new knowledge and ideas that is relevant to the context of their learning as well as applying it to real life situations (Reid, 2005). This would help students become involved in making decisions and having ownership of their learning (New Zealand MOE, 2007).

\subsubsection{Facilitating Shared Learning}

Facilitating shared learning is essential for improving students’ learning. Respondents held the view that students learn as they engage in shared activities in the classroom. Further, having "other people from the community participating in class activities could be helpful to build shared learning in a learning community” (New Zealand MOE, 2007, p. 34). Respondents pointed out that this would engage students in a broader learning community with whom they could learn to communicate. Such an approach would help students build appropriate language which would also to assist them in connecting with their peers. This study has shown that the role of language is crucial in shared learning and for cognitive development (Reid, 2005). The importance of language must be appreciated because it helps students understand one another and transfer knowledge amongst peers (Osborne \& Freyberg, 1985). Respondents supported Reid’s (2005) idea that it is important to keep building on knowledge gained through shared learning in the science classroom. Despite its importance, respondents thought that the ability of learners to share with one another would be a challenge because of the diverse personal differences among students.

\subsubsection{Using Prior knowledge, Learning and Experience}

Using prior knowledge, learning and experience is crucial for student's effective learning. In agreeing with Osborne \& Freyberg (1985), respondents thought that students' knowledge about the previous 
science topics was very important and could influence learning in the classroom. Respondents also affirmed that "students would learn better when they were able to integrate new learning with what they already understood” (New Zealand MOE, 2007, p. 34). Such an approach would enhance students learning output. Furthermore, the approach would also assist students’ learning in other areas as well as connecting it to their home settings (Manu'atu, 2009; Bakalevu, 2009). In this way, students’ would maintain links and connections with their home knowledge and practices as well as relating it to what they learn at school.

\subsubsection{Providing Sufficient Opportunities for Learning}

Providing sufficient opportunities would be helpful for students to expand their learning capacity. Agreeing with Driver (1985), respondents held the view that students should be given a more supportive and flexible environment to be able to learn better in a science classroom. Respondents believed that learning opportunities needed to be student-centered to stimulate the learning process. The study suggests that enough time should be given for students to engage in a variety of learning activities (New Zealand MOE, 2007). In support of Driver (1985), respondents affirmed that science teachers needed to ensure students were involved in practical activities to allow them to create new knowledge and to gain a better understanding of science. The data also suggests that science teachers must develop the art of learning to improvise with any available resources to make students learning meaningful. All this would enable students to expand and transfer acquired knowledge to new learning contexts (New Zealand MOE, 2007).

\subsection{Perceived Assessment Strategies for OBSC}

The form of assessment suitable for assessing OBSC must be contextual and fair. Respondents emphasised that students would need to be assessed individually to ensure appropriate judgments were made on the performance of each student (Muralidhar, 2009). Such an approach would mean that 
students’ performance and achievement would be based on their abilities. Doing this would also help to improve the teaching and learning processes in the science classroom (Absolum, 2006; Hall, 2005a). The data indicated that assessment should focus on assessment for learning. Students should be assessed against specified criteria (MOE, 2007) based on agreed standards.

\subsubsection{Assessment for Learning}

Respondents concluded that assessment for learning would be essential for OBSC. The data indicates that the learning could be measured according to already written outcomes. Such an approach focuses on what learners can do as a result of learning (Muralidhar, 2009) and requires explicit and planned criteria of the whole curriculum (MOE, 2007). Respondents claimed that this would allow teachers to focus their teaching on contextual content which would encourage students to be able to analyse, interpret and make predictions. Students' assessment should be integral to their learning. This approach would involve judgment of students' performances based on explicit criteria as well as providing feedback on the teaching and learning process. How students performed against the criteria would be a good measure for both teachers and students. The data also reveals that OBSC would involve assessment tasks that are learner-centered and likely to require minimal resources, facilities and scientific apparatus. Suitable assessment tasks suggested by respondents included practical activities and experiments, research and investigations, oral presentation, written essays, tests, home work and assignments.

\subsubsection{Criterion-Referenced Assessments}

The demonstration of specified outcomes by students would require the use of criterion-referenced assessment. Such an assessment approach would be a standards-based assessment to measure students’ competence and achievements. This assessment approach would be likely to involve the setting of specific written standards for student learning in a science classroom. In agreeing with Hall (2005a), 
respondents pointed to the need to rename criterion-reference assessment as standards-based assessment to enable science teachers to judge the achievement of students. Assessment should have a positive impact on learning, through a continuous process of internal assessment rather than a one-off external final examination (Hall, 2005a). Respondents asserted that such assessment practices would provide the standards for an effective monitoring and reporting system, thus maintaining an integral part of the schools accountability system to students, parents and key stakeholders (Absolum, 2006; Hall, 2005a; Muralidhar, 2009).

To understand the justification for adopting standards-based assessment, the distinctions between normreferenced and criterion-referenced assessments must be clearly understood. In agreement with Hall's (2005a. p 237), the study concurs that criterion-referenced assessment focuses on judging whether students have met pre-specified written criteria in respect of what constitutes an acceptable performance in a course. In this way, individual students are not compared with each other but with written criteria. The criteria would focus on what is required for different levels. Moreover, respondents suggested that the assessment activities should be flexible. The norm-referenced assessment however "focuses on educational measurement strategies that directly compare students in respect of their performance” (Hall, 2005a. p 237). The study reveals that while examinations and other assessment tasks are still valid in terms of the content, the critical feature is that the final grade of a student is based on his or her performance in relative to others who have taken the same examination (Hall, 2005a). Such an approach to assessment concurs with the "field of psychological testing, focusing on measurement of intelligence, aptitude, personality and attitudes” (Hall, 2005a. p 237). It also places a strong emphasis on comparing individuals with 'norms' of performance as defined by the population to which the individuals belong (Hall, 2005a). 


\subsubsection{Competency-Based Assessment}

The study shows that OBSC should be assessed on students' competence. Such an assessment approach enables teachers to judge students’ performance and achievement against written criteria (Hall, 2005a). Respondents agreed that students assessed on competency based assessment would be required to demonstrate whether they had achieved the skill or not. In a science activity, there are important skills needed for carrying out scientific investigations. Furthermore, the skills are based on all human senses. In agreeing with Reece and Walker (2003), assessment of competence or skills acquired by students would be essential to show the practical aspect of the learning process. The respondents also agreed that there are certain skills involved how an investigation is conducted, how results are recorded, processed and presented and in how conclusions are deduced. In this way, science teachers would only have to inform students whether they had reached the required level or not of a particular skill. Respondents suggested that students who did not achieve competency assessment must be given remedial work and be given another opportunity to demonstrate the required skills.

\subsubsection{Achievement-Based Assessment}

The data indicates that OBSC could also be assessed on student's achievements. Respondents claimed that this assessment approach would allow teachers to judge students’ achievement against pre-specified levels of performance. Each of these written criteria would be based on the knowledge and understanding of the science content (Hall, 2005a). Respondents suggested the use of a rubric scale from $0-5$ with clearly defined descriptors that correspond to different levels of performance extracted from the unit outcomes in the science syllabus (Reece \& Walker, 2003). In this way, the descriptors would provide a list of criteria in an ascending scale. As Hall (2005a) also says, such an assessment approach would provide graded judgments according to the level of performance attained by individual students. Further, in agreeing with Reece and Walker (2003), respondents also pointed to the use of the 'rubric scale' to 
guide the assessment criteria which are context specific to the learner and the assessment tasks. Therefore, students assessed on achievement-based assessment would need to demonstrate whether they have achieved the level of performance prescribed on the scale. Such levels are the assessment standard and would assist science teachers to establish individual achievements in the classroom for each unit outcome, as well as overall achievement. In this way, science teachers would be able to identify strengths and weaknesses of students and may suggest remedial work for low or under achievers.

\subsection{Perceived Monitoring, Recording and Reporting Systems}

Effective monitoring, recording and reporting systems would be required in the secondary schools. Such systems would be crucial for schools accountability and transparency. The study reveals that there is a need for a better system of informing parents and fee payers about their children's performance and achievement.

\subsubsection{Secondary Science Monitoring System}

The study shows that schools require an effective recording system for monitoring of students' performance and achievement. Respondents suggested that this monitoring system would require prespecified written statements on science outcomes so that students’ performance and achievements could be easily monitored. The data also reveals that effective monitoring cannot take place without accurate student records. Interviews could be conducted either between the science teacher and the student, or the parents, or jointly including both students and parents. Teachers would be required to monitor individual students’ progress from the beginning to the end of each semester. Doing so would allow science teachers to map students’ progress and clearly identify their learning pathways. In this way, such an approach would give opportunity for collaborative dialogue between science teachers and parents. This study has shown that students' weaknesses and strengths could be identified and discussed to find ways for students 
to improve their learning. Such an approach would be a dialectical monitoring strategy that aims to inform parents on issues affecting their child's performance and achievements. Further, the monitoring system would help establish a good relationship between the teachers, school administration, parents and the school community through systems of accountability and transparency.

\subsubsection{Secondary Science Recording System}

The study data reveals that schools require a more effective recording system for keeping accurate records of student's performance, progress and achievement. In schools, the use of a standard record book would be essential for keeping good and accurate records. Respondents suggested that it would be ideal for a student record book to be prepared by the CDC and distributed to all secondary schools. Such a record book would have appropriate columns to record assessment tasks, the nature of the assessment and appropriate weightings. This recording system would be essential for monitoring students’ performance and achievements within a term or semester. Respondents suggested the use of student folios. Respondents also affirmed that this filing system could contain up-to-date information of skills the students had achieved. Such records would be useful for teacher-student and teacher-student-parent meetings. Furthermore, these folios could also be useful in the event of students being transferred from one school to another, ensuring that accountability and transparency would be maintained by the school administration.

\subsubsection{Secondary Science Reporting System}

Schools require an effective reporting system not only for informing parents of students’ performance and achievement but also for teachers’ effective feedback. Student reporting has a very important role in schools accountability to parents and key education stakeholders. The study reveals that since teachers are responsible for students' learning in the class, they are therefore required to monitor and report on their 
achievements on a regular basis. As explained earlier, with OBSC they would be assessed and reported against pre-specified written statements of achievement. Such an approach would allow teachers to report clearly on students’ performance and achievements. Teachers would also need to show to parents and fee payers whether students have begun to understand, already achieved or are confidently achieving the desired outcomes. The reporting system would have to use a consistent reporting framework. Respondents suggested that a reporting format should be prepared by CDC and distributed to secondary schools throughout the country. Such a system would be useful for teacher-student and teacher-parent meetings with a set reporting format to represent a full account of students' achievement to parents, the MOE and other interested stakeholders.

\subsection{Potential Problems, Issues and Challenges, and Perceived Strategies 5.8.1 Perceived Problems, Issues and challenges}

This study identifies problems, issues and challenges that might impede effective implementation of OBSC in secondary schools. These are potential impediments or inhibitors. Respondents claimed that there would be various problems, issues and challenges within the classroom setting, teaching and learning processes, assessment practices, teacher education and training programme, and policy issues in the MOE. Effective implementation of OBSC would require a collective effort to address these problems, issues and challenges at all these levels.

First, the study reveals that the lack of understanding about the OBE approach and pedagogical content knowledge of OBSC would impede its implementation. The lack of such understanding could discourage science teachers as the curriculum implementers in the school system. Second, respondents argued that the lack of teaching and learning resources, facilities and infrastructure would hinder effective implementation of OBSC. This acute shortage would affect the teaching and learning processes as well as 
assessment, monitoring and reporting of student achievements. Unless schools were properly equipped with the required resources and facilities, the implementation process could not take place effectively. The study data reveals that students cannot really learn science well without teaching and learning resources and proper science laboratories to make a supportive learning environment for the learning of science. Third, the study has indicated that the lack of qualified and competent secondary science teachers could inhibit the effective implementation of OBSC. Science teachers would be the facilitators and implementers of the new curriculum. Because of this, respondents think that science teachers should be thoroughly knowledgeable in science content and pedagogy. The study shows that science is currently taught by untrained teachers in most secondary schools. This would create a considerable challenge in the implementation process. Fourth, this study reveals that overcrowding and the reduction of time allocation for teaching secondary science would not support effective implementation of OBSC. Respondents saw the issue of overcrowding as a serious problem. It has already placed a lot of pressure on learning resources and the whole teaching process in the science classroom. Consequently, science teachers have not been able to assist students individually. Respondents thought the teacher-student ratio of 1: 35 needed to be effectively monitored. The study has suggested that the MOE should develop a policy to encourage school-aged children to enter schools at the right age and also to zone schools according to catchment areas for student placement and enrollment. Doing so would ensure students would be enroled according to their age and placed at zoned schools. Insufficient time allocation for teaching secondary science would impede the effective implementation of OBSC. The study reveals that as science is a practical subject, it would need more time than the proposed allocation. Furthermore, respondents felt that even the current number of teaching periods per week is higher than the proposed number and there were already difficulties in teaching the prescribed content. The reduction of periods per week allocated for science would worsen the situation. Fifth, the study shows that teacher resistance would discourage effective implementation of OBSC as well as the difficulty of changing the school culture. Respondents 
claim that the current school culture would be hard to change if classrooms were not well resourced, or provided with qualified science teachers. It would further damage the relationship between students and teachers in the classroom or school as a learning environment.

The study also indicates that science teachers would resist implementation of OBSC if they were not sure of what to do in the science classroom. Respondents believed that teachers' lack of understanding of the OBE approach and pedagogical content knowledge of OBSC would make science teachers resist the implementation process. Sixth, the study reveals that the lack of monitoring of existing education policies in the MOE would impede effective implementation of OBSC in secondary schools. Respondents commented that MOE policies are extremely important. In order for OBSC to be effectively implemented, appropriate divisions such as NESU, Secondary School and Inspectorate Divisions that have collaborative responsibilities with the CDC would have to ensure policies are strengthened and monitored. Seventh, the study shows that lack of OBE integration in the teacher education and training programme at the SOE of SICHE would impede the effective implementation of OBSC. Respondents suggested that teacher education and training would be an essential vehicle for teaching the new science curriculum. They also suggested that as OBSC is soon to be implemented, there is an urgent need for integration of OBE approach and the pedagogical content knowledge of OBSC in such a programme. Such integration would align curriculum development with teacher education and training, particularly for preparing future teachers for the implementation process. Eighth, the study indicates that lack of government support and commitment would impede effective implementation of OBSC. Respondents noted that current schools in the country depend very much on financial and technical assistance from the national government. Such assistance includes funding of school grants, supplying basic school equipment, facilities and building classrooms. Another factor respondents commented on was that with 
the current fee free school policy, it is up to the MOE to ensure all schools are resourced with appropriate facilities, classrooms and school laboratories.

\subsubsection{Strategies for Addressing Perceived Problems, Issues and Challenges}

A number of strategies have been identified for schools, education authorities, provincial and church agencies, teacher education institution, other key stakeholders and various divisions within the MOE to collaborate and lessen negative effects prior to the implementation process. Respondents have identified a number of strategies for addressing potential problems, issues and challenges so that positive measures can be taken prior to the implementation process.

First, according to the study there is a need for greater stakeholder awareness. Respondents agreed that proper understanding of OBE and OBSC would help lessen confusion and frustration amongst teachers, administrators and other stakeholders. For this, science teachers in secondary schools should be made aware of the OBE approach and its implication for the teaching and learning processes. Furthermore, understanding the different roles stakeholders play in the implementation process is essential. This study reveals that if key education stakeholders such as the provincial government, education authorities, church organisations, youth representatives, parents, teachers and students are fully aware and understand the curriculum shift of the OBE approach and appropriate pedagogical content knowledge, then the implementation process will be well received and conducted smoothly. Second, according to the respondents, there is a real need for sufficient resources including teaching and learning materials, facilities and the building of appropriate classrooms for OBSC to be implemented. Such assistance would include student books, apparatus and equipment, consumables and educational charts. Although there are materials already available in secondary schools, there would be a need for greater supplies of basic resource materials to cater for the new teaching and learning approach. Third, according to the findings, 
there would be a need for providing both teacher in-service training for current teachers and the integration of OBE and OBSC in the Teacher Education and Training Programme. Respondents suggested that MOE should take the responsibility in consultation with SOE of SICHE of providing teacher in-service training and capacity building programmes for practicing teachers. The study data recommends that such training should focus on OBE and pedagogical content knowledge of OBSC. Such integration is likely to upgrade and improve teacher education and training in the country. Fourth, the study reveals that there would be a need for strengthening and creation of new education policies. Respondents suggested that current education policies needed to be evaluated within the context of the CRRP. For instance, NESU, Secondary School and Inspectorate Divisions should evaluate existing policies in reference to the requirements of the OBE approach. Such an approach would not only help teachers to comply with teaching regulations but would also allow teachers to implement the new OBSC consistently. And fifth, the study has also indicated the need for establishing a collaborative link between MOE and other institutions. It is important that other education providers and institutions are well informed about the OBE model and its philosophies. Respondents saw that networking within and outside of MOE were vital for collaboration and sharing of information in the education sector.

\subsection{Summary}

The OBE model is an ideal approach to fulfill the current curriculum shift recommended in the National Education Strategic Plans. OBE promises a high level of learning for all learners and places more emphasis on a practical curriculum that prepares learners for real life. The focus is to address the needs of the majority of school leavers. OBE has its shortcomings; however, Solomon Islands is adopting appropriate aspects of the OBE to solve its current needs. OBSC is a syllabus derived from the OBE model. It is designed for students to acquire scientific knowledge, skills, attitudes and values that are integrated with indigenous knowledge and practices which are useful for survival and continuity after 
school. It also better prepares students who will go to medical, engineering and technological studies. The implementation of OBSC would require a good community understanding of OBE and teachers with good pedagogical content knowledge. This would encourage participatory and interactive learning with practical and activity-based science lessons. Since OBE is assessment-driven, it must use assessment strategies that are integrated with criterion-referenced or standards-based assessment, which are based on competency and achievements. This would set standards for students to achieve. Keeping accurate student records for effective monitoring and reporting of student performance and achievements is crucial for schools’ accountability. Finally, for effective implementation of OBSC, identified problems, issues and challenges would need to be acted on immediately.

I will now present the final chapter of this thesis. This chapter provides the research summaries, contributions, implications and recommendations, and final thoughts to conclude the research project. 


\section{CHAPTER SIX}

\section{SUMMARY OF FINDINGS, CONCLUSIONS, IMPLICATIONS AND RECOMMENDATIONS}

\subsection{Introduction and Overview}

Chapter Five presented the analysis and discussions of the findings of this study. This chapter provides the main conclusions and a summary of the study. First, it provides a summary of the findings. Second, it presents the contributions that are significant to the study. Third, it presents the research implications and recommendations for putting into action. The chapter concludes with a brief description of limitations encountered during the study and the final thought to summarise the entire research project.

\subsection{Summary of Findings}

The summary of findings is based on the four sub-questions of this study. These questions explore science teachers' perceptions of the meanings and understandings of OBE and implementation of OBSC in Solomon Islands. The first question asked for the respondents' conceptualisation of OBE and OBSC, and relevance and appropriateness for Solomon Islands. The second question asked for respondents' views on how OBSC could be implemented effectively in terms of teaching and learning. The third question gathered information on how OBSC could be assessed, monitored, recorded and reported on in relations to students’ performance, progress and achievement. The fourth question looked for information on the potential problems, issues and challenges that might impede or inhibit implementation of OBSC and ways for addressing these. 


\subsubsection{Conceptualisation of the OBE Model and Curriculum Approach}

According to this study, OBE has attracted many researchers globally, including the Solomon Islands. There are proponents and opponents of OBE. The way OBE is conceptualised by respondents suggests that this education approach can be interpreted in a number of ways, based on the varying assumptions and contexts. The respondents see that OBE would be the means of providing the necessary knowledge, skills, values and attitudes for the nation through a balanced school curriculum for the ten years of basic education in Solomon Islands. This study shows that OBE is conceptualised in a number of ways:

First, OBE is conceptualised as an outcome-focused approach because of the value placed on outcomes as the product for students to have acquired by the end of the learning process. It is thought that effective demonstration of outcomes at the end of each learning activity is what matters in this approach. Second, OBE is conceptualised as a learner or student-centered approach because it is really focused on the learner. This approach places students as learners at the centre of the learning activity. According to this study, students will learn effectively and acquire essential knowledge, skills and values or attitudes if supported with appropriate and sufficient teaching and learning resources, facilities and school infrastructure. Third, OBE is conceptualised as an assessment-driven approach because of the way assessment is conducted and administered. According to this study, actual demonstration of outcomes acquired from the learning process through classroom assessment is crucial. It is the evidence of outcomes learnt and achieved from teacher and student engagement in the classroom. Assessment in this case must reflect the student's performance, competence and achievement for each unit, each semester or the whole year. Fourth, OBE is conceptualised as an approach based on success and not failure because of the positive perceptions of students' abilities to do better while at school. According to this study, being positive about the learner and their learning will create a clear sense of direction for both the teaching and learning processes and as such will enhance effective learning. Lastly, OBE is conceptualised as an 
approach similar to indigenous teaching and learning in Solomon Islands because of similarities employed in the styles of delivery. According to this study, this approach would have a positive impact on the teaching and learning in the science classroom. Students are likely to engage in learning with more enthusiasm as this approach is not new, being more like the ongoing process of everyday life at home. The OBE model also employs a curriculum approach that focuses on learning by doing. Such an approach involves the paradigm shift from teacher-centered to student-centered learning. The design downwards or backwards of the curriculum is an important feature of this approach which ensures that the learning outcomes are aligned with the teaching and learning activities, and assessment practices in the classroom.

\subsubsection{Conceptualisation of OBSC}

The OBSC is viewed as education for life in Solomon Islands. OBSC is a syllabus developed for secondary science using the OBE approach. The study shows that the acquisition of scientific knowledge, understanding, skills and values is crucial for the survival and continuity of the Solomon Islands culture and traditions. First, the OBSC is defined as an outcomes- focused curriculum. The syllabus has been developed to provide the opportunity for students to acquire scientific knowledge, understandings, skills and values in order for them to be scientifically literate. This study sees this as an opportunity for indigenous knowledge of the Solomon Islands culture, values, beliefs and traditions to be researched, recorded and documented for school use in the country.

Second, the development of OBSC is perceived to have a potentially positive impact on science teaching and learning to promote better understanding of science in secondary schools. Scientific knowledge and understanding is useful for post-school real life situations; for instance, being good citizens by being able to make positive contributions on science related issues in the environment. According to this study, the 
development and implementation of OBSC is likely to have a positive impact on the Solomon Islands education system, particularly in the areas of teacher education and training, empowering teachers through teacher-in service training and capacity building programmes as well as improving the quality of science curriculum materials for teaching and learning.

\subsubsection{Teaching, Learning and Teacher Support Strategies for OBSC}

The teaching and learning of OBSC is based on the philosophy of the OBE model. This philosophy entails the importance of outcomes as the end product for students as learners. The vision is for students to prove to science teachers that they have learnt and achieved certain science outcomes. The designed downwards or backwards strategy of OBSC is believed to encapsulate the required processes involved in the new teaching, learning and assessment practices.

First, the teaching of OBSC in secondary schools is crucial for students' learning in the science

classroom. The role of the teacher as classroom facilitator is essential to student learning particularly in giving direction in the continued learning activity. According to this study, the approach that is suitable for teaching OBSC is the activity-based teaching approach which involves hands-on activities in a practical science class. This will enable students to learn and apply knowledge and skills in a practical way as well as provide an avenue for them to share and expand their knowledge, understanding and skills through activity-based learning.

Second, the learning of OBSC in secondary schools is crucial for student's acquisition and mastery of knowledge, understandings, skills and values or attitudes. The position and role of students as learners in the learning process must be acknowledged. Science teachers must know and appreciate where students are at in their learning to allow positive engagement in the learning process. This is essential for 
contextual learning which helps students understand the context of each learning activity. Having identified students' learning abilities and difficulties, teachers can then plan and map out students' learning with a clear direction towards achieving the desired outcomes. Students will learn better through being involved in an interactive, participatory and shared learning approach.

Third, science teachers must take the initiative to provide the supportive environment necessary in the classroom. Such strategies are requirements of the OBE model and are essential for creating a supportive environment and providing opportunities for effective learning of OBSC. Furthermore, making connections between students’ prior knowledge, learning and experience is very important for enhancing reflective thought through a student-centered learning approach.

\subsubsection{Assessment, Monitoring, Recording and Reporting of students Performance, Progress and Achievements}

Regular assessment, monitoring, recording and reporting are all related to the philosophy of the OBE model. It is crucial that effective assessment practices and efficient monitoring, recording and reporting systems are established in secondary schools. This is for transparency and accountability to students, parents, MOE and other key education stakeholders. According to this study, effective classroom assessments, and monitoring and reporting of students’ performance, progress and achievement is a very important aspect of OBE.

First, the study notes that a suitable form of assessment for OBSC would be the criterion-referenced or standards-based assessment. This assessment strategy focuses on assessment for learning. It is conducted on a regular basis and therefore would give good feedback for both teachers and students. The study suggests that students should be assessed using competence and achievement-based assessments. The 
study concludes that use of effective continuous assessment in the classroom would also improve performance and achievements in a summative form of assessment at the end of the academic year.

Second, the study affirms that monitoring, recording and reporting systems must be reviewed and strengthened in secondary schools. Although some secondary schools are currently implementing their own systems, the study notes that there is a need for a simple and unified monitoring, recording and reporting system in all schools. Efficient monitoring, recording and reporting systems are essential as 'checks and balances' as well as to ensure fair reporting on students' performance, progress and achievement. It is also important to provide a good basis for teacher-student, teacher-parent and teacherstudent-parent interviews as well as providing a descriptive and meaningful record of students' achievements.

\subsubsection{Potential Problems, Issues and Challenges, and Strategies towards Effective Implementation of OBSC}

A number of problems, issues and challenges are identified, that might impede the implementation of OBSC in secondary schools. These potential impediments have emerged from all sectors within the education system in Solomon Islands. Collectively these must be addressed in good time prior to the proposed curriculum implementation. This study has identified problems, issues and challenges that include: a need for better teaching and learning resources, facilities and science laboratories; the need for better qualified and competent science teachers; a need for the integration of OBE and pedagogical content knowledge in the teacher education and training programme; a need for new policies and monitoring of existing policies in secondary schools; the need for a collaborative link within the divisions of the MOE to assume partnership and responsibility between MOE, other institutions and education providers. 
There are a number of strategies that can be utilized to solve identified problems, issues and challenges so as to enhance an effective implementation process. The strategies require a combined effort by all stakeholders to understand OBE and participate in the implementation process. The strategies include: on-going awareness and wider stakeholder consultation; science teacher in-service training and capacity building; integration of OBE and OBSC in the teacher education and training programme; development and strengthening of education policies; creating good networking within and outside of MOE; and seeking on-going government commitment and support for financial and technical assistance towards the implementation of OBSC in Solomon Islands.

\subsection{Research Contributions}

This section of the chapter will outline the contribution of this study. First, the findings of this study can be used for the development of a module on OBE and pedagogical content knowledge of OBSC. In this way, key stakeholders can be informed with accurate information on the new curriculum approach and how it is to be implemented in secondary schools.

Second, understanding OBE and the appropriate pedagogical content knowledge of OBSC will help curriculum officers to improve the structure, format and content of OBSC. Further, improved understanding will also assist secondary science teachers to enhance teaching and learning processes as well as improving assessment, monitoring and reporting of student achievements.

Third, such study findings can be integrated into a module for providing teacher in-service training and capacity building programmes as well as upgrading the teacher education and training programme. Linking the study findings with professional development programmes is essential for giving secondary science teachers the confidence and ability to deliver OBSC. Fourth, findings from this research will 
significantly improve the implementation of OBSC under the current CRRP in the Solomon Islands education system.

\subsection{Research Implications from the Study}

Research implications are an important aspect of any research to suggest possible actions to be taken based on informed results from the research. Having identified the issues from the literature and study findings, I will now present the implications that have emerged from this study.

First, the implementation of OBSC will require a learning community that is thoroughly familiar with OBE and OBSC. These key stakeholders would benefit from appropriate educational seminars. Inservice training to update teachers, education officers, education authorities, school administration, parents and key stakeholders is essential. The use of a prepared module on the OBE model and pedagogical content knowledge of OBSC is crucial for enhancing teacher in-service training, capacity building and upgrading of teacher education and training programmes in Solomon Islands. Second, the implementation of OBSC would require resources, facilities, equipment, consumables and science laboratories. Therefore, it is essential that the schools be sufficiently resourced and be able to sustain its resources on long term basis. Third, the implementation of OBSC would require MOE to strengthen its research unit. This unit would coordinate and consult with education authorities and school administrations to develop, monitor and implement education policies which would assist the implementation of OBSC. Such policies include: the number of student enrollments per class; teaching time allocation; assessment and standards; school resourcing standards; and monitoring and reporting of student achievements. Additional policy issues include: zoning of schools for student selection and placement; and fair teacher posting systems. 


\subsection{Recommendations for Action}

Based on the above implications, the following are recommendations for MOE and relevant education authorities to consider prior to the implementation of OBSC in secondary schools.

First, as an immediate action, it is necessary to consult with all stakeholders to enlist them as partners in the implementation of OBSC in secondary schools. A module on the OBE model and pedagogical content knowledge of OBSC and its implication on teaching and learning processes, assessment practices, and monitoring, recording and reporting systems should be developed and sent out to secondary schools for teacher in-service training and capacity building programmes. Second, there is a need for the integration of indigenous knowledge of the Solomon Islands culture, values, beliefs and traditions in the student activity books and teacher guides for providing contextual and meaningful learning of science in the education system. Third, appropriate divisions in the MOE need to develop new policies on classroom assessments and standards as well as developing monitoring, recording and reporting systems in line with the OBE model. The necessary reviewing and strengthening of current policies on school resourcing standards, student enrollment, teacher posting and zoning of schools for student placement are essential to avoid over- crowding and problematic student placements in secondary schools. Furthermore, MOE should implement criterion-referenced or standards-based assessments through competency and achievement-based assessments. Fourth, the MOE in consultation with SOE of SICHE needs to develop modules on OBE and pedagogical content knowledge of OBSC for upgrading the teacher education programme and providing pre- and in-service teacher training. It is necessary that learning theories and education philosophies are included in such a programme. Furthermore, the MOE is to create an effective network between key education stakeholders in order to share relevant information on OBE, pedagogical content knowledge and logistics for implementing OBSC in secondary schools. 


\subsection{Research Limitations}

Having undertaken this research project, I now reflect on the constraints that I encountered in the process of this study.

First, this study only engaged 22 respondents of both practicing and former secondary science teachers in Honiara, Solomon Islands. This is a very small sample compared with the number of secondary science teachers working in secondary schools throughout Solomon Islands. The respondents used for the study were selected due to their participation in the science advisory and science working committees. Consequently, information given by some of the respondents may be limited, being based on their knowledge from handouts and participation in workshops and seminars. They may not be completely unbiased 'generalisations' made on the views and perceptions on behalf of science teachers nationwide.

Second, having undertaken my field work during a period of tribal land dispute, my data collection may have been affected. While the court decision was in my clan's favour, the rival clan has continued to cause strife. Pressure from my parents and family to actively participate in the resolution of the conflict was intense during my time in Honiara.

Third, suffering the effects of malaria and other health issues also affected me during the data collection. Because of these, I had to collect data during the weekend to compensate for time lost during weekdays. These were unforeseen circumstances that negatively affected my data collection in Solomon Islands. 


\subsection{Future Research Studies}

OBE is a new curriculum approach being undertaken under the current CRRP in Solomon Islands. This study has contributed significantly to this new development. Having done the study, I consider it useful for further investigations to be undertaken in the following areas.

First, since OBE in Solomon Islands is seen to be related to curriculum development based on the experiences from other countries, a longitudinal study on the implementation of OBSC in Solomon Islands would be necessary. In particular, it would be of value to study the implications of the paradigm shift of teaching and learning processes in the classroom and to evaluate the appropriateness and applicability of the OBE model in Solomon Islands. Such a study could include the perceptions and experiences of secondary science teachers.

Second, understanding the impacts of continous assessment using explicit criteria in the classroom would be fundamental to developing a national policy on assessment. It would therefore be necessary to investigate what type of continuos assessment could work best for the OBE model in Solomon Islands. Furthermore, the need exists to explore the likely impacts of criterion-referenced or standard-based assessment using competency and achievement-based assessments. The perceptions and experiences of students should be included in any studies on assessment practices in Solomon Islands secondary schools.

Third, OBE must be integrated with the teacher education and training program in Solomon Islands. To this effect, there is a need for study on how this integration could be done effectively to provide an effective teacher education and training programme. The perceptions and experiences of lecturers and teacher educators at the teacher training institution would be very useful in soliciting accurate guidance on the integration process. 
Fourth, there is an acute shortage of resources, facilities and infrastructure that would need to be addressed for the successful implementation of OBSC. Appropriate studies on resources, facilities and infrastructure are needed. Studies could also explore alternative ways that the government and education authorities could co-operate to overcome the resource problem. The perceptions and experiences of science teachers, school principals and education authorities would be useful in soliciting information and data on solving resource problems.

\subsection{Final Thought}

Solomon Islands is faced with considerable challenges. Its education system has been blamed for the recent social and ethnic conflict. People quickly pointed to the lack of practical skills and societal values in the school curriculum. The education system needs to implement a curriculum approach that is not too resource-intensive and one where the learning outcomes can be easily delivered, assessed, monitored and reported in a cost-effective and efficient way. Such a curriculum should focus on holistic learning and training students to be ready for future challenges in the workplace or in their communities.

An underlying aim of this study was to find ways in which OBSC could contribute to solving national

demands and challenges. One of the key findings of this study is the strong suggestion for the inclusion of cultural knowledge and practices in the OBSC. To illustrate this more clearly, I offer my own 'curriculum haus framework’ for cultural knowledge and practices integration of OBSC (See appendix I). 
Absolum, M. (2006). Clarity in the classroom: Using formative assessment - building learner focused relationships. Auckland: Holder Education.

Acharya, C. (2006). Outcome-based education: A new paradigm for learning. Singapore: CDTL link. Retrieved August, 18, 2009, from www.cdtl.nus.edu.sg/link/nov2003/obe.htm.

Anderson, G. (1998). Fundamentals of education research. London: Routeledge Farmer.

Atwech, B., \& Keitel, C. (2007). Social (In) justice and international collaborations in mathematics education. In B. Atweh, A. Barton, M. Borba, N. Gough., C. Keitel, C. Vistro - Yu, and R.Vithal (Eds), Internationisation and globalisation in mathematics and science education (pp 95 - 112). Dordrecht: Springer, c2007.

Bakalevu, S. (2009). Endangering culturally responsive teaching. In K.Sanga and K. H. Thaman (Eds), Re - thinking education curricula in the Pacific: Challenges and prospects (pp 58 - 70). Wellington: He Parekereke, Institute for Research and Development in Maori and Pacific Education.

Banks, J.A. (2001). Cultural diversity and education: Foundation, curriculum and teaching (4 ${ }^{\text {th }}$ ed.). Needham heights: Pearson Education.

Bell, B.F. (1993). Children's science, constructivism and learning in science. Geelong - Victoria: Deakin University Press.

Bell, J. (1993). Doing your research project: A guide for first time researchers in education and social science $\left(2^{\text {nd }}\right.$ ed.). Buckingham: Open University Press.

Bentley, D., \& Watts, M. (1989). Learning and teaching in school science: Practical alternatives. Buckingham: Open University Press.

Bentley, B. (2007). Complex curriculum work without better teachers resourcing. Education forum office, New Zealand. Retrieved March, 21. 2009, from http://www.educationforum.org.nz.

Berlach, R.G. (2004, Nov 28 - Dec 2). Outcomes-based education \& the death of knowledge. Paper presented at The Australian Association for Research in Education Conference. The University of Melbourne, Victoria, Australia. Retrieved July, 30, 2009, from www.aare.edu.au/04pap/ber04768

Bouma, G. D. (1996). The research process ( $3^{\text {rd }}$ ed.). Melbourne: Oxford University Press.

Brandy, L. (1995). Curriculum development (5 ${ }^{\text {th }}$ ed.). Sydney: Prentice hall Pty ltd.

Brady, L., \& Kennedy, K. (1999). Curriculum construction. Sydney: Prentice Hall. 
Bugotu, F., Maeke, D., Paia, H., Ramoni, M., \& Arnold, B. (1973). Education for what? A report on the findings of the British Solomon Islands Protectorate: Educational policy review committee. Honiara: Government Printers.

Burns, R.B. (2000). Introduction to research methods. (4 ${ }^{\text {th }}$ ed.).Melbourne: Longman.

Burns, R., \& Squires, D. (2002). Curriculum organisation in outcomes-based education. San Francisco: Far west lab for Educational Research and Development.

Clark, J. (1997). Educational research: Philosophy, politics and ethics. Palmerston North: ERDC Press, Massey University.

Copper, H. (1998). Synthesizing research: A guide for literature reviews ( $3^{\text {rd }}$ ed.). Thousand Oaks, London: Sage Publications.

Cohen, L. (2003). Research methods in education. London: Routeledge Farmer.

Creswell, J.W. (1994). Research design: Qualitative and quantitative approaches. Thousand Oaks, London: Sage Publications.

Creswell, J.W. (2003). Research design: Qualitative and quantitative, and mixed methods approach. Thousand Oaks, California: Sage Publications

Creswell, J.W. (2008). Educational research: Planning and evaluating qualitative and quantitative research. New Jersey: Pearson Education.

Daudau, P. (2007). School based assessment for Solomon Islands school certificate (2007 - 2008). Honiara: Curriculum Development Centre.

Denscombe, M. (2003). The good research guide: For small-scale social research projects (2 ${ }^{\text {nd }}$ ed.). Maidenhead: Open University Press.

Denzin, N. K., \& Lincoln, Y.S. (Eds) (1998). Collecting and interpreting qualitative materials. Thousand Oaks, California: Sage Publications.

Donnelly, K. (2007). Australia's adoption of outcomes based education: A critique. Issues in Educational Research, 17(2), 183-206. Retrieved July 30, 2009, from http://www.iier.org.au/iier17/donnelly.html.

Douglas, N., \& Douglas, N. (Eds.) (1994). Solomon Islands. Pacific Islands Year Book (17 ${ }^{\text {th }}$ Ed.).Suva: Fiji Times Ltd.

Driver, R. (1985). The pupil as scientist? Milton Keynes: The Open University Press.

Education and Support Agency. (1995). Seen but not heard: Voices of Pacific Islands learners. Wellington: Education and Support Agency.

Ezzy, D. (2002). Qualitative analysis. Crows nest NSW 2065, Australia: Allen and Urwin. 
Fasi, U. (2009). Towards an equality of education. In K.Sanga and K. H. Thaman (Eds), Re - thinking education curricula in the Pacific: Challenges and prospects (pp 87 - 101). Wellington: He Parekereke, Institute for Research and Development in Maori and Pacific Education.

Fitoo, B. (2009). Citizenship education in the social studies curriculum of Solomon Islands. Unpublished masters' thesis. Faculty of Education, Victoria University of Wellington.

Gegeo, D. (1998). Indigenous knowledge and empowerment: Rural development examined from with in. In The Contemporary Pacific Vol 10 (2) Fall. Hawaii: University of Hawaii Press.

Gegeo, D., \& Gegeo, K. (2000). The critical villager: Transforming language and education in Solomon Islands. In James W. Tolletson (ed), Language policies in education: critical issues. Lawrence Erbans Associates.

Glense, C. (2006). Becoming qualitative researchers: An introduction (3 ${ }^{\text {rd }}$ ed.). Sydney: Pearson Education, Inc.

Grundy, S. (1987). Curriculum: Product or praxis. London: The Falmer Press.

Hall, C. (1996). The national qualification framework in 1996 and beyond. A call for reflection and the nature of outcomes- based education. New Zealand annual review of education, 6, 71 -87.

Hall, C. (2005a). The national certificate of educational achievement (NCEA). Is there a third way?. In J. Codd and K. Sullivan (Eds). Education policy direction in Aoteorea New Zealand (pp 235 - 265) Victoria: Thomson/Dunmore Press.

Hall, C. (2005b). Outcomes-based education approach to Aid evaluation: Some concerns. In K. Sanga, C. Hall, C. Chu, and L. Crowl (Eds). Re-thinking aid relations in pacific education (pp 293 311). Wellington: He Parekereke, Victoria University of Wellington.

Hall, C., \& Jones, E. (2004). Assessment \& evaluation: A concept framework for education and training. Victoria University of Wellington, Faculty of Education (class handout).

Hayes, A. (2007, 15 ${ }^{\text {th }}$ May). OBE is not sustainable in Papua New Guinea. The National Press.

Israel, M., \& Hay, I. (2006). Research ethics for social scientists. Thousand Oaks, California: Sage Publications Inc.

Jita, L., Maree, J., \& Ndlalane, T. (2007). Lesson study (Jyugyo kenkyu) from Japan to South Africa: A science and mathematics intervention program for secondary school teachers. In B. Atweh, A Barton, M. Borba, N. Gough, C. Keitel, C. Vistro - Yu, and R. Vithal (Eds), Internationisation and globalisation in Mathematics and Science Education (pp 465 - 486). Dordrecht: Springer, c2007.

Johansson Fua, S. (2009). Ko hota fa"ugnamotu’a ko hota kahu'u - A knowledge system for redesigning Tongan curriculum. In K.Sanga and K. H. Thaman (Eds), Re - thinking education curricula in the Pacific: Challenges and prospects (pp 196 - 221). Wellington: He Parekereke, Institute for Research and Development in Maori and Pacific Education. 
Johnson, B., \& Christensen, L. (2008). Educational research: Quantitative, qualitative and mixed approaches ( $3^{\text {rd }}$ ed.). Thousand Oaks, California: Sage Publications.

Katzer, J., Cook, K.H., \& Crouch, W.W. (1991). Evaluating information: A guide for users of social science research ( $4^{\text {th }}$ ed.). New York: McGraw Hill, Inc.

Killen, R. (2003). Effective teaching strategies - lessons from research and practice ( $3^{\text {rd }}$ ed.). South Melbourne: Thomson Science Press.

Killen, R. (2007). Effective teaching strategies - lessons from research and practice (4 ${ }^{\text {th }}$ ed.). South Melbourne: Thomson Science Press.

King, J., \& Evans, M. (1991, October). Can we achieve outcomes-based education? Educational leadership, 73-75.

Koya, C.F. (2009). Sustainable living in the pacific: Exploring the role of multiculturalism in teacher education. In K.Sanga and K. H. Thaman (Eds), Re - thinking education curricula in the Pacific: Challenges and prospects (pp 102 - 123). Wellington: He Parekereke, Institute for Research and Development in Maori and Pacific Education.

Krueger, R.A., \& Casey, A.M. (2000). Focus group discussion. Thousand Oaks, California: Sage Publication.

Luft, J., Bell, R., \& Ges - Newsome, J. (2008). Science as inquiry. Arlington, Virginia: National Science Teachers Association Press.

Maha, A. (2009). A reflection on the reform and implementation of primary curriculum in Papua New Guinea. In K.Sanga and K. H. Thaman (Eds), Re - thinking education curricula in the Pacific: Challenges and prospects (pp 29 - 42). Wellington: He Parekereke, Institute for Research and Development in Maori and Pacific Education.

Mahalingam, R., \& McCarthy, C. (2000). Multicultural curriculum: New directions for social theory, practice and policy. New York: Routledge.

Malasa, D. (2007). Effective School leadership: An exploration of issues inhibiting effective school leadership in Solomon Islands secondary schools. Unpublished masters' thesis, University of Waikato. Accessed September, 15 2009, from http://waikato.researchgateway.ac.nz/

Maneipuri, J. (2002). Solomon Islands education system: Issues and challenges In F. Pene., A.M. Taufe' ulungaki, and C. Benson (Eds.), Tree of opportunity: Re - thinking pacific education (pp 102 - 103). Institute of Education: University of the South Pacific.

Manu, S. (2009). Developing curriculum for basic education in the pacific: Some considerations. In K.Sanga and K. H. Thaman (Eds), Re - thinking education curricula in the Pacific: Challenges and prospects (pp 43 - 47). Wellington: He Parekereke, Institute for Research and Development in Maori and Pacific Education. 
Manu'atu, L. (2009). Pacific processes and pedagogies. In K.Sanga and K. H. Thaman (Eds). Re - thinking education curricula in the Pacific: Challenges and prospects (pp 172 - 182). Wellington: He Parekereke, Institute for Research and Development in Maori and Pacific Education.

Mason, J. (1996). Qualitative research. London: Sage Publication.

Maxwell, J. (1996). Qualitative research design. Thousand Oaks, California: Sage Publications

May, T. (1997). Social research: Issues, methods and process $\left(2^{\text {nd }}\right.$ ed.). Buckingham: Open University Press.

McKinley, E. (2009). Maori and curriculum: Lessons from a curriculum developer's notebook. In K.Sanga and K. H. Thaman (Eds), Re - thinking education curricula in the Pacific: Challenges and prospects (pp 183 - 195). Wellington: He Parekereke, Institute for Research and Development in Maori and Pacific Education.

McGee, C. (1997). Teachers and curriculum decision making. Palmerston North: The Dunmore Press.

Mertens, D.M. (1998). Research methods in education and psychology: Integrating diversity with quantitative and qualitative approaches. Thousand Oaks, London: Sage Publication.

Ministry of Education. (1982). The research act. Honiara: Ministry of education.

Ministry of Education. (2004). The curriculum review, reform project and implementation document. Honiara: Curriculum Development Centre.

Ministry of Education. (2005a). Education act, 1978. Honiara: Ministry of education.

Ministry of Education. (2005b).Technical vocational education \& training policy. Honiara: Ministry of education.

Ministry of Education. (2006). Education strategic plan: 2007 - 2009, Honiara: Ministry of Education.

Ministry of Education. (2007). Education strategic framework 2007 - 2015. Honiara: Ministry of Education.

Ministry of Education. (2008). National Curriculum Statement. Honiara: Ministry of Education.

Muralidhar, S. (2009). Assessment as celebration of learning: Are we ready for it. In K.Sanga and K. H. Thaman (Eds), Re - thinking education curricula in the Pacific: Challenges and prospects (pp 71 - 86). Wellington: He Parekereke, Institute for Research and Development in Maori and Pacific Education.

Nabobo - Baba, U. (2009). Fijian epistemology: Examining aspects of Vugalei cultural pedagogies, processes and possible features. In K.Sanga and K. H. Thaman (Eds), Re - thinking education curricula in the Pacific: Challenges and prospects (pp 137 -158). Wellington: He Parekereke, Institute for Research and Development in Maori and Pacific Education. 
New Zealand Ministry of Education. (2007). The New Zealand curriculum. Wellington: Learning Media limited.

Neyland, J. (2007). Globalisation, ethics and mathematics education. In B. Atweh, A. Barton, M. Borba, N. Gough, C. Keitel, C. Vistro - Yu, and R. Vithal (Eds), Internationization and globalisation in mathematics and science Education (pp 113 - 128). Dordrecht: Springer, c2007.

Norman, P. (2006). Outcomes-based education: A PNG perspective. Contemporary PNG studies. Retrieved November 15, 2009, from findarticles.com/p/articles/mi_6982/is_5/ai_n28532443/

O’Neil, J. (1994). Aiming for new outcomes: The promise and reality. Educational leadership, 51 (6), $6-10$.

Osborne, R., \& Freyberg, P. (1985). Learning in science: The implications of children's science. Auckland: Heinemann Education.

Pasikale, A. (1996). Pacific Islands learning. In Seen, but not heard: Voices of Pacific Islands learning. Wellington: ETSA, p. 47 - 63.

Patton, M.Q. (2002). Qualitative research and evaluation methods (3 ${ }^{\text {rd }}$ ed.). London: Sage Publication.

Potter, P. (2005). Curriculum and societal needs: Stakeholders' perception of Solomon Islands secondary school curriculum. Unpublished masters' thesis. Avondale College of Education, Australia.

Print, M. (1993). Curriculum development and design ( $2^{\text {nd }}$ ed.). New SouthWales: Allan and Unwin Pty ltd.

Punch, K. F. (1998). Introduction to social research: Quantitative and qualitative approaches. Thousand Oaks, London: Sage Publications.

Punch, K.F. (2003). Survey research: The basics. Thousand Oaks, California: Sage Publications

Punch, K. F. (2005). Introduction to social research: Quantitative and qualitative approaches. Thousand Oaks, London: Sage Publications.

Reid, G. (2005). Learning styles and inclusion. London: Paul Chapman Publications.

Renagi, R. (2010). Outcomes-based education is failing PNG. Keith Jackson's PNG attitude. Retrieved January 22, 2010, from asopa.typepad.com/.../outcomesbased-education-is-failing-png.html

Rodi, F., Rore, T., Manurapu, J., Sadakapatu, C., \& Herriot, A. (2001). Review of curriculum in the context of basic education needs: Report to the MEHRD. Honiara: Ministry of Education.

Sanga, K. (2004). Making philosophical sense of indigenous pacific research. In Tubeni Baba (eds.et.al), Researching the pacific and indigenous peoples: Issues and perspectives. Auckland: Centre for Pacific Studies. 
Sanga, K., \& Walker, K.D. (2005). Apem moa Solomon Islands leadership. He Parekereke: Institute for Research and Development in Maori and Pacific Education, Victoria University of Wellington.

Sanga, K. (2009). Curriculum as process: Essential phases and features of Ausae pedagogy. In K.Sanga and K. H. Thaman (Eds), Re - thinking education curricula in the Pacific: Challenges and prospects (pp 222 - 235). Wellington: He Parekereke, Institute for Research and Development in Maori and Pacific Education.

Spady, W.G. (1993). Outcomes-based education. Belconnen: Australian Curriculum Studies Association.

Spady, W.G. (1994). Outcomes-based education: Critical issues and answers. Arlington, VA: American Association of School Administrators.

Spady, W.G. (1998). Paradigm lost: Reclaiming America's educational future. Arlington, VA: American Association of School Administrators.

Spady, W.G., \& Marshall, K. (1994). 'Light, not heat, on OBE'. The American School Board Journal. Vol. 181, pp. 29 - 33

Stern, P.C., \& Kalof, L. (1996). Evaluating social science research (2 ${ }^{\text {nd }}$ ed.). New York: Oxford University Press.

Taufe'ulungaki, A. (2009). Tonga's values in education: Some issues and questions. In K.Sanga and K. H. Thaman (Eds), Re - thinking education curricula in the Pacific: Challenges and prospects. (pp 125 - 136). Wellington: He Parekereke, Institute for Research and Development in Maori and Pacific Education.

Teaero, T. (2009). Curriculum policies and framework in the context of pacific values: A view from Kiribati. In K.Sanga and K. H. Thaman (Eds), Re - thinking education curricula in the Pacific: Challenges and prospects (pp159 - 171). Wellington: He Parekereke, Institute for Research and Development in Maori and Pacific Education.

Thaman, K.H. (2002). Towards culturally democracy in Pacific Education: An imperative for the $21^{\text {st }}$ century. In F. Pene., A.M .Taufe’ ulungaki and C. Benson (Eds.), Tree of opportunity: Re thinking pacific education (pp 21 - 29). Institute of Education: University of the South Pacific.

Thaman, K.H. (2009). Introduction: The need to re - think pacific curriculum. In K.Sanga and K. H. Thaman (Eds), Re - thinking education curricula in the Pacific: Challenges and prospects (pp 13 - 27). Wellington: He Parekereke, Institute for Research and Development in Maori and Pacific Education.

Towers, J.M. (1996). An elementary school principal' experiences with implementing an outcomesbased curriculum. Catalysts for change. Vol 25, pp $19-23$.

Ward, M., Sikua, D., \& Banks, T. (2005). Donor hamonisation for improved aid effectiveness. In K. Sanga, C. Hall, C. Chu, and L. Crowl (Eds). Re-thinking aid relations in pacific education (320 - 335). Wellington: He Parekereke, Victoria University of Wellington. 
Warsal, D. (2009). The impacts of culture on women's leadership in Vanuatu secondary schools. Unpublished masters' thesis, University of Waikato. Accessed October 10, 2009, from http://waikato.researchgateway.ac.nz/

Wengraf, T. (2001). Qualitative research interviewing. Thousand Oaks, California: Sage Publications Inc.

Wiersma, W. (1995). Research methods in education. Needham heights Massachusetts: Allyn and Bacon.

Yin, R.K. (1994).Case study research: Design and methods ( $2^{\text {nd }}$ ed.). Thousand Oaks, California: Sage Publications. 


\section{APPENDICES}

\begin{tabular}{|l|l|}
\hline Appendix A & Participant information sheet \\
\hline Appendix B & One-on-one interview questions \\
\hline Appendix C & Focus group interview questions \\
\hline Appendix D & Participant consent form - Interviews \\
\hline Appendix E & Participant consent form - Focus Group \\
\hline Appendix F & Joint agreement form \\
\hline Appendix G & Ethics approval, Victoria University of Wellington \\
\hline Appendix H & Research permit, Solomon Islands \\
\hline Appendix I & Curriculum haus framework for OBSC \\
\hline
\end{tabular}




\section{APPENDIX A: INFORMATION SHEET}

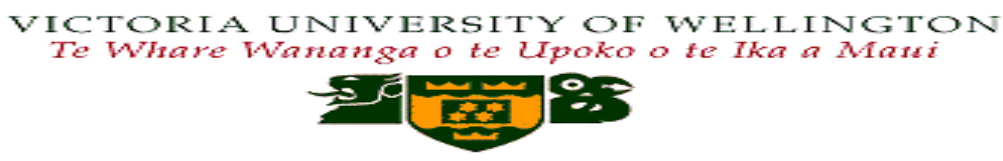

My name is Patrick Daudau and I am a post graduate student at Victoria University of Wellington, New Zealand. I am conducting this research in order to present a thesis as a major research component for my Master of Education degree. In my research, I would like to explore teachers' perceptions about the appropriateness of outcomes - based science curriculum (OBSC) and how such a curriculum would be effectively implemented, assessed, monitored and, reported. Moreover, the study will also identify potential problems, issues and challenges that may impede the implementation process and how such impediments/obstacles could be solved or mitigated. OBSC is new in Solomon Islands, despite the fact that, the knowledge and values of the OBE curriculum approach are widely acknowledged and experienced by other countries. In the case of Solomon Islands, much is yet to be explored about OBE and implementation of OBSC. In essence, to gain understanding about the curriculum approach, it is important to undertake research to gather varieties of perceptions that will help construct a framework for effective implementation of OBSC that is relevant and contextual for Solomon Islands.

This study uses qualitative procedures in research, where, focus discussion groups and one-on-one interviews are the methods for gathering data. Practicing and former science teachers, who are members of the science advisory and working committees, will be asked to participate. Semi-structured questions will be used and respondents will be encouraged to respond based on their personal interpretation. A tape recorder will be used for recording the discussions and the interviews which will last between $45-90$ minutes. The information collected will be collated and arranged according to themes, which will then be verified and analyzed to generate data for the study. This research project is done under the auspices of the Victoria University of Wellington, New Zealand and ethical approval has been obtained from the Faculty of Education Human Ethics Committee to collect data. All data collected for this study, will be securely stored and destroyed after the research project has been completed. Participation is voluntary. Therefore, those who are selected are free to withdraw from the study without question should he/she feels the need to do so. All information collected and transcribed will be kept confidential.

This study is deemed worthwhile for a number of reasons. First, the documentation of its findings will be pivotal for further policy in curriculum, assessment, teacher education and research development in Solomon Islands. Second, the thesis when completed will be shelved at the Victoria University of Wellington library and a copy will be shelved at the University of the South Pacific, Solomon Islands Centre for students and future references.

My supervisor, Associate Professor Kabini Sanga can be contacted for further information, if necessary, email: Kabini.sanga@vuw.ac.nz

Thank you for your assistance and understanding

Mr Patrick Daudau

(Researcher) 


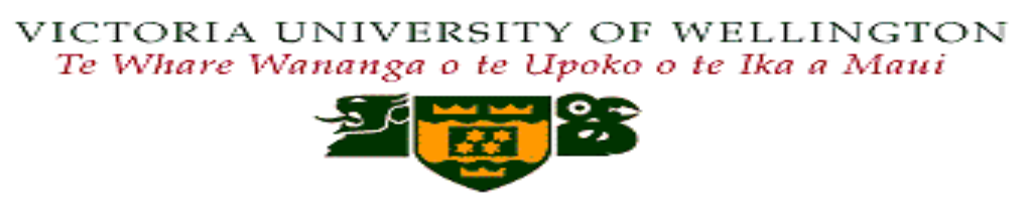

In your opinion as a practicing/former secondary science teacher and based on your involvement and experiences in the current CRRP,

1. What is your understanding about the OBE model and its curriculum approach?

2. How would you define OBSC and to what extent is OBSC appropriate or relevant?

3. What are the teaching and learning strategies for enhancing effective delivery and better understanding of OBSC?

4. How would you assess OBSC?

5. Based on your answer in question 4, how would you monitor and report students' performance, progress and achievements?

6. What are the potential problems, issues, and challenges that might impede the implementation of OBSC and how would you solve these obstacles?

7. Do you have other important comments about the OBE model and implementation of OBSC that you would like to share with me? 


\section{APPENDIX C: FOCUS GROUP QUESTIONS}

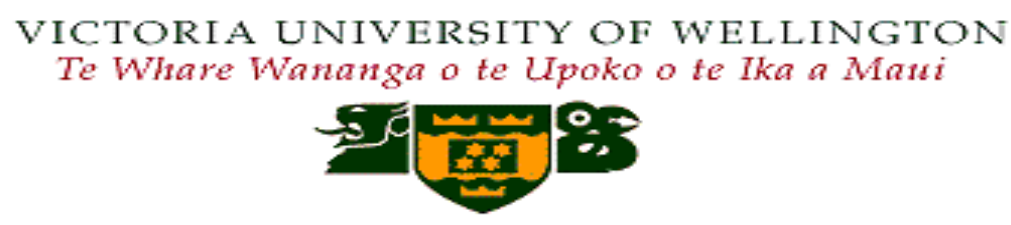

In your opinion as practicing/former secondary science teachers and based on your involvement and experiences in the current CRRP;

1. What are your understandings about OBE model and its curriculum approach?

2. How would you define OBSC and to what extent is OBSC appropriate or relevant?

3. What are the teaching and learning strategies for enhancing effective delivery and better understanding of OBSC?

4. How would you assess OBSC?

5. Base on your answer in question 4, how would you monitor and report students’ performance, progress and achievements?

6. What are the potential problems, issues, and challenges that might impede the implementation of OBSC and how would you solve these obstacles?

7. Are there other important comments about the OBE model and implementation of OBSC that you would like to share with the focus group? 


\section{APPENDIX D: CONSENT FOR INTERVIEW}

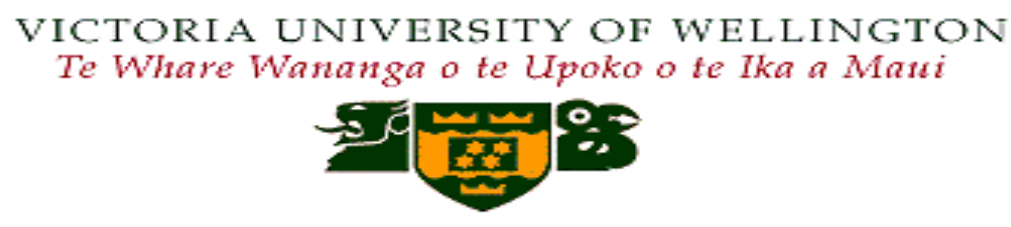

I have been given and do understand the explanation of the research project. I also understand from the explanation that any information provided will be kept confidential to the researcher and the supervisor. I understand that I may withdraw from this research project without having to give reasons or without being penalized in any way.

I also understand that the information provided during the research will be destroyed or if electronically stored will be wiped out after the scripts have been documented for its intended purpose. I also understand that the data I provide will be used for the research project only. hereby agree to participate in the research project

Sign (Respondent)

Date:

Sign (Researcher)

Date: 


\section{APPENDIX E: CONSENT FOR FOCUS GROUP}

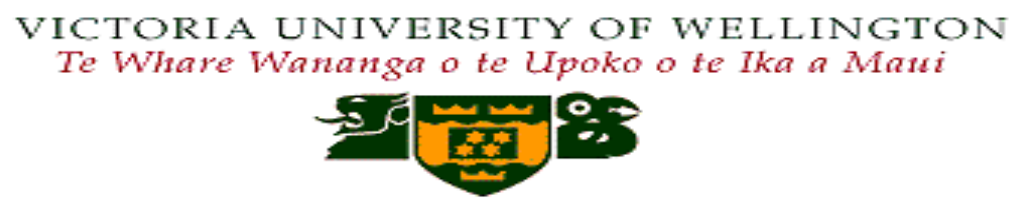

- I have been given adequate information and have understood the nature and objectives of the research project and been given the opportunity to seek further clarifications and explanations

- $\quad$ I understand that I may withdraw my participation individually or as a group from the project before $19^{\text {th }}$ July 2009. I understand that I may do so without providing reasons, and that data already collected will be destroyed by the researcher

- I understand that my information or opinions I provide will be confidential. Only the researcher and the supervisor will have access to the information provided

- I give permission for our discussion to be tape recorded

- I I understand that the tape recording of discussions will be electronically wiped out one (1) year after the research project completion. All data collected will be destroyed by the researcher

- $\quad$ I agree to participate in this research project

- $\quad$ I agree and promise to keep the proceedings of the group discussion confidential

- $\quad$ I would like to receive a copy of the findings

- In duly agreeing to the terms above, I individually herewith place my signature

Name:

Signature:

Date: 


\section{APPENDIX F: JOINT AGREEMENT FORM}

\section{VICTORIA UNIVERSITY OF WELLINGTON}

Te Whare Wananga o te Upoko o te Ika a Maui

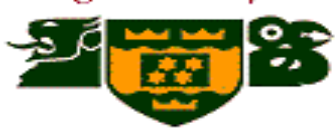

Permanent Secretary/Principal/Director/Head of School of do make the following statements

1. I on behalf of hereby give approval for Mr. Daudau to conduct research at in June/July, 2009

2. That permission is given to Mr. Daudau to conduct research at through interviews/focus group discussion with the selected respondent (s)

3. That I, head of organisation and respondent (s) selected to participate in the study will fully cooperate with Mr. Daudau

4. As an academic work, the data may be viewed by Mr. Daudau’s Supervisor.

I, Patrick Daudau, the researcher and student of VUW make the following statements

1. I agree to conduct research at , Honiara, Solomon Islands

2. That all times, I shall maintain a high standard of ethical behaviour during the course of my research project

3. That I shall respect the rights and privacy of all respondents

4. That the head of organisation is my point of contact before contacting respondent (s)

5. That a copy of the thesis will be provided to interested parties

We hereby agree

(PS/Principal/Director/HOS-SICHE)

(Researcher)

Date:

Date: 
TE WHARE WANANGA OTE UTPOKO O TE IKA A MĀUI

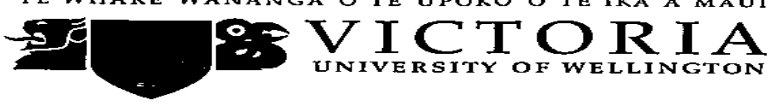

$8^{\text {th }}$ June 2009

Patrick DauDau

MEd Student

Victoria University of Wellington Faculty of Education

C/- Te Kura Mãori

Donald Street

Wellington

\section{Dear Patrick}

\section{RE: Ethics application TKM/2009/30: RM 16644}

I am pleased to advise you that your ethics application 'Teachers' perceptions of outcomes-based science curriculum: A case study of science teachers in Solomon Islands.' with the requested amendments, has been approved by the Victoria University of Wellington Faculty of Education Ethics Committee. Please note that the approval for your research to commence is from the date of this letter.

Good luck with your research.

Yours Sincerely<smiles>CCCCC(C)CC(C)C(C)(C)C</smiles>

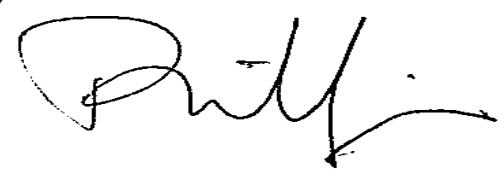

Dr Hazel Phillips

Co-Convener

Victoria University of Wellington Faculty of Education Ethics Committee

COLLEGE OF EDUCATION Te Whānau o Ako Pai

PO Box 17-310, Karori, Wellington 6012,. New Zealand

Phone +64-4-4639500 Fax +64-4-4639649 Website www.vuw.ac.nz/education 


\section{THE RESEARCH ACT 1982 \\ (No. 9 of 1982)}

\section{RESEARCH PERMIT}

Permission is hereby given to:

1. Name: Patrick Daudau

2. Country: Solomon Islands

3. To undertake research in (subjects): Exploring Case Study on Secondary Science Teachers' Perceptions about the appropriateness of outcome-based science curriculum and how such curriculum could be effectively implemented in Solomon Islands.

4. Ward(s): Honiara

5. Province(s):

6. Conditions:

a. To undertake research only in the subject areas specified in 3 above.

b. To undertake research only in the ward(s) and Province(s) specified in 4 and 5 above.

c. To observe with respect at all times local customs and the way of life of people in the area in which the research work is carried out.

d. You must not, at any time, take part in any political or missionary activities or local disputes.

e. You must leave 4 copies of your final research report in English with the Solomon ${ }^{1}$ Islands Government Ministry responsible for research at your own expense.

f. A research fee of $S B D 300.00$ and deposit sum of $S B D 200.00$ must be paid in full or the Research Permit will be cancelled. (See sec. 3 Subject. 7 of the Research Act).

g. This permit is valid until 31/07/09 provided all conditions are adhered to.

$\mathrm{h}$. No live species of plants and animals may be taken out of the country without approval from relevant authorities.

i. A failure to observe the above conditions will result in automatic cancellation of this permit and the forfeit of your deposit.

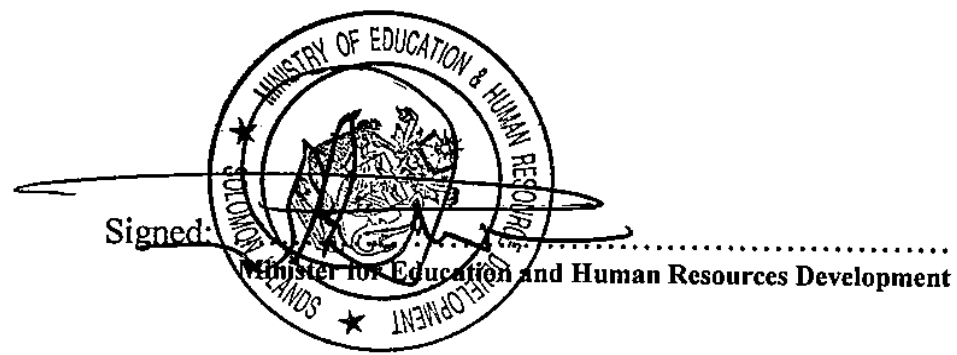

Date: 117109 


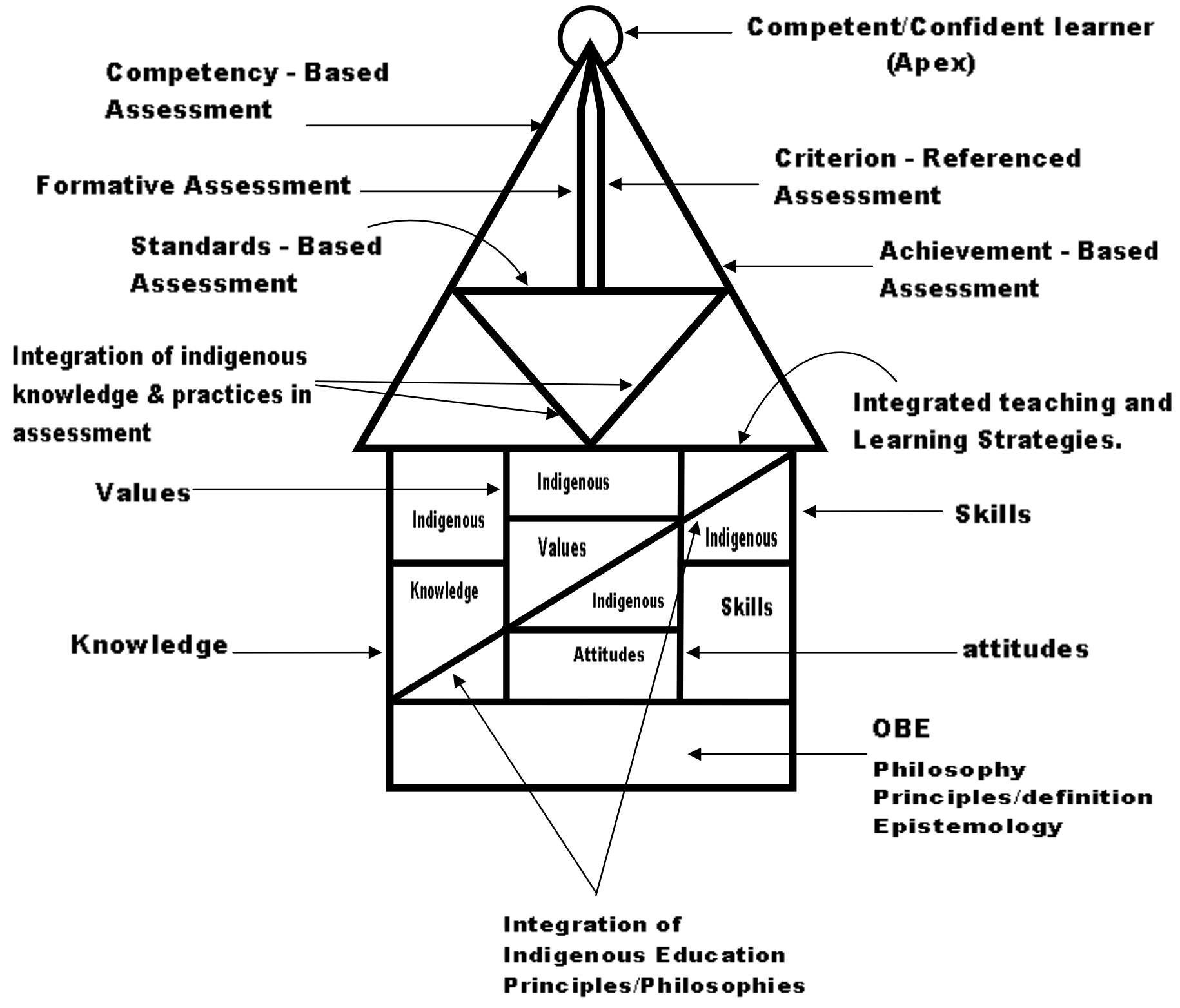

Figure 3: Curriculum Haus framework for integration of cultural knowledge and practices in the OBSC for Solomon Islands secondary schools 